Aus der Abteilung Nephrologie und Rheumatologie

(Prof. Dr. med. G. A. Müller)

im Zentrum Innere Medizin

der Medizinischen Fakultät der Universität Göttingen

\title{
Die Rolle von Bone Morphogenetic Protein 4 und 7 bei der hypertensiven Nephrosklerose
}

\author{
INAUGURAL-DISSERTATION \\ zur \\ Erlangung des Doktorgrades \\ der Medizinischen Fakultät \\ der Georg-August-Universität zu Göttingen
}

vorgelegt von

Imad Maatouk

aus

Bad Homburg

Göttingen 2012 
Dekan: Prof. Dr. med. C. Frömmel

I. Berichterstatter: Prof. Dr. med. F. Strutz

II. Berichterstatter: Priv.-Doz. Dr. rer. nat. Y. Hagos

Tag der mündlichen Prüfung: 13.11.2012 


\section{Inhaltsverzeichnis}

1. Einleitung 6

1.1 Klinische Relevanz des Themas 6

1.2. Volkswirtschaftliche Relevanz 6

$\begin{array}{ll}1.3 \text { Pathophysiologie der Nephrosklerose } & 7\end{array}$

1.4 Therapeutische Möglichkeiten 9

1.5 Bone Morphogenetic Proteins 9

1.5.1 Einleitung 9

1.5.2 Rezeptoren und nachgeschaltete Signalkaskaden 10

$\begin{array}{ll}1.6 \text { BMP-7 } & 10\end{array}$

1.6.1 BMP-7 und bekannte Wirkungen bei der Niereninsuffizienz 11

1.6.2 Reversibilität der Kalzifikation als möglicher therapeutischer Effekt von BMP-7 12

$\begin{array}{ll}1.7 \text { BMP-4 } & 12\end{array}$

1.7.1 Gefäßrelevante Wirkungen von BMP-4 13

1.8 Weitere bedeutsame Zytokine und Mediatoren bei der Nephrosklerose $\quad 14$

$\begin{array}{ll}\text { 1.8.1 Angiotensin II (AT II) } & 14\end{array}$

1.8.2 Transforming growth factor- $\beta 1$ (TGF- $\beta 1) \quad 15$

1.9 Aufgabenstellung 16

2. Material und Methoden $\quad 17$

2.1 Material 17

2.1.1 Geräte 17

2.1.2 Gebrauchsmaterial 18

2.1.3 Chemikalien $\quad 19$

2.1.4 Antikörper 20

$\begin{array}{ll}2.1 .5 \text { Stimulanzien } & 20\end{array}$

$\begin{array}{ll}2.1 .6 \text { Kit-Systeme } & 20\end{array}$

2.1.7 Allgemeine Puffer und Lösungen 21

2.1.8 Verwendete Zelllinien $\quad 22$

2.1.9 Patientenmaterial 23

2.1.10 Computerprogramme 23

2.2 Verwendete Techniken $\quad 23$

2.2.1 Charakterisierung der Gewebe mittels Masson-Goldner-Färbung 23

2.2.2 Immunhistochemie für BMP-4 und BMP-7 24

2.2.3 Real-Time-PCR (RT-PCR) 24

2.2.4 Westernblot $\quad 28$

$\begin{array}{ll}2.2 .5 \text { Proliferationsassay } & 31\end{array}$

2.2.6 Statistische Analyse $\quad 32$

3. Ergebnisse 33

3.1 Masson-Goldner-Färbung 33

3.2 Immunhistochemie für BMP-7 36

3.3 Immunhistochemie für BMP-4 36

3.4 Real-time PCR 39

3.4.1 Einfluss der Stimulation von AT II auf die Expression von BMP-7 39

3.4.2 Einfluss der Stimulation von AT II auf die Expression von BMP-4 40

3.5 Westernblot für BMP-4 und BMP-7 41

3.6 Proliferationsassay 41

3.6.1 Einfluss von BMP-7 auf die Proliferationsrate von proximalen Tubuluszellen 42

3.6.2 Einfluss von BMP-4 auf die Proliferationsrate von proximalen Tubuluszellen 43 
3.6.3 Einfluss von BMP-7 auf die Proliferationsrate von Fibroblasten 44

3.6.4 Einfluss von BMP-4 auf die Proliferationsrate von Fibroblasten 45

4. Diskussion $\quad 46$

4.1 Fibrose $\quad 46$

4.1.1 Deutlich erhöhter Fibrosierungsgrad bei der Nephrosklerose 46

4.1.2 Nierenfibrose als morphologisches Korrelat der Niereninsuffizienz $\quad 46$

4.1.3 Zur Pathophysiologie der Fibrosierung $\quad 47$

4.2. Begrenzte therapeutische Möglichkeiten bei Nephrosklerose 48

4.3 Die Rolle von BMP's in der Pathophysiologie der Nephrosklerose 49

4.4 Bisherige Erfahrung im klinischen Einsatz von BMP-7 in der Traumatologie 49

4.5 Charakterisierung von BMP-7 und BMP-4 in nephrosklerotisch verändertem und gesundem humanen Nierengewebe $\quad 50$

4.6 Unterschiedliche Expressionsmuster von BMP-7 in der PCR 51

4.7 Charakterisierung der BMP's in unterschiedlichen Krankheitsstadien notwendig 53

4.8 Regulation der Expression von BMP's durch Angiotensin II und andere Zytokine 54

4.9 Auswirkungen von BMP's auf die Proliferationsraten von humanen Fibroblasten und

Tubuluszellen - Mögliche BMP-Interaktion mit zahlreichen Zytokinen und Noxen 56

4.10 Die EMT als Untersuchungsgegenstand weiterer Forschung zum Einfluss von BMP's $\begin{array}{ll}\text { auf renale Zellpopulationen } & 58\end{array}$

$\begin{array}{ll}\text { 5. Zusammenfassung } & 61\end{array}$

6. Anhang: Abkürzungsverzeichnis $\quad 62$

$\begin{array}{ll}\text { 7. Literaturverzeichnis } & 64\end{array}$ 
Teile dieser Arbeit sind in eine Publikation der Arbeitsgruppe eingeflossen:

Bramlage CP, Tampe B, Koziolek M, Maatouk I, Bevanda J, Bramlage P, Ahrens K, Lange K, Schmid H, Cohen CD, Kretzler M und Muller GA (2010): Bone Morphogenetic Protein (BMP)-7 expression is decreased in human hypertensive nephrosclerosis. BMC Nephrology $\underline{11,31}$ 


\section{Einleitung}

\subsection{Klinische Relevanz des Themas}

Die chronisch progrediente Niereninsuffizienz stellt eines der zentralen Probleme der Nephrologie dar. Die vaskuläre Nephropathie als Folge der Hypertonie ist nach der diabetischen Nephropathie die zweithäufigste Ursache für die chronische Niereninsuffizienz und für $16 \%$ der dialysepflichtigen Niereninsuffizienzen verantwortlich (Abb. 1). Die sogenannte benigne Nephrosklerose kann als renale Manifestation der arteriellen Hypertonie bezeichnet werden und stellt das morphologische Korrelat der vaskulären Nephropathie dar. Die zunehmende Inzidenz charakterisiert die Bedeutung dieses Krankheitsbildes für die zunehmende Anzahl von Patienten mit dialysepflichtiger chronischer Niereninsuffizienz. Bemerkenswert ist, dass die Wachstumskurven für die diabetische Nephropathie als häufigste Ursache $(35 \%)$ zunehmend abflachen, während bei der vaskulären Nephropathie eine kontinuierliche Zunahme der Inzidenz zu verzeichnen ist. In der Altersklasse der über 70jährigen tritt die vaskuläre Nephropathie überdurchschnittlich häufig auf. Es kann somit in den nächsten Jahren mit einer weiteren deutlichen Zunahme dieses Krankheitsbildes gerechnet werden (Frei und Schober-Halstenberg 2006).

\subsection{Volkswirtschaftliche Relevanz}

Von 1997 bis 2005 ist im Durchschnitt ein jährlicher Zuwachs der Prävalenz der Patienten in dauerhafter Nierenersatzbehandlung von 4,8\% zu verzeichnen. Das aktuelle Wachstum liegt aktuell nur noch bei ca. 2\%. Am 31.12.2005 wurden 63.427 Patienten mit Dialyseverfahren versorgt. Aktuellere Zahlen liegen leider nicht vor. In der Nachsorge nach Nierentransplantation befanden sich 23.724 Patienten, was einer Gesamtprävalenz von 1.057 Patienten pro 1 Millionen Einwohner entspricht. Die Kosten betragen derzeit $40.000 €$ pro Patient an der Hämodialyse. Daraus ergibt sich eine immense Belastung für das Gesundheitssystem (Frei und Schober-Halstenberg 2006). 


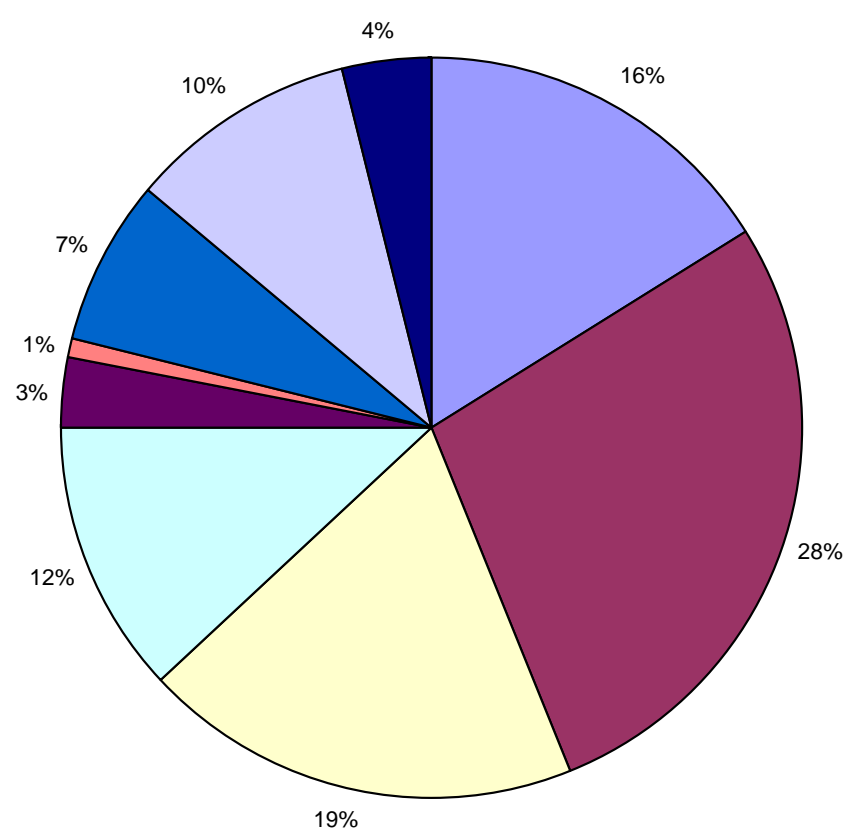

口Vaskuläre Nephropathie

$\square$ Diabetes mellitus

$\square$ Glomerulonephritis

口 Interstitielle Nephritis

—Systemerkrankungen

$\square$ Angeboren

口Zystennieren

口Unbekannt

- Sonstige

Abbildung 1: Diagnoseverteilung aller Dialysepatienten in Nierenersatztherapie (Prävalenz) in 2005 n = 46597 (Daten aus Frei und Schober-Halstenberg 2005/2006, S.35)

\subsection{Pathophysiologie der Nephrosklerose}

Man schätzt, dass 2-3 \% der Patienten mit vaskulärer Nephropathie eine terminale Niereninsuffizienz entwickeln. Aufgrund der hohen Prävalenz der arteriellen Hypertonie mit über 10 Millionen betroffenen Patienten in Deutschland stellt diese den wichtigsten Risikofaktor für die Progression fast aller Nierenerkrankungen dar (Kron 2009). Die mittels Biopsie gestellte Diagnose einer benignen Nephrosklerose führte in einer neueren Studie in über 50\% der Fälle innerhalb von 10 Jahren zu terminalem Nierenversagen. Ein hohes Serumkreatinin und schlecht eingestellte Blutdruckwerte führten zu signifikant erniedrigten renalen Überlebensraten bei dem untersuchten Patientenkollektiv $(n=60)$ (Dasgupta et al. 2007). Die mikrovaskulären Veränderungen der Nephrosklerose weisen keine Spezifität für die Hypertonie auf, sondern sind auch bei einem Diabetes mellitus und der Hypercholesterinämie zu finden. Dieses stützt die Annahme, dass neben der Hypertension auch andere pathogenetische Mechanismen bei der Entstehung der vaskulären Nephropathie eine wichtige Rolle spielen. Sie wird häufig bei Patienten beobachtet, die über einen längeren Zeitraum hyperton sind. Histologisch findet sich in den afferenten Arteriolen eine Verdickung durch eine hyaline Arteriosklerose. Durch eine Verengung des Gefäßlumens kommt es zu 
einem Sauerstoffmangel mit konsekutiver Schädigung von Glomeruli und Tubuli. Es finden sich Hinweise darauf, dass auch genetische Faktoren eine Rolle bei der Pathogenese der Nephrosklerose spielen und zu einer erhöhten renalen Suszeptibilität für die Hypertonie führen (O'Dea et al. 1998; Van Dijk et al. 2006). In frühen Phasen der Nephrosklerose findet sich eine Hypoperfusion bei zunächst erhaltener glomerulärer Filtrationsrate (GFR) als Folge der erhöhten Filtrationsfraktion. In fortgeschrittenen Stadien nimmt die GFR zunehmend parallel zur sinkenden Perfusion ab. $\mathrm{Zu}$ diesem Zeitpunkt manifestieren sich auch eine Albuminurie und pathologische Abweichungen in der Wasser- und Salzexkretion. Eine Feinregulation des Gefäßtonus der afferenten Arteriolen wird über den Vasodilatator Stickstoffmonoxid (NO) vermittelt. Die Ausschüttung von NO durch Endothelzellen ist vom Blutfluss abhängig, der eine kontinuierliche (laminäre) Scherspannung auf das Gefäßendothel ausübt. Bei einer Reduktion des Blutflusses wie bei der Nephrosklerose bleibt die NOAusschüttung aus. Des Weiteren führt dieses zu Stimulation des Renin-AngiotensinAldosteron-System (RAAS) mit konsekutiver Blutdrucksteigerung (Juncos et al. 1995).

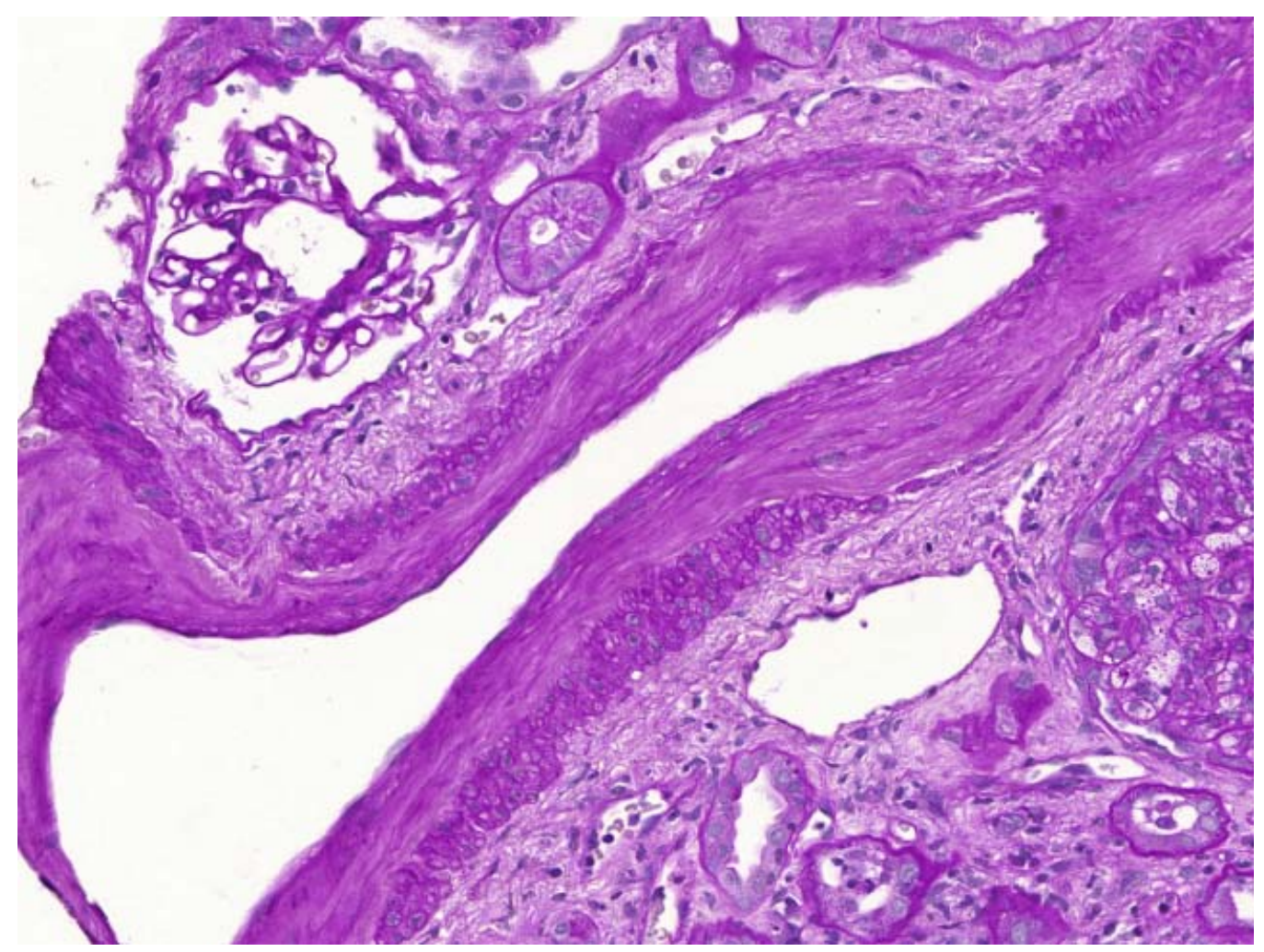

Abbildung 2: Bild einer Nephrosklerose mit einer Gefäßwandverdickung durch eine hyaline Arteriosklerose und konsekutive Schädigung von Glomeruli (linker oberer Bildrand) und Tubuli (rechter unterer Bildrand). Bild mit freundlicher Genehmigung von Prof. Dr. med. Gröne (DKFZ Heidelberg) zur Verfügung gestellt. 


\subsection{Therapeutische Möglichkeiten}

Die therapeutischen Möglichkeiten zur Behandlung der Nephrosklerose sind begrenzt.

Durch die optimale Einstellung verschiedener Progressionsfaktoren wie der arteriellen Hypertonie und des Diabetes mellitus kann das Fortschreiten der Erkrankung lediglich verlangsamt werden. Eine Einschränkung der renalen Funktion wird zumeist erst in einem sehr späten Stadium erkannt, da erst dann ein Anstieg der Retentionswerte durch den Verlust der exkretorischen Funktion auszumachen ist (Wiederkehr et al. 2005).

Zum Einsatz kommen Medikamente, die mit dem Renin-Angiotensin-Aldosteron-System (RAAS) interagieren. Zum einen sind dies Enzymhemmstoffe des Angiotensin-ConvertingEnzyms, das für die Umwandlung von Angiotensin I in Angiotensin II verantwortlich ist (ACE-Hemmer), zum anderen Angiotensin1(AT I)-Rezeptor-Antagonisten. Als weitere Therapieoption hat sich in den letzten Jahren klinisch auch ein direkter Renininhibitor (Aliskiren) etabliert (Riccioni et al. 2010). Die Fibrose als morphologisches Korrelat des fortschreitenden Funktionsverlustes der Niere ist in dieser Phase der Erkrankung oft schon weit fortgeschritten. Eine Verlangsamung des Fortschrittes kann daher nicht als hinreichendes Ziel angesehen werden. Seit einigen Jahren werden große Hoffnungen in den möglichen therapeutischen Nutzen von Bone Morphogenetic Protein 7 (BMP-7) gesetzt. Bei den Bone Morphogenetic Proteins (BMP's) handelt es sich um unter anderem für die renale Organogenese bedeutsame Zytokine. In Tierexperimenten konnten für das in dieser Arbeit untersuchte Bone Morphogenetic Protein 7 (BMP 7) regenerative Wirkungen beschrieben werden (Bechtel und Zeisberg 2009). Ein weiteres Molekül, dessen Bedeutung in der humanen Nephrosklerose noch unbekannt ist, ist das Bone Morphogenetic Protein 4 (BMP-4). Proinflammatorische Eigenschaften bei der Atherosklerose führen zu der Annahme, dass es möglicherweise auch eine Rolle bei der Pathogenese der Nephrosklerose spielt (Sorescu et al. 2004). Auf die beiden Proteine soll im folgenden Abschnitt eingegangen werden.

\subsection{Bone Morphogenetic Proteins}

\subsubsection{Einleitung}

Bei den Bone Morphogenetic Proteins (BMP) handelt es sich um die größte Subfamilie der TGF- $\beta$-Superfamilie (Bramlage et al. 2005). Entdeckt wurden diese die Knochenbildung stimulierenden Proteine durch Beobachtungen, daß bei subkutaner Verabreichung von Proteinextrakten aus Knochenmatrix bei Ratten eine ektope Knochenbildung hervorgerufen 
werden kann. Die Moleküle wurden Bone-Morphogenetic-Proteins genannt (Urist 1965; Urist et al. 1983). Bis zum heutigen Zeitpunkt konnten über 30 verschiedene BMPs nachgewiesen werden. Über die Funktion bei der Knochenbildung hinaus wird den BMPs eine zentrale Bedeutung bei der Embryogenese verschiedener Organe zugeordnet. Zahlreiche Experimente konnten die Wirkung von BMPs auf Gewebedifferenzierung, -wachstum und -regeneration in unterschiedlichen Organen belegen (Ducy und Karsenty 2000). Für BMP-7 konnten bereits zahlreiche protektive und sogar regeneratorische Effekte auf die Niere nachgewiesen werden. Zudem ist für BMP-4 ein Einfluss auf die Atherosklerose bekannt. Mechanische Reize induzieren die Expression von BMP-4, wodurch zytokinvermittelte Entzündungsprozesse in Gang gesetzt werden. Beide BMPs könnten somit einen Einfluss auf die Nephrosklerose haben.

\subsubsection{Rezeptoren und nachgeschaltete Signalkaskaden}

Die Wirkung der in dieser Arbeit untersuchten BMPs 4 und 7 wird über die Rezeptoren BMPR-IA, IB (Synonym Alk-3 und Alk-6) und BMPR-II vermittelt. Diese gehören zu den Rezeptoren der TGF- $\beta$-Superfamilie (ten Dijke et al. 1994). Die Signalvermittlung verläuft über verschiedene Smadproteine (u.a. smad 1, 5 und 8) (Heldin et al. 1997; Massague 2000; Wrana 2000).

Die TGF- $\beta$-Rezeptoren besitzen eine relativ kurze extrazelluläre Region, einen transmembranären und einen zytoplasmatischen Abschnitt. Typ-II-Rezeptoren haben eine sogenannte Typ-I-Box, welche eine wichtige Rolle bei der Signaltransduktion spielt (Kingsley 1994; Yamashita et al. 1996).

Die Bindung am Typ-I-Rezeptor setzt eine Anlagerung an den Typ-II-Rezeptor voraus. Der Typ-I-Rezeptor moduliert dann die Signaltransduktion (Massague 1992).

Die Signalvermittlung verläuft über die bereits erwähnten Smad-Proteine. Letztere werden vom Typ-I-Rezeptor phosphorylisiert und mit Hilfe des Mediators Smad 4 in den Nukleus eingebracht, wo die Wirkung wahrscheinlich durch die Koaktivierung der Genexpression und die direkte Induktion der Gen-Transkribierung vermittelt wird (Derynck et al. 1998). Die Wirkung von TGF- $\beta 1$ wird über smad-2 und smad-3 vermittelt.

\subsection{BMP-7}

BMP-7 ist ein Homodimer und hat ein Molekulargewicht von 35kD. Das Monomer hat ein Gewicht von 16-18kD (Ozkaynak et al. 1990). 
BMP-7 wird in zahlreichen Zellen während der renalen Organogenese exprimiert. Es lässt sich am Tag 9,5 postkoital in den Wolffschen Gängen nachweisen. Am Tag 12,5 postkoital wird BMP-7 vorwiegend im Epithel der Ureterknospe exprimiert, eine etwas geringere Expression findet sich in den kondensierenden mesenchymalen Zellen. $\mathrm{Zu}$ einem späteren Zeitpunkt sind auch Transkripte in weiteren Strukturen wie den Podozyten der Glomeruli auszumachen.

BMP-7-defiziente Mäuse kommen mit kleinen dysplastischen Nieren zur Welt und versterben innerhalb weniger Tage an den Folgen der Niereninsuffizienz. Die Nieren dieser Mäuse weisen pro histologischem Schnitt nur 3\% der Glomeruli von Kontrolltieren auf. Die Fehlbildung kommt durch einen Untergang der Mesenchymzellen am Tag 12 postkoital zustande, aus denen sich durch Mesenchymal-Epitheliale-Transition (MET) im Verlauf die Tubulusepithelzellen generieren. Daraus ergibt sich die Annahme, dass BMP-7 ein wichtiger Faktor für die Entwicklung dieser Zellen ist (Dudley et al. 1995; Luo et al. 1995).

\subsubsection{BMP-7 und bekannte Wirkungen bei der Niereninsuffizienz}

In verschiedenen Modellen des chronisch progredienten Nierenversagens konnte eine protektive Wirkung von BMP-7 im Hinblick auf die Niereninsuffizienz gezeigt werden. So kann die Applikation von BMP-7 im Modell der unilateralen ureteralen Obstruktion (UUO) die interstitiellen Entzündungsprozesse und die Fibrogenese für fünf Tage aufhalten. Es sicherte die renale Durchblutung und verhinderte die Apoptose von Tubulusepithelzellen, was sich in einer reduzierten tubulären Atrophie niederschlug. Im Vergleich zu dem ACEHemmer Enalapril war die Wirkung von BMP-7 deutlich effektiver (Hruska et al. 2000).

Im Modell der Lupusnephritis und des Alport-Syndroms, die beide in eine progrediente Niereninsuffizienz münden, konnte durch die Applikation von BMP-7 eine Progression dosisabhängig gehemmt werden. Dabei kam es zu einer signifikanten Erhöhung der Matrixmetalloproteinase-2 im Gewebe der mit rekombinantem BMP behandelten Mäuse als Hinweis auf eine erhöhte Matrixdegradation (und damit Zeichen für eine verminderte Fibrosierung). Des Weiteren fiel eine deutlich reduzierte Glomerulosklerose auf, was analog zu den Beobachtungen in der Organogenese eine Wirkung von BMP auf die Gefäße postulieren lässt, auf die im folgenden Abschnitt noch eingegangen werden soll (Zeisberg et al. 2003 a).

Einer der Hauptwirkmechanismen von BMP-7 scheint die Hemmung der Epithelialmesenchymalen Transition (EMT) zu sein. Dabei wirkt das Protein den Effekten von TGF- $\beta 1$ 
entgegen und kann diese sogar rückgängig machen. Die antagonisierende Wirkung spielt sich auf der Ebene der genannten Smadprotein-Signalkaskade ab (siehe 1.5.2).

Diese Effekte lassen sich für die Nierenfibrose im Tiermodell sowohl in vitro als auch in vivo nachweisen (Zeisberg et al. 2003 b).

In Versuchen mit Fibroblasten vermag BMP-7 eine Mesenchymal-Epitheliale Transition zu (MET) vermitteln, was die regenerative Wirkung unterstreicht und in dem Ausmaß bei keiner anderen Substanz festgestellt werden konnte.

\subsubsection{Reversibilität der Kalzifikation als möglicher therapeutischer Effekt von BMP-7}

Es konnte gezeigt werden, dass BMP-7 über die möglichen antifibrotischen Effekte hinaus ein potentielles Therapeutikum der vaskulären Kalzifikation im Kontext des chronischen Nierenversagens ist. In einem Mausmodell der Arteriosklerose mit LDL-Rezeptor-defizienten Mäusen, bei denen durch chirurgische Eingriffe eine Urämie induziert wurde, konnte durch eine Behandlung der Mäuse mit BMP-7 eine signifikante Reduktion der Kalzifikation atheromatöser Plaques erreicht werden. Dabei kommt es zu einer Supression von Osteocalcin, einem Marker für osteoblastische Aktivität, der bei einem Mausmodell für Atherosklerose vermehrt exprimiert wird. Durch Applikation von BMP-7 kann diese vermehrte Expression herunterreguliert werden (Davies et al. 2003). Neben den protektiven Effekten bei der Fibrosierung könnte hier ein weiterer Benefit einer Applikation von BMP-7 liegen. Speziell für die Nephrosklerose liegen noch keine Daten für BMP-7 vor. Insbesondere für die mögliche Interaktion zwischen dem für die Pathogenese der Nephrosklerose bedeutsamen RAAS und BMP-7 stehen Untersuchungen aus. Die protektiven und regenerativen Effekte bei verschiedenen Nierenerkrankungen und der Arteriosklerose lassen jedoch eine Bedeutung bei der Nephrosklerose vermuten.

\subsection{BMP-4}

Bei BMP-4 handelt es sich um ein Homodimer mit einem Molekulargewicht von $30 \mathrm{kD}$. Das Monomer hat ein Gewicht von 13 kD. Das Molekül hat eine starke Ähnlichkeit mit BMP-2 und lässt sich bereits am Tag 6,5 postkoital nachweisen. BMP-4 spielt eine Rolle bei der Genese verschiedenster Organe, ein Wirkmechanismus liegt hier ebenfalls in der Regulation der mesenchymal-epithelialen Interaktionen (Jones CM et al. 1991). BMP-4-defiziente Mäuse versterben an Tag 6,5 der Embryogenese und weisen zahlreiche Organfehlbildungen auf. Bei den meisten Tieren lässt sich eine ausgebliebene mesodermale Differenzierung feststellen. An den Stellen, an denen das Molekül besonders intensiv exprimiert wird, konnte eine 
peritubuläre Differenzierung von Mesenchymzellen beobachtet werden. Aus diesen Beobachtungen wird die Annahme formuliert, dass BMP-4 aktiv an der Regeneration geschädigter Tubuluszellen beteiligt ist (Winnier et al. 1995; Dunn et al. 1997). Heterozygote Mäuse weisen unterschiedliche renale Phänotypen auf. Die renalen Abnormalitäten zeigen sich in der Ausbildung dysplastischer Nieren, erweiterter Harnleiter und der Anlage von doppelten Ureteren, was auf die Bedeutung des Proteins speziell bei der Nephrogenese hindeutet (Miyazaki et al. 2000). Der Ausbildung zystischer, dysplastischer Nierenabschnitte geht eine erhöhte Apoptoserate im metanephritischen Gewebe voraus (Miyazaki et al. 2003).

\subsubsection{Gefäßrelevante Wirkungen von BMP-4}

Es existieren Hinweise darauf, dass BMPs eine Rolle bei der Arteriosklerose spielen. So wurde von einer Arbeitsgruppe eine erhöhte Expression von BMP-4 und anderen osteogenetischen Faktoren in arteriosklerotischen Plaques beschrieben. Dabei fand sich eine besonders ausgeprägte Expression bei fortgeschrittenen Phasen der Sklerosierung in kollagenreichen kalzifizierenden Läsionen. Es scheinen Parallelen zwischen der Regulation von Knochenformation und -regeneration und der Pathogenese der Gefäßkalzifikation in der Arteriosklerose beim Menschen $\mathrm{zu}$ bestehen (Dhore et al. 2001). Mechanische Reize, die auf Gefäße ausgeübt werden, induzieren die Expression von BMP-4 und lösen so eine inflammatorische Reaktion aus (Sorescu et al. 2003). Zahlreiche Versuche deuten darauf hin, dass BMP-4 eine Rolle bei frühen Stadien der Atherosklerose spielt. Die Atherosklerose wird entgegen früherer Annahmen, bei denen man lediglich von einer vaskulären Ablagerung verschiedener Lipide und Lipoproteine ausging, heute als hochkomplexer Prozess verstanden, bei dem inflammatorische Reaktionen eine bedeutende Rolle spielen (Libby 2002). Die oszillatorische (schwingende) Scherspannung, die an Gefäßverzweigungen und -schleifen auftritt, geht mit einem erhöhten Auftreten vaskulärer Läsionen einher, an denen sich im Verlauf eine Atherosklerose entwickelt (Zarins et al. 1983). Solche Scherspannungen induzieren die endotheliale Expression von BMP-4, welches die Expression von interzellulärem Adhäsionsmolekül 1 (ICAM-1) fördert und so eine Monozytenadhäsion erleichtert. Dies charakterisiert BMP-4 als ein mechanosensitives, autokrines Zytokin, welches proatherogene inflammatorische Antworten vermittelt. Dies geschieht unter anderem über die erhöhte Produktion von reaktiven Sauerstoffspezies (ROS) mittels Nikotinamin-Adenin-Dinukleotid-Phosphat (NADPH)-Oxidasen, die zu Sauerstoffradikalen mit den Eigenschaften von freien Radikalen konvertieren können. Die Unterform von NADPH-Oxidasen, die bei der Mediation der Wirkung von BMP-4 eine Rolle 
spielt, wird als nox-1 bezeichnet (Sorescu et al. 2004). Erhöhte Sauerstoffradikalaktivität führt zu einer reduzierten Bioverfügbarkeit von Stickstoffmonoxid, einem potenten körpereigenen Vasodilatator (Guzik et al. 2000). In Tierversuchen induzierte die Applikation von BMP-4 bei Mäusen eine Hypertension, einem bekannten Risikofaktor für die Progredienz der Atherosklerose und der Nephrosklerose. In dieser Studie fanden sich ebenfalls Hinweise darauf, dass die Blutdrucksteigerung mittels Stimulation von NADPH-Oxidasen stattfindet, darauf die Bioverfügbarkeit von NO abnimmt und so die endothelabhängige Vasodilatation beeinträchtigt wird. Durch Noggin, einem BMP-Antagonisten, konnte diese Wirkung komplett aufgehoben werden (Miriyala et al. 2006). In weiteren Untersuchungen an verschiedenen endothelialen Zellen konnte gezeigt werden, dass eine laminäre Scherspannung, die an geraden, unverzweigten Gefäßabschnitten als antiatherogener Faktor wirkt, zu einer verminderten Expression von BMP-4 führt. Die Regulation der Expression von BMP-4 findet dabei über intrazelluläre Signalkaskaden, in denen zyklisches Adenosinmonophosphat (cAMP) involviert ist, statt (Csiszar et al. 2007). Für die Nephrosklerose liegen noch keine Daten zu BMP-4 vor, jedoch kann aufgrund der beschriebenen Eigenschaften von BMP-4 eine Relevanz bei der Pathogenese der Nephrosklerose vermutet werden.

\subsection{Weitere bedeutsame Zytokine und Mediatoren bei der Nephrosklerose}

\subsubsection{Angiotensin II (AT II)}

Das für die Blutdruckregulation und die glomeruläre Filtrationsrate relevante Peptid Angiotensin II kann in der Niere synthetisiert werden und hat einen relevanten Einfluss auf die Fibrogenese bei der Nephrosklerose. Über einen verminderten afferenten Blutfluss infolge einer Gefässkontraktion wird das Renin-Angiotensin-System stimuliert, was zu einer erhöhten Konzentration von Angiotensin II führt. Dieses führt zu einer Blutdrucksteigerung und kann die Expression interstitieller Matrixkomponenten wie Kollagen I und Fibronektin in Fibroblasten (Ruiz-Ortega und Egido 1997) und Kollagen IV in Tubulusepithelzellen induzieren (Wolf et al. 1999). Über die direkte Interaktion mit BMP-4 und BMP-7 und AT-II in der Niere sind noch keine Ergebnisse veröffentlicht worden. Da das RAAS zentral bedeutsam in der Pathogenese der Nephrosklerose ist, soll die Auswirkung von AT-II auf die 
Expression der BMPs untersucht werden, um weitere Erkenntnisse über die Wirkmechanismen beider Proteine zu erlangen.

\subsubsection{Transforming growth factor- $\beta 1$ (TGF- $\beta 1)$}

TGF- $\beta 1$ wird als das bedeutendste Zytokin in der Fibrogenese angesehen. Es stellt den ersten isolierten Faktor der so genannten TGF- $\beta$-Superfamilie, zu der auch die in dieser Arbeit untersuchten BMP's -7 und -4 gehören, dar und diente daher der Namensgebung dieser Peptidgruppe. Beim Menschen sind zurzeit drei Isoformen von TGF- $\beta$ identifiziert worden. Die in der Fibrogenese am besten untersuchte Form stellt die Isoform 1 dar. Sie steigert die Synthese von extrazellulärer Matrix (ECM) (Border und Noble 1994) und hat eine positive Wirkung auf die Proliferation und Aktivierung von Fibroblasten, die über die Freisetzung von Fibroblast Growth Factor (FGF-2) durch Fibroblasten selbst gesteuert wird. Transgene Mäuse, die TGF- $\beta 1$ überexprimieren, entwickeln eine Niereninsuffizienz mit vermehrter interstitieller Fibrose (Kopp et al. 1996). Über die Interaktion zwischen TGF- $\beta 1$ und BMP-7 sind bereits zahlreiche Arbeiten publiziert worden (Zeisberg und Kalluri 2004). 


\subsection{Aufgabenstellung}

Die Hypothese dieser Arbeit ist, dass BMP-4 und BMP-7 einen wesentlichen Einfluss auf die Pathogenese der adulten humanen Nephrosklerose ausüben.

In der vorliegenden Arbeit sollte daher die Rolle von BMP-4 bzw. BMP-7 bei der humanen hypertensiven Nephrosklerose untersucht werden.

Hierbei sollten die folgenden Fragen beantwortet werden:

A) Werden die beiden BMPs in der adulten humanen Niere exprimiert und ist die Expression vergleichbar zu den Ergebnissen in Tiermodellen?

B) Zeigt sich eine veränderte Expression bei der hypertensiven Nephrosklerose?

C) Werden die Faktoren durch das Angiotensin II, das eine wesentliche Rolle bei der Hypertonie spielt, beeinflusst?

D) Sind die protektiven Funktionen, wie beispielsweise die Hemmung der Proliferation von Fibroblasten, auf menschliche Zellen übertragbar? 


\section{Material und Methoden}

\subsection{Material}

\subsubsection{Geräte}

Analysewaage, 1213 MP

Sartorius, Göttingen

Autoklav

Biomedis, Gießen

$\mathrm{CO}_{2}$-Inkubator Nuaire ${ }^{\mathrm{TM}}$ Autoflow

Nuaire, Plymouth, USA

Eismaschine

Entwicklungsmaschine Curix 60

Ziegra, Isernhagen

Fluor $\mathrm{S}^{\mathrm{TM}}$-MuktiImager

Fluoreszenzreader für Mikrotiterplatten Mikrolumat LB 96 P

Heizblock

Kühlzentrifuge, GS-6R

Kühlzentrifuge, Mikroliterzentrifuge 5402

Lichtmikroskop

Magnetrührer (beheizbar), IKAMAG RCT

Nanopore Wasser-Anlage, Ultrafree 20

Netzgerät PowerPac 1000 für Blot

pH-Meter MP 220

Agfa, Leverkusen

BioRad, München

E\&G Berthold, Bad

Wildbad

Liebisch, Bielefeld

Beckmann, München

Eppendorf, Hamburg

Leica, Solms

IKA Labortechnik, Staufen

Millipore, Eschborn

BioRad, München

Mettler Toledo, Columbus, USA

Pipettierhilfe pipetus-akku

Photometer Gene Quant II

Hirschmann, Eberstadt

Pharmacia

Biotech,

Cambridge, UK

Real-time RT-PCR MX3000P

Stratagene, La Jolla, USA

Durchflusszytometer FACS-Calibur

Becton Dickinson, Franklin

Lakes, USA

Spektralphotometer, Genesys 5

Spectronic, München

Sterilbank, Hera Save

Heraeus, Hanau

Stickstofftank, Chronos ${ }^{\circledR}$ Biosave ${ }^{\circledR}$

Messer, Griesheim

Thermocycler Mastercycler personal ${ }^{\circledR}$

Waage Sartorius excellence

Eppendorf, Hamburg

Wärmebad

Sartorius, Göttingen

Schütt Labortechnik,

Göttingen

Wippe Duomax 1030

Heidolph, Schwabach 


\subsubsection{Gebrauchsmaterial}

0,5-ml-Reagenzgefäß

1,5-ml-Reagenzgefäß

2,0-ml-Reagenzgefäß

Combitips plus 2,5 ml, $10 \mathrm{ml}$, steril

Einfrierröhrchen Nunc Cryo Tube ${ }^{\mathrm{TM}}$ Vials

Falcon 15-ml-Röhrchen, steril

Falcon 50-ml-Röhrchen, steril

Falcon 7105 Bottle Top Filter, steril

Falcon Zellkulturflasche mit Luftfilter, T25, T75

Filterpapier 2MM

Filterpapier Microscience

Glaswaren

Mehrkanalpipette, Dispenser Multipipette ${ }^{\circledR} 4780$

Mikroliter Pipetten 2,5 $\mu 1,10 \mu 1,100 \mu 1,200 \mu 1,1000 \mu 1$

Mikrotiterplatten Falcon Microtest ${ }^{\mathrm{TM}}$ 96, 96 Vertiefungen

Neubauer Zählkammer

Objektträger Lab Tec ${ }^{\circledR}$ Chamber Slide ${ }^{\mathrm{TM}}$ System

Parafilm „M“

Pasteurpipetten

Pasteurkapillarpipetten

Petrischalen Cellstar ${ }^{\circledR}$

Pipetten $2 \mathrm{ml}, \mathrm{ml}, 10 \mathrm{ml}, 25 \mathrm{ml}$

Pipettenspitzen $2,5 \mu 1,10 \mu 1,100 \mu 1,1000 \mu 1$

Röntgenfilm FUJI Super RX

Skalpelle

Spritzen 2ml, 5ml, $10 \mathrm{ml}$

Zellschaber
Eppendorf, Hamburg

Eppendorf, Hamburg

Eppendorf, Hamburg

Eppendorf, Hamburg

Nalge Nunc, Naperville,

USA

Becton Dickinson, Franklin

Lakes, USA

Becton Dickinson

Becton Dickinson

Becton Dickinson

Whatman, Wiesloch

Schleicher \& Schell, Dassel

Schott, Mainz

Eppendorf, Hamburg

Eppendorf, Hamburg

Becton Dickinson, Franklin

Lakes, USA

Saaringia, Deutschland

Nalge Nunc, Naperville,

USA

Pechiney, Chicago, USA

Brand, Deutschland

WU, Mainz

Greiner, Solingen

Greiner, Solingen

Sarstedt, Nümbrecht

FUJI, Tokyo, Japan

pfm, Köln

Braun, Melsungen

Saarstedt, Newton, USA 


\subsubsection{Chemikalien}

Alle Chemikalien besaßen, sofern nicht anders angegeben, den Reinheitsgrad ,pro analysi““

Accutase

Aceton

Acrylamid / Bis 30\%

Ammoniumpersulfat (APS)

Angiotensin II

Bovines Serum-Albumin (BSA)

Bradford Reagenz

Calciumchlorid $\left(\mathrm{CaCl}_{2}\right)$

Dimethylsulphoxid (DMSO)

Dinatriumhydrogenphosphat $\left(\mathrm{Na}_{2} \mathrm{HPO}_{4}\right)$

Dithiotreitol (DTT)

DMEM-Medium

Dulbecco's PBS

Essigsäure \%

Ethanol

Foetales Kälberserum (FCS), US-Standard

Glycerol

Glycin

IMDM-Medium

Kaliumdihydrogenphosphat $\left(\mathrm{KH}_{2} \mathrm{PO}_{4}\right)$

L-Ascorbinsäure

L-Glutamin 200nM

Magermilchpulver

Methanol

Natriumchlorid $(\mathrm{NaCl})$

Natriumdeoxycholat

Natriumdodecylsulfat (SDS)

Natronlauge $(\mathrm{NaOH}) 1 \mathrm{M}$

Nitrocellulosemembran Hybond ${ }^{\mathrm{TM}}-\mathrm{ECL}^{\mathrm{TM}}$

Nuclease-freies Wasser
PAA, Pasching, Österreich

Merck, Darmstadt

BioRad, München

Fluka, Buchs, Schweiz

Sigma-Aldrich, München

Paesel \& Lorei, Hanau

BioRad, München

Merck, Darmstadt

Serva, Heidelberg

Merck, Darmstadt

Sigma-Aldrich, München

GIBCO BRL

PAA, Pasching, Österreich

Merck, Darmstadt

Roth, Karlsruhe

GIBCO BRL

Sigma-Aldrich, München

Sigma-Aldrich, München

GIBCO BRL

Merck, Darmstadt

Sigma-Aldrich, München

PAA, Pasching, Österreich

Merck, Darmstadt

Merck, Darmstadt

Merck, Darmstadt

Sigma-Aldrich, München

Serva, Heidelberg

Merck, Darmstadt

Amersham Biosciences,

Freiburg

Ambion, Cambridgeshire, UK 
Phenylmethansulfonsäurefluorid (PMSF)

Plasmocin $25 \mathrm{ng} / \mathrm{ml}$

Ponceau S

Rainbow Marker RPN 756

Renal Epithelial Growth Medium

Roti®-Blue 5x Konzentrat

Salzsäure (HCl) $1 \mathrm{M}$

Tergitol (NP-40)

Tetramethylethylendiamin (TEMED)

Tris-Base

Trypanblau

Trypsin-EDTA 1x

Tween ${ }^{\circledR} 20$

B-Mercaptoethanol

\subsubsection{Antikörper}

\section{Anwendung:}

Ziege Monoklonaler BMP-7-Antikörper WB

Ziege Monoklonaler BMP-4-Antikörper WB

Ziege Monoklonaler BMP-7-Antikörper

Ziege Monoklonaler BMP-4-Antikörper

Kaninchen Anti-Ziege-Antikörper

\subsubsection{Stimulanzien}

Rekombinantes humanes BMP-7

Rekombinantes humanes BMP-4

Angiotensin II

\subsubsection{Kit-Systeme}

Dako EnVision System anti-rabbit ${ }^{\circledR}$
Boehringer, Mannheim

invivogen, Toulouse,

Frankreich

Sigma-Aldrich, München

Amersham Biosciences,

Freiburg

Promocell, Heidelberg

Roth, Karlsruhe

Merck, Darmstadt

Sigma-Aldrich, München

Sigma-Aldrich, München

Sigma-Aldrich, München

Biochrom Seromed, Berlin

PAA, Pasching, Österreich

Boehringer, Mannheim

Sigma-Aldrich, München

R\&D Systems, Wiesbaden

R\&D Systems, Wiesbaden

WB, IMH Santa Cruz

Biotechnology, Santa Cruz, USA

WB, IMH Santa Cruz

Biotechnology, Santa Cruz, USA

WB, IMH Santa Cruz

Biotechnology, Santa Cruz, USA
R\&D Systems, Wiesbaden

R\&D Systems, Wiesbaden

Sigma-Aldrich, München 
Cell Proliferation Biotrak ELISA System, version 2

Enthält:

- 5-Brom-2-deoxyuridin (BrdU) in PBS

- Fixierlösung

- Blocking Reagenz

- Maus Anti-BrdU HRP, Fab Fragmente

- Verdünnungslösung für Antikörper

- 10x PBS als Waschpuffer

- Tetramethylbenzidin

(TMB)

(DMSO) (v/v) als Substratlösung

RNeasy Mini Kit

Enthält:

- RNeasy Mini Spin Säulen

- 1,5-ml-Sammelgefäß

- 2,0-ml-Sammelgefäß

- RLT-Puffer

- RW1-Puffer

- RPE-Puffer

- RNase-freies Wasser
Amersham Biosciences,

Freiburg 
Tris gepufferte Lösung (TBS) 10x, eingestellt auf pH 7,6

Tris-Base

$\mathrm{NaCl}$

$\mathrm{ddH}_{2} \mathrm{O}$
$60,5 \mathrm{~g}$

$87,5 \mathrm{~g}$

$1000 \mathrm{ml}$

\subsubsection{Verwendete Zelllinien}

\section{$\underline{\text { Renale Fibroblastenzellinie TK-173 }}$}

Die Zelllinie Tk-173 wurde von G.A. Müller und Mitarbeitern etabliert (Muller et al. 1995). Dabei handelt es sich um renale Fibroblasten, die aus einer zur Transplantation vorgesehenen Normalniere gewonnen wurden und mit dem für SV40 Large T-Antigen kodierenden pSV3gpt Vektor (Mulligan und Berg 1981) immortalisiert wurden.

\section{Proximale Tubuluszelllinie HK-2}

Die Zelllinie Hk-2 wurde von RJ Ryan und Mitarbeitern etabliert. Es handelt sich um renale proximale Tubuluszellen aus einer Normalniere, die mittels eines rekombinanten Retrovirus, das die HPV 16 E6/E7 Gene enthält, immortalisiert wurden. Die Zellen weisen nach einjähriger serumfreier Kultivierung funktionelle, immunhisto- und zytochemische Charakteristika von differenzierten proximalen Tubuluszellen auf. Das Wachstum von HK-2Zellen ist abhängig von epidermal growth factor (Ryan et al. 1994). 


\subsubsection{Patientenmaterial}

Immunhistochemisch (IMH) untersucht wurden 15 Nieren von Patienten mit hypertensiver Nephrosklerose (freundlicherweise von Herrn Prof. Dr. H.-J. Gröne, Heidelberg zur Verfügung gestellt) und 15 Kontrollnieren aus Tumornephrektomiematerial bei Nierenkarzinomen. Die Biopsien stammten von Patienten der Universitätsmedizin Göttingen. Eine Einwilligung der Patienten lag vor. Ein Ethikantrag wurde bei der Ethikkommission der Universitätsmedizin Göttingen gestellt. Diesem stimmte die Ethikkommission zu (Ref-No \#11/10/04).

\subsubsection{Computerprogramme}

Microsoft Word 2003 für Windows, Version 11.0

Microsoft Excel 2003 für Windows, Version 11.0

STATISTICA, Version 9.1

MxPro $^{\text {TM }}$ QPCR Software
Microsoft, Redmont, USA

Microsoft, Redmont, USA

Statsoft, Hamburg

Stratagene, La Jolla, USA

\subsection{Verwendete Techniken}

\subsubsection{Charakterisierung der Gewebe mittels Masson-Goldner-Färbung}

Zur Ermittlung des tubulointerstitiellen Verhältnisses wurde eine Masson-Goldner-Färbung verwendet, bei der sich das Zytoplasma rot färbt, während sich das Bindegewebe grünlich anfärbt. Nach Fixierung der Gewebsproben in wässriger Formalinlösung (4\%Formaldehyd) und Entwässerung mittels in der Konzentration aufsteigender Alkoholreihe wurden diese in Xylol inkubiert und im Anschluss in Paraffin eingebettet. Nach Erkalten der paraffingebetteten Gewebeproben wurden mittels eines Mikrotoms von den Paraffinblöcken 3 $\mu \mathrm{m}$ dicke Schnitte angefertigt. Über Nacht wurden die Proben dann bei $37^{\circ} \mathrm{C}$ im Wärmeschrank getrocknet, in Xylol entparaffiniert und in absteigender Alkoholreihe rehydriert.

Die entparaffinisierten Proben wurden nach der Methode von Masson und Goldner angefärbt (Bach 1963). Dafür wurden die Schnitte 5 min in dem roten Farbstoff Ponceau S und 15 sec mit Goldorange (Moldatophosphorsäure) gefärbt, die Waschschritte wurden mit 1\% Essigsäure durchgeführt, im Anschluss erfolgte die Färbung für 30-40 sec in Lichtgrün. Die 
fotographische Dokumentation erfolgte an einem Mikroskop der Firma Leica mit einer Digitalkamera der Firma Zeiss.

\subsubsection{Immunhistochemie für BMP-4 und BMP-7}

Die Paraffinschnitte wurden wie bereits beschrieben entparaffinisiert und für die immunhistochemischen Untersuchungen zunächst zur Antigendemaskierung in ein hitzestabiles mit Citratpuffer gefülltes Gefäß gegeben und $3 \times 5 \mathrm{~min}$. bei $600 \mathrm{~W}$ in der Mikrowelle erhitzt.

Bei der Immunhistochemie wurden Paraffinschnitte mit primären Antikörpern (polyklonale Ziegen-Antikörper, Santa Cruz Biotechnology) gegen BMP-7 und BMP-4 (jeweils 1:100) verwendet. Nach Inkubation mit einem sekundären Antikörper, der an den Primärantikörper bindet (rabbit anti-goat), wurde das Dako EnVision System anti-rabbit ${ }^{\circledR}$ eingesetzt. Die Färbung erfolgte mit dem roten Farbstoff AEC (3-Amino-9-Ethylcarbazol).

Die Gegenfärbung erfolgte für $5 \mathrm{~min}$ mit Hämatoxylin. Anschließend wurden die Schnittpräparate für 5 min. in Leitungswasser gebläut und dann in wässrigem Eindeckmedium (IMMU-Mount Cat.Nr.9990402) eingedeckt. Die Photodokumentation erfolgte analog zu den Masson-Goldner-Färbungen.

\subsubsection{Real-Time-PCR (RT-PCR)}

\section{RNA-Isolierung}

Die RNA aus den verwendeten Zellen wurde in einem Kombinationsverfahren mit Hilfe des RNeasy Mini Kits der Firma Qiagen nach den Anweisungen des Herstellers und nach Chomczynski isoliert. Die RNA wurde mit Hilfe von Säulen, die mit einer SilikaGelmembran ausgestattet sind, gebunden und durch verschiedene Waschschritte mit Ethanol aufgereinigt (Chomczynski und Sacchi 1987; 2006). Zusätzlich wurde ein DNAse-Verdau integriert, um cDNA zu entfernen, die zu Ergebnisverfälschungen führen könnte.

\section{Reaktionsansatz für den DNase I-Verdau:}

RNase freie DNase I $\quad 10 \mu 1$

RDD-Puffer $\quad 70 \mu 1$

Nach einer 15 min. Inkubation wurde die so erhaltene RNA in einem letzten Schritt mit nukleasefreiem Wasser durch Zentrifugation bei 10000 Upm aus der Membran gelöst. 
Die RNA-Konzentration wurde mit Hilfe des Photometers GeneQuant der Firma Pharmacia Biotech bestimmt.

\section{Umschreibung der RNA in cDNA}

Die gewonnene RNA wurde für $10 \mathrm{~min}$. bei $70^{\circ} \mathrm{C}$ mit $1 \mu 10 \mathrm{mM}$ dNTP-Mix als Nukleotidgemisch und $1 \mu 1$ Oligo DT-Primer inkubiert.

Die First-Strand-Synthese der cDNA erfolgte durch Reverse-Transkriptase für 50 min. bei $42^{\circ} \mathrm{C}$.

\section{Ansatz für die Reverse Transkription:}

$3 \mu \mathrm{g} \quad$ RNA

$1 \mu 1 \quad$ Oligo DT

$1 \mu 1 \quad 10 \mathrm{mM}$ dNTP - Mix

$4 \mu \mathrm{l} \quad$ First Strand Buffer

$1 \mu \mathrm{l} \quad \mathrm{DTT}$

$0,5 \mu \mathrm{l}$ RNAse OUT

$1 \mu 1 \quad$ Superscript

Nach der Reversen Transkription wurde die RNAse für $15 \mathrm{~min}$. bei $70^{\circ} \mathrm{C}$ inaktiviert.

\section{Quantitative PCR}

Für die quantitative PCR wurde der SYBR Green PCR Master Mix der Firma Stratagene verwendet. Bei SYBR Green handelt es sich um einen Fluoreszenzfarbstoff, der ausschließlich an doppelsträngige DNA bindet und proportional zur vorhandenen doppelsträngigen DNA-Menge fluoresziert (Wittwer et al. 1997). Für die gewünschte Detektion der relativen Influenz von AT II auf die Expression der Zielgene wurde das Programm Comparative Quantitation (Calibrator) der MxPro ${ }^{\text {TM }}$ QPCR Software der Firma Stratagene gewählt. Als Calibrator wurden Zellen verwendet, die nicht mit AT II stimuliert worden waren. In den beschriebenen Versuchen wurde Cyclophilin A (PPIA) als housekeeping-Gen verwendet (Radonic et al. 2004).

Die Primer für die quantitative PCR wurden von der Firma Primerdesign generiert.

Die Spezifität der Primer wurde mit Hilfe eines Abgleichs der Datenbank des national center for biotechnology information (NCBI) überprüft. 


\section{Verwendete Primer}

$\begin{array}{llcl}\text { Zielgen } & \text { Sequenz (vorwärts/rückwärts) } & \text { Annealing Temperatur } & \text { Zyklenzahl } \\ \text { PPIA } & \text { TGGGCAACATAGTGAGACG } & 60^{\circ} \mathrm{C} & 40 \\ & \text { TGTACAGTGGCATGATAATAGC } & 60^{\circ} \mathrm{C} & 40 \\ \text { BMP-4 } & \text { TGACCACCTCAACTCAACCAACCA } & 60^{\circ} \mathrm{C} & 40 \\ & \text { AGCATGGAGATGGCACTCAGTTCA } & 60^{\circ} \mathrm{C} & 40 \\ \text { BMP-7 } & \text { CCTCCATTGCTCGCCTTG } & 60^{\circ} \mathrm{C} & 40 \\ & \text { TATGCTGCTCATGTTTCCTAATAC } & 60^{\circ} \mathrm{C} & 40\end{array}$

\section{Ansatz für die QT-PCR:}

$6 \mu \mathrm{l}$ cDNA $(3 \mu \mathrm{g} / \mathrm{ml})$

12,5 $\mu$ l SYBR Green PCR Master Mix 2x konzentriert (Stratagene)

$1 \mu 1 \operatorname{ROX}(1: 500$ verdünnt)

$1 \mu \mathrm{l}$ Primer Mix bei PPIA 0,5 $\mu 1$

$4,5 \mu \mathrm{H}_{2} \mathrm{O}$ bei PPIA $5 \mu \mathrm{l}$

Primer Mix:

$0,5 \mu \mathrm{l}$ Vorwärts-Primer $(20 \mathrm{pmol} / \mu \mathrm{l})$

$0,5 \mu \mathrm{l}$ Rückwärts-Primer $(20 \mathrm{pmol} / \mu \mathrm{l})$

$10 \mu \mathrm{H}_{2} \mathrm{O}$

Die Durchführung der quantitativen PCR erfolgte im Mx 3000P der Firma Stratagene nach folgendem Temperaturprotokoll:

$10 \min 95^{\circ} \mathrm{C} \quad$ erster Zyklus

$15 \mathrm{~s} 95^{\circ} \mathrm{C}$

$1 \min 60^{\circ} \mathrm{C}$

$30 \mathrm{~s} 72^{\circ} \mathrm{C} \quad 30-35$ Zyklen

$30 \mathrm{~s} 95^{\circ} \mathrm{C}$

$1 \min .60^{\circ} \mathrm{C}$

$30 \mathrm{~s} 95^{\circ} \mathrm{C} \quad$ letzter Zyklus

Von allen Proben, einschließlich der Kontrollen, wurden Tripletts pipettiert. 


\section{Auswertung}

Die Ergebnisse wurden mit Hilfe des Programmes MXPro 3000 ausgewertet. Hierbei wird die Kinetik der PCR-Reaktion ausgenutzt. Der CT-Wert steht dabei für die Zyklenzahl, die benötigt wurde, bis sich das Fluoreszenzsignal deutlich vom Hintergrund abhebt. Je geringer der CT-Wert ausfällt, desto mehr cDNA des gesuchten Gens ist in der Probe vorhanden. 


\subsubsection{Westernblot}

\section{Proteinisolierung}

Zunächst wurden die beschriebenen Zelllinien in T75-Kulturflaschen kultiviert. Vor der Lyse in Lysispuffer, der PMSF zur Hemmung endogener Proteasen enthielt, wurden die Zellen drei Mal mit kaltem PBS gewaschen. Es folgte die Zugabe von $3 \mathrm{ml}$ Lysispuffer und das anschließende Abschaben mit dem Zellschaber zur mechanischen Lyse. Das erhaltene Lysat wurde für $5 \mathrm{~min}$. bei $4^{\circ} \mathrm{C}$ und $1000 \mathrm{~g}$ zentrifugiert. Der Überstand, der die Proteine enthielt, wurde im Gefrierschrank bei $-20^{\circ} \mathrm{C}$ eingefroren oder direkt weiterverwendet.

Die Proteinkonzentration wurde mit dem Verfahren nach Bradford (Bradford 1976) bestimmt. Es wurden $50 \mu \mathrm{l}$ des Überstandes mit 2,45 ml Bradford-Reagenz verdünnt und für 10min. inkubiert. Die Messung erfolgte an dem Photometer Genesys 5 der Firma Spectronic bei einer Wellenlänge von $595 \mathrm{~nm}$.

\section{Lysispuffer}

Natriumdeoxycholat $\quad 0,4 \mathrm{~g}$

Nonidet P-40 $1 \mathrm{ml}$

EGTA $1,9 \mathrm{~g}$

Tris $1 \mathrm{M}, \mathrm{pH} \mathrm{7,4} \quad 1 \mathrm{ml}$

$\mathrm{ddH}_{2} \mathrm{O} \mathrm{pH} \mathrm{7,4} \quad 100 \mathrm{ml}$

PMSF (3\% (w/v) in Isopropanol) $\quad 1: 500(\mathrm{v} / \mathrm{v})$

\section{SDS-Polyacrylamidgel-Elektrophorese (SDS-PAGE)}

Zur Auftrennung der Proteine unter denaturierenden Bedingungen wurde die Polyacrylamidgelelektrophorese nach Laemmli (Laemmli 1970) angewendet. Das Protein wurde zunächst mit Aceton ausgefällt. Es wurden unterschiedliche Proteinmengen eingesetzt $(10,25,50,100,200 \mu \mathrm{g})$. Durch Zugabe von Mercaptoethanol zum Probenpuffer und Erhitzung der Proben bei $95^{\circ} \mathrm{C}$ für unterschiedliche Zeiten $(3,5,10,15$ min.) im Heizblock, wurden Disulfidbrücken aufgebrochen. Es wurden 30-150 $\mu$ g Protein pro Spur eingesetzt.

\section{Minigel und verwendete Puffer}

15\%-Trenngel:

$\begin{array}{ll}\text { dd } \mathrm{H}_{2} \mathrm{O} & 2,5 \mathrm{ml} \\ 1,5 \mathrm{M} \text { TrisPuffer } & 2,5 \mathrm{ml} \\ 10 \% \text { SDS } & 100 \mu \mathrm{l}\end{array}$


Acrylamid/ Bis $\quad 5 \mathrm{ml}$

$10 \%$ APS $\quad 50 \mu 1$

TEMED $\quad 5 \mu \mathrm{l}$

\section{Sammelgel}

dd $\mathrm{H}_{2} \mathrm{O} \quad 6,1 \mathrm{ml}$

0,5M TrisPuffer $\quad 1,5 \mathrm{ml}$

$10 \%$ SDS $\quad 100 \mu 1$

Acrylamid/ Bis $\quad 1,3 \mathrm{ml}$

$10 \%$ APS $\quad 50 \mu 1$

TEMED $\quad 10 \mu 1$

\section{Proteintransfer}

Die aufgetrennten Proteine wurden mittels einer angelegten Gleichspannung aus dem Gel auf eine Nitrozellulose-Membran überführt. Dazu wurden gemäß den Angaben des Herstellers eine Membran, zwei Filterpapiere und 2 Vliese für 10 min in Transferpuffer inkubiert. Für den Blot wurden ein Vlies, ein Filterpapier, das Gel, die Membran, ein Filterpapier sowie ein weiteres Vlies zusammengelegt und in die Kassette eingebaut. Der Transfer fand bei konstanter Spannung von $80 \mathrm{~V}$ bei $4^{\circ} \mathrm{C}$ über Nacht statt. Nach dem Transfer wurde die Membran für unterschiedliche Zeiten $(2 \mathrm{~h}, 6 \mathrm{~h}, 12 \mathrm{~h}, 24 \mathrm{~h})$ bei Raumtemperatur oder $4^{\circ} \mathrm{C}$ in einer Blocklösung inkubiert. Die Membran wurde dreimal für 5 min mit TBS gewaschen, bevor sie mit dem primären Antikörper inkubiert wurde.

Der primäre Antikörper wurde in unterschiedlicher Verdünnung (1:1000, 1:500, 1:250,1:100) mit verschiedenen Inkubationszeiten (6 h, 12 h, 24 h) auf die Membran gegeben. Nach 3x 10 min. Waschen wurden die Membranen mit einem entsprechenden HRP-konjugierten Sekundärantikörper in unterschiedlichen Verdünnungen $(1: 5000,1: 1000,1: 200)$ inkubiert. Die Detektion erfolgte mittels Chemilumineszenz mit einem ECL-Kit (Amersham) unter Beachtung der Angaben des Herstellers und einem Röntgenfilm (Kodak) am Kodak-X-Omat.

\section{Transferpuffer}

Tris-Base

$3,03 \mathrm{~g}$

Glycin

$14,4 \mathrm{~g}$

Methanol

200ml

$\mathrm{dd}_{2} \mathrm{O}$

$1000 \mathrm{ml}$ 
Als Blocklösung wurde 5\% Magermilch (w/v) in TBS mit $0.05 \%$ Tween 20 eingesetzt. Alternativ wurde auch eine Blocklösung mit 3\% Magermilch und 0.05\% Tween und Lösungen mit $0.1 \%$ Tween eingesetzt.

Die Antikörper wurden in derselben Lösung auf die Membran gegeben.

Es wurden zahlreiche unterschiedliche Protokolle ausgetestet, um den gewünschten Nachweis von BMP-4 bzw BMP-7 zu erhalten.

\section{Allgemeine Zellkultur}

Das Arbeiten mit Zellkulturen erfolgte nach den allgemeinen Arbeitsbedingungen, wie von Freshney (Pollard 1990) beschrieben. Alle Arbeiten fanden unter einer Sterilbank statt. Die Zellen wurden in einem Brutschrank bei $37^{\circ} \mathrm{C}, 100 \%$ relativer Luftfeuchtigkeit und $5 \% \mathrm{CO}_{2}$ in der Begasungsluft kultiviert. Für die kontinuierliche Kultur wurde für Tk-173 DMEMMedium, supplementiert mit 0,5 mM/ml L-Glutamin, 10\% (v/v) FCS und 0,1\% Plasmocin und für Hk-2 Renal epithelial cell growth medium (Promocell) verwendet, wobei es sich um ein Basalmedium handelt, das mit Epidermal Growth Factor $10 \mathrm{ng} / \mathrm{ml}$, Insulin $5 \mu \mathrm{g} / \mathrm{ml}$, Hydrocortison $36 \mathrm{ng} / \mathrm{ml}$, Triiodothyronin 6,7 ng/ml, Transferrin $5 \mu \mathrm{g} / \mathrm{ml}$ und Selen $5 \mathrm{ng} / \mathrm{ml}$ angereichert wurde.

Für Tk-173 Primärkulturen wurde DMEM-Medium mit 0,5 mM/ml L-Glutamin, 20\% (v/v) FCS und 0,1\% Plasmocin Beimengung benutzt. Das Subkultivieren der transformierten Fibroblasten erfolgte nach drei bis fünf Tagen, das der Epithelzellen nach fünf bis sieben Tagen, wenn die Zellen konfluent waren. Zuerst wurden die Zellen mit 7 ml PBS gewaschen. Anschließend wurden die Fibroblasten mit $2 \mathrm{ml}$ Trypsin-EDTA bei $37^{\circ} \mathrm{C}$ für 5 min abtrypsiniert. Die Tubuluszellen wurden mit $2 \mathrm{ml}$ Accutase für $5 \mathrm{~min}$. bei $37^{\circ} \mathrm{C}$ abgelöst. Es erfolgte ein Waschgang mit $7 \mathrm{ml}$ des entsprechenden Mediums, dann wurden jeweils $2 \times 10^{6}$ Zellen in neue T75-Zellkulturflaschen mit $12 \mathrm{ml}$ Medium ausgesät. Die Kultivierung von Primärzellen erfolgte in T12,5 Flaschen. 50\% der Zellen wurden eingefroren, der Rest wieder in Zellkulturflaschen ausgesät.

\section{Kryokonservierung und Auftauen von Zellen}

Die zur Lagerung bestimmten Zellen wurden, wie oben beschrieben, abgelöst und resuspendiert. Jeweils $0,8 \mathrm{ml}$ der Zellsuspension und $0,8 \mathrm{ml}$ Einfriermedium (DMEM/FCS/DMSO 40/40/20 v/v/v) wurden in einem Kryoröhrchen vermischt. Danach erfolgte für $24 \mathrm{~h}$ die Lagerung der Kryoröhrchen in einer Styroporbox bei $-80^{\circ} \mathrm{C}$ und im Anschluss die Überführung in den Stickstofftank $\left(-196^{\circ} \mathrm{C}\right)$. Zum Auftauen der Zellen wurden 
die Kryoröhrchen im Wasserbad bei $37^{\circ} \mathrm{C}$ erwärmt. Nachdem das Medium am Rand aufgetaut war, wurden $\mathrm{zu} 10 \mathrm{ml}$ gekühltem DMEM 20\% FCS-Medium gegeben und vermischt. Anschließend folgten zwei Waschschritte in entsprechendem Medium und die Kultivierung, wie beschrieben, in T-12,5-Zellkulturflaschen.

Die verwendeten Zellen wurden zur Untersuchung auf Mykoplasmen-Infektionen alle vier Wochen mittels DAPI-Färbung einer DNS-Fluoreszenzuntersuchung unterzogen.

\section{Stimulationsversuche}

Um die möglichen Auswirkungen von Angiotensin II auf die Expression von BMP-4 und BMP-7 bei den genannten Zelllinien festzustellen, wurden diese mit mit Angiotensin II stimuliert.

HK-2-Zellen wurden für $12 \mathrm{~h}$ mit Angiotensin II in Konzentrationen von $10^{-7}, 10^{-5}$, und $10^{-3}$ stimuliert. Im Anschluss erfolgte die oben beschriebene RNA-Isolierung zur Bestimmung möglicher Auswirkungen auf die BMP-Expression.

\subsubsection{Proliferationsassay}

Mittels eines nicht-radioaktiven Proliferationsassays sollte in vivo untersucht werden, ob BMP-4 oder BMP-7 eine Auswirkung auf die Proliferation von renalen Fibroblasten oder proximale Tubuluszellen hat. Bei der Methode handelt es sich um einen indirekten ELISA, der auf einem Nachweis des Thymidinanalogons Bromodeoxyuridin (BrdU) beruht (Gratzner 1982). Der Test wurde in drei Schritten durchgeführt: BrdU-Inkorporation, Inkubation mit einem Peroxidase-gebundenen Anti-BrdU-Antikörper und Detektion mit Hilfe einer Substratlösung. Es wurde mit einem Kit von Amersham Biosciences gearbeitet. Für alle Stimulationsansätze wurde IMDM verwendet. Es wurden jeweils Sextetts mit verschiedenen Zusätzen angesetzt.

Bei den Assays mit Tubuluszellen (HK-2) wurden $100 \mu \mathrm{l} /$ Well Zellsuspension (70000 Zellen/ml) in 96-Well-Platten pipettiert und für $24 \mathrm{~h}$ in renal epithelial cell growth medium kultiviert. Bei den Assays mit Fibroblasten (TK-173) wurde eine Zellsuspension von 40000 Zellen/ml verwendet, die für 24h in DMEM-Medium mit 0,5 mM/ml L-Glutamin, $10 \%$ (v/v) FCS und 0,1\% Plasmocin kultiviert wurden. Im Anschluss wurden die Zellen für $24 \mathrm{~h}$ in IMDM kultiviert. Danach fand die Inkubation für 24h und 48h in $100 \mu \mathrm{l}$ IMDM/Well mit verschiedenen Zusätzen statt. Es wurden Sextetts mit den folgenden Zusätzen angesetzt: BMP-4 oder BMP-7 in Konzentrationen von 1, 10 und 100 ng/ml, als Negativkontrolle diente 
IMDM ohne Zusätze, für die Positivkontrolle renal epithelial cell growth medium für die HK2-Zellen bzw. DMEM mit den oben beschriebenen Supplementen für die TK-173-Zellen. Nach der Stimulation wurden die Zellen für 4h in Medium mit einer BrdU-Konzentration von $10 \mu \mathrm{M}$ bei $37^{\circ} \mathrm{C}$ inkubiert. Im Anschluss wurden die Zellen für $3 \times 5 \mathrm{~min}$. in der Waschlösung (PBS) auf der Wippe gewaschen, danach folgten die Zellfixation und DNA-Denaturierung mit Fixationslösung (Ethanol) für $30 \mathrm{~min}$, die Blockierung in Blocking Reagenz (1\% w/v Protein in $50 \mathrm{mM}$ Tris- $\mathrm{HCl}$ ) für $30 \mathrm{~min}$. und eine Inkubation mit dem Peroxidase-gebundenen Antikörper für $2 \mathrm{~h}$. Nach $3 \times 5$ min. Waschen in PBS wurden $100 \mu \mathrm{l}$ Substratlösung (Tetramethylbenzidin (TMB) in 15\% Dimethylsulphoxid) für 10 min hinzugefügt. Die Messung der OD erfolgte bei $450 \mathrm{~nm}$ (Dynatech MR 400, Denkendorf, Deutschland). Als zusätzliche Kontrollen dienten ein so genannter Assay blank-Ansatz, bei dem keine Zellen kultiviert wurden, um festzustellen, ob unspezifische Signale auftreten und ein unspezifischer Bindungs-Ansatz, bei dem keine Inkubation der Zellen mit BrdU stattfand, um auszuschließen, dass der Peroxidase-gekoppelte Sekundärantikörper unspezifisch bindet.

\subsubsection{Statistische Analyse}

Die statistische Auswertung erfolgte mit Hilfe der Software STATISTICA (data analysis software system), version 9.1 .

Für die Resultate aus den Zellkulturexperimenten (RT-PCR und Proliferationsassay), die als Prozent der Negativkontrolle angegeben wurden, wurde ein t-Test durchgeführt, um statistisch signifikante Unterschiede zu erfassen. Aufgrund der kleinen Fallzahlen mit 3 Wiederholungsversuchen können die p-Werte nur als Ergänzung der deskriptiven Statistik betrachtet werden. Die Ergebnisse wurden bei den Proliferationsassays als Mittelwert mit Minimum/Maximum und bei den PCR-Ergebnissen als Mittelwert mit Standardabweichung dargestellt. Als statistisch signifikant wurden p-Werte $<0,05$ definiert. 


\section{Ergebnisse}

\subsection{Masson-Goldner-Färbung}

Zur Untersuchung des tubulointerstitiellen Verhältnisses diente eine Masson-GoldnerFärbung, bei der sich das Zytoplasma rot färbt, während das Bindegewebe grünlich erscheint. Das Verfahren diente dazu zu überprüfen, ob der Anteil an fibrotischem (interstitiellem) Gewebe in den Proben von Patienten mit der Diagnosestellung „Nephrosklerose“ erhöht ist. Da es sich um menschliches Gewebe aus Nierenbiopsien handelte, standen für Forschungszwecke nur begrenzte Gewebemengen zur Verfügung. Bei den Proben aus den gesunden Kontrollen zeigte sich in 3 exemplarisch ausgezählten Schnitten ein durchschnittlicher Anteil von 75,6\% Tubuli, im Vergleich zu 12,9\% Interstitium. Der Anteil an interstitiellem Gewebe variierte, je nach Schnitt, zwischen 31\% und 15,2\% (Tabelle 1). In den nephrosklerotisch veränderten Nieren zeigte sich im Vergleich in 3 exemplarisch ausgezählten Schnitten ein Anteil von durchschnittlich 48,6\% Tubuli zu 43,4\% Interstitium (Tabelle 2). Hier variierte der Anteil des Interstitiums, als Ausdruck für den Fibrosierungsgrad, zwischen 50,8\% und 46,25\%. In dem Gewebe der Patienten mit Nephrosklerose zeigte sich somit ein deutlicher Rückgang an funktionellem Gewebe, als Charakteristikum für die fortgeschrittene Erkrankung.

Patientendaten lagen leider nur für die Patienten mit Nephrosklerose vor (Tabelle 3). Hier zeigte sich eine mittlere Erkrankungsdauer von 14 Jahren, bei bereits fortgeschrittenem renaler Funktionseinschränkung mit einer Kreatininclearance von 39 ml/min im Median und einer pathologisch gesteigerten Proteinurie von 0,5 g/Tag. Referenzwerte liegen für die Kreatininclearance zwischen 80 und $140 \mathrm{ml} / \mathrm{min}$ und für die Proteinausscheidung bei $0,150 \mathrm{~g} / \mathrm{Tag}$.

Diese Daten untermauern die Annahme, dass es sich um ein klinisch fortgeschrittenes Krankheitsstadium handelte. 


\begin{tabular}{|l|l|l|l|l|l|l|}
\hline Gesichtsfelder & Nummer & Tubulus & Interstitium & Glomeruli & Gefäße & Vergrößerung \\
\hline 2 & $03 / 03$ V55 & $60 \%$ & $31 \%$ & $7 \%$ & $2 \%$ & 200 \\
\hline 5 & $05 / 03$ V55 & $77,7 \%$ & $10,2 \%$ & $9,2 \%$ & $2,9 \%$ & 200 \\
\hline 5 & $07 / 03$ V55 & $73,9 \%$ & $15,7 \%$ & $7,7 \%$ & $2,7 \%$ & 200 \\
\hline
\end{tabular}

Tabelle 1: Auswertung der Trichomfärbung an gesunden Kontrollen. Dargestellt sind der Anteil an Tubuli, Interstitium, Glomeruli und Gefäßen in je nach Schnitt 2 und 5 ausgezählten Gesichtsfeldern bei 200-facher Vergrößerung.

\begin{tabular}{|l|l|l|l|l|l|l|}
\hline Gesichtsfelder & Nummer & Tubulus & Interstitium & Glomeruli & Gefäße & Vergrößerung \\
\hline 5 & $101740 / 03$ & $38,4 \%$ & $50,7 \%$ & $7,4 \%$ & $4,5 \%$ & 200 \\
\hline 5 & $100167 / 03$ & $56,7 \%$ & $32,1 \%$ & $5,5 \%$ & $5,7 \%$ & 200 \\
\hline 4 & $100999 / 03$ & $47,8 \%$ & $46,3 \%$ & $4,5 \%$ & $1,5 \%$ & 200 \\
\hline
\end{tabular}

Tabelle 2: Auswertung der Trichromfärbung bei der Nephrosklerose. Dargestellt sind der Anteil an Tubuli, Interstitium, Glomeruli und Gefäßen in je nach Schnitt 4-5 ausgezählten Gesichtsfeldern bei 200-facher Vergrößerung.

\begin{tabular}{ll}
\hline Patientenzahl & 12 \\
Alter (Median) & 64.5 (Quartil 25.-75.: 58,5-67,5) \\
Männer / Frauen (n) & $9 / 3$ \\
Krankheitsdauer (Jahre) & $14(7-25.8)$ \\
Kreatininclearance (ml/min) (Median) & 39.0 (Quartil 25.-75.: 15.5-56.4) \\
Proteinurie (g/Tag) (Median) & 0.5 (Quartil 25.-75.: 0.2-1.4)
\end{tabular}

Tabelle 3: Darstellung der Patientendaten für die Masson-Goldner-Färbung und die Immunhistochemie. Dargestellt sind die Daten der Patienten mit histologisch gesicherter Nephrosklerose. 


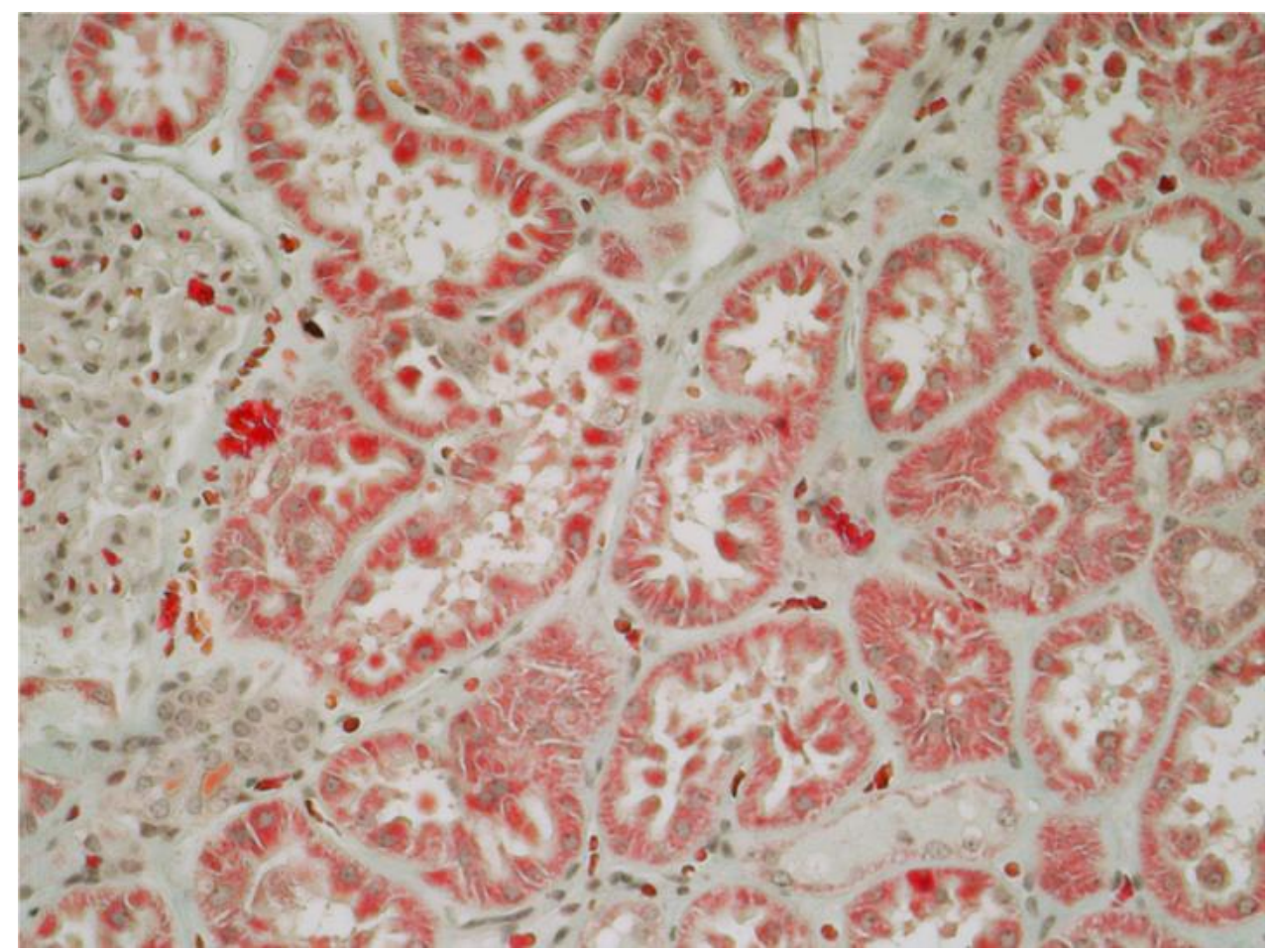

\section{Kontrollniere $(A)$}

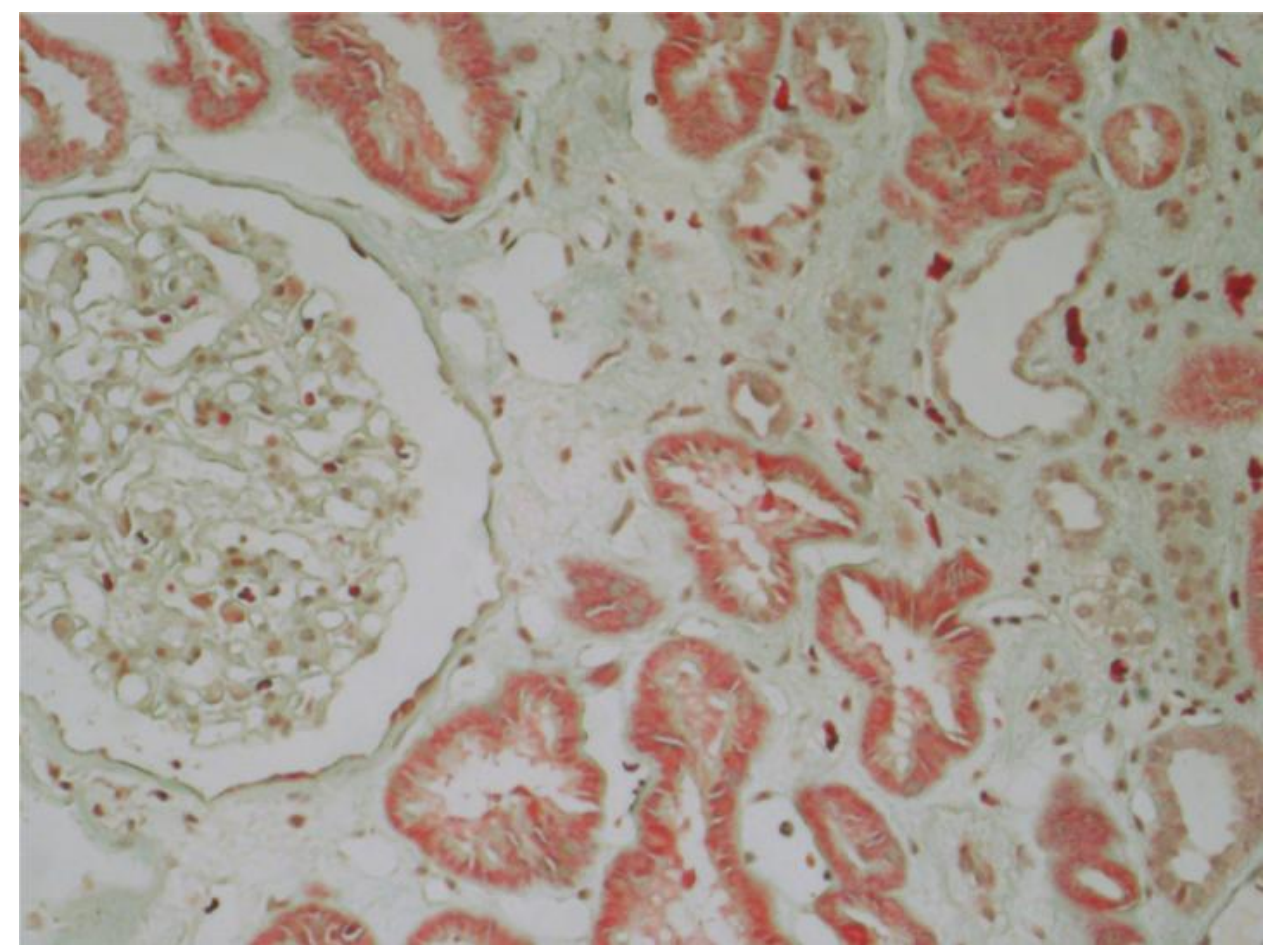

\section{Nephrosklerose (B)}

Abbildung 3 A und B Darstellung des tubulo-interstitiellen Verhältnisses (200-fache Vergrößerung). Hier zeigte sich eine deutlich erhöhte interstitielle Fibrosierung (grünliche Färbung) bei der Nephrosklerose (B). 


\subsection{Immunhistochemie für BMP-7}

Die Immunlokalisation von BMP-7 wurde zunächst mittels immunhistochemischer Färbung an Paraffinschnitten charakterisiert. Es ließen sich ähnliche Expressionsmuster im gesunden Nierengewebe wie im nephrosklerotischen Nierengewebe nachweisen.

Im gesunden Nierengewebe war die Expression von BMP-7 vorwiegend endoluminal in den distalen Tubulusepithelien und in den Sammelrohren nachzuweisen. In den proximalen Tubuluszellen fand sich keine Expression von BMP-7.

Bei der Nephrosklerose fand sich ebenfalls eine endoluminale Expression in distalen Tubulusepithelien und in den Sammelrohren. Bei gleichen Expressionsmustern zeigte sich die Intensität der Expression bei der Nephrosklerose insgesamt deutlich vermindert.

\subsection{Immunhistochemie für BMP-4}

Für BMP-4 zeigte sich insgesamt eine niedrigere Expression im Vergleich zur Expression von BMP-7. Die Expressionsmuster waren ähnlich wie bei BMP-7 vorwiegend endoluminal in den distalen Tubulusepithelien und in den Sammelrohren nachzuweisen. In den proximalen Tubuluszellen zeigte sich ebenfalls keine Expression. Bei den Schnitten aus nephrosklerotischen Nieren zeigte sich analog zu den Ergebnissen bei BMP-7 das gleiche Expressionsmuster wie bei den gesunden Kontrollen. Allerdings fand sich bei BMP-4 kein Hinweis auf einen quantitativen Unterschied in der Expression. 


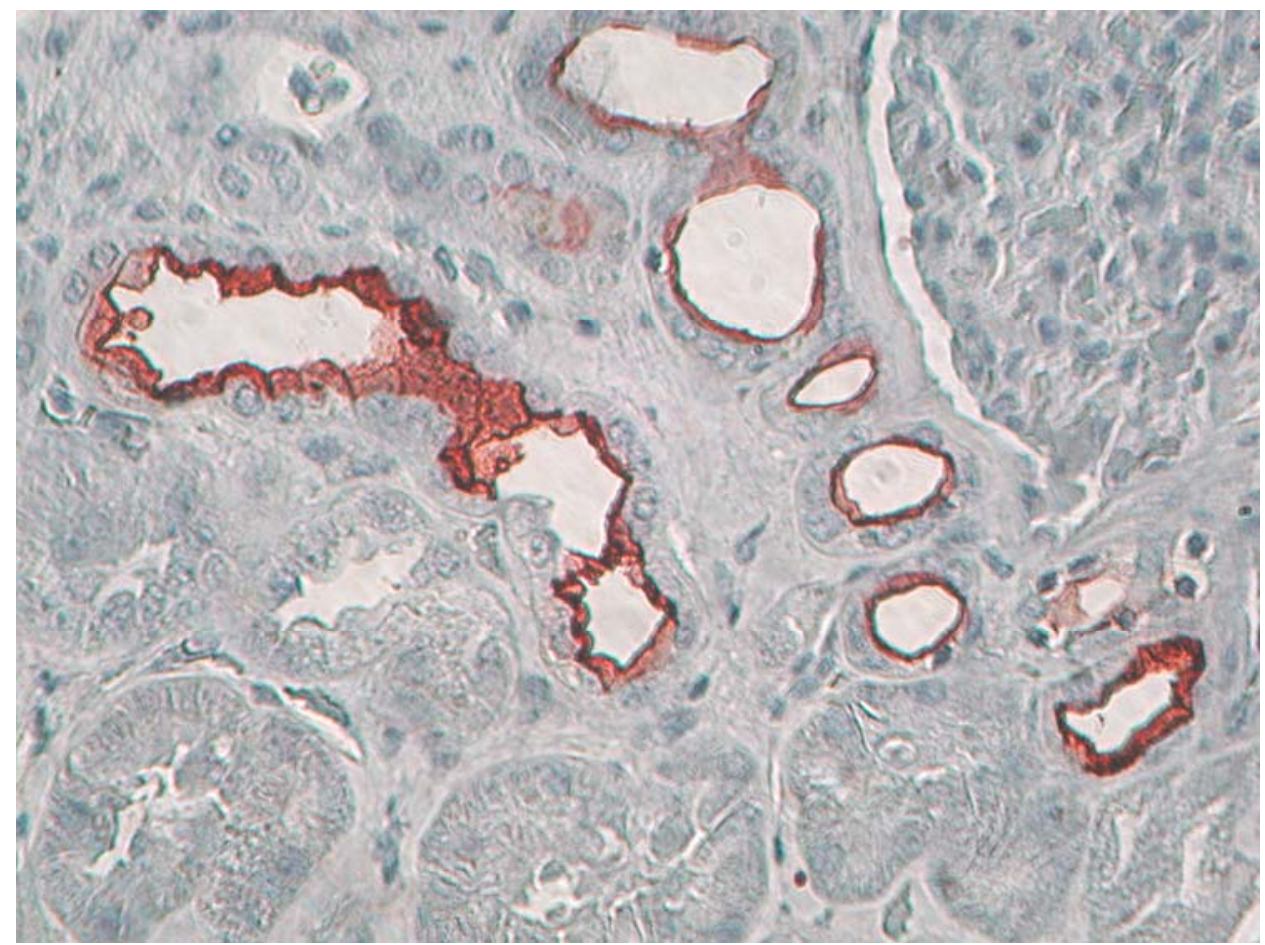

\section{Kontrollniere (A)}

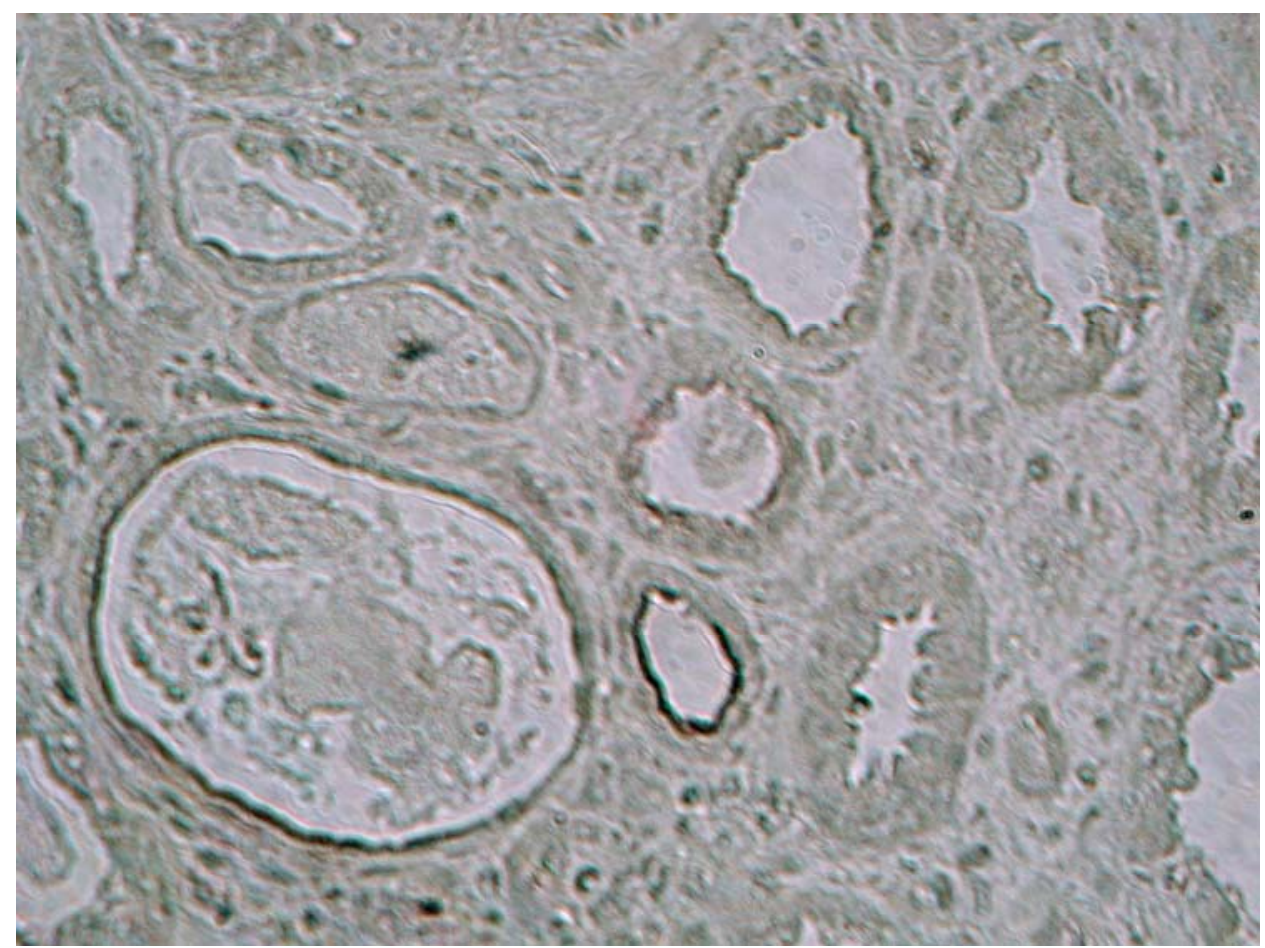

\section{Nephrosklerose (B)}

Abbildung 4 A und B Immunhistochemie für BMP-7 in gesundem Nierengewebe und in nephrosklerotischem Nierengewebe (400-fache Vergrößerung). Die Färbung erfolgte mit dem roten Farbstoff 3-Amino-9-Ethylcarbazol (AEC). Mit Antikörper für BMP-7 endoluminale Expression in den Tubuli (A, B). Im nephrosklerotischen Nierengewebe zeigte sich eine verminderte Expression (B). 


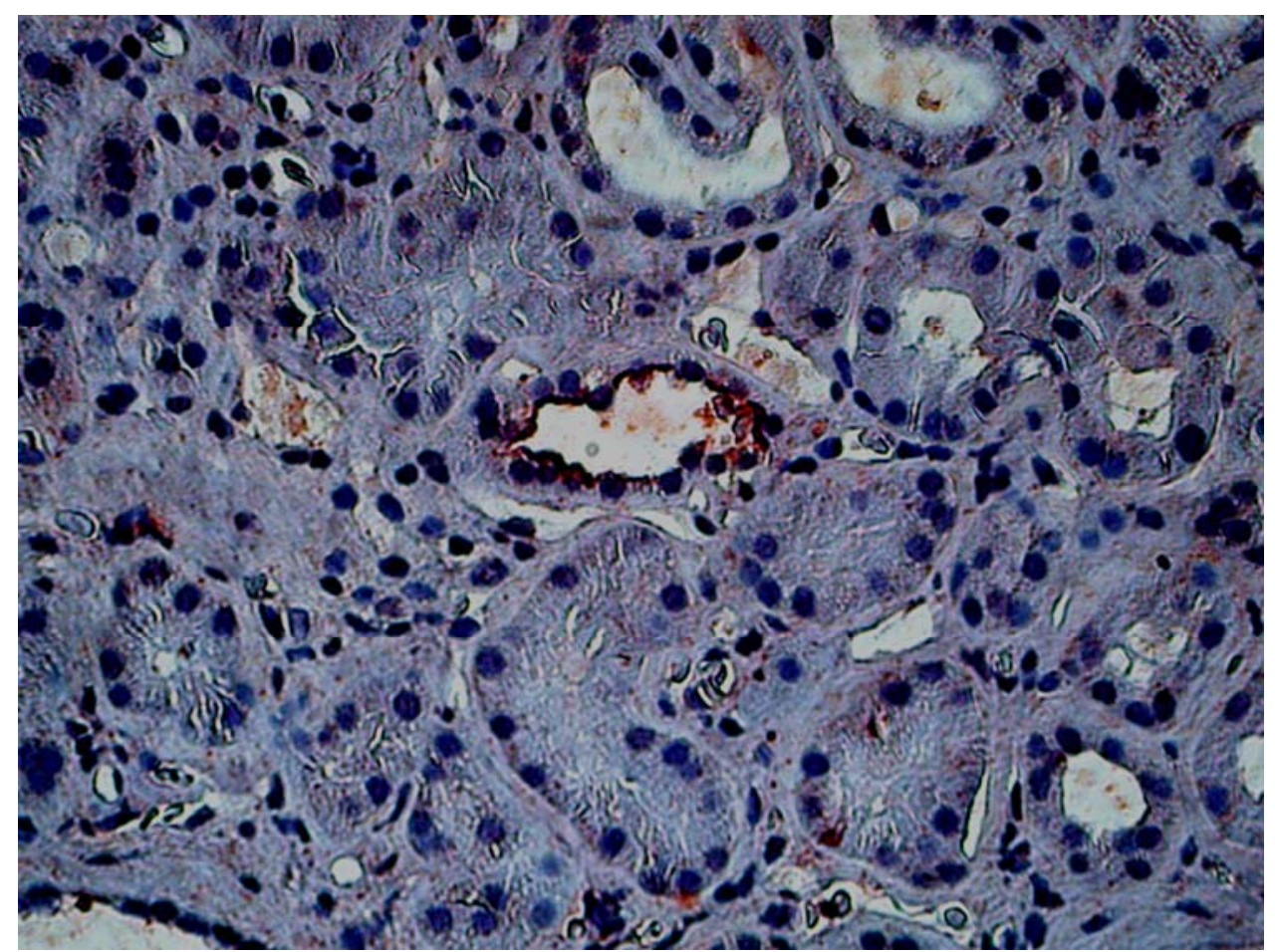

\section{Kontrollniere $(A)$}

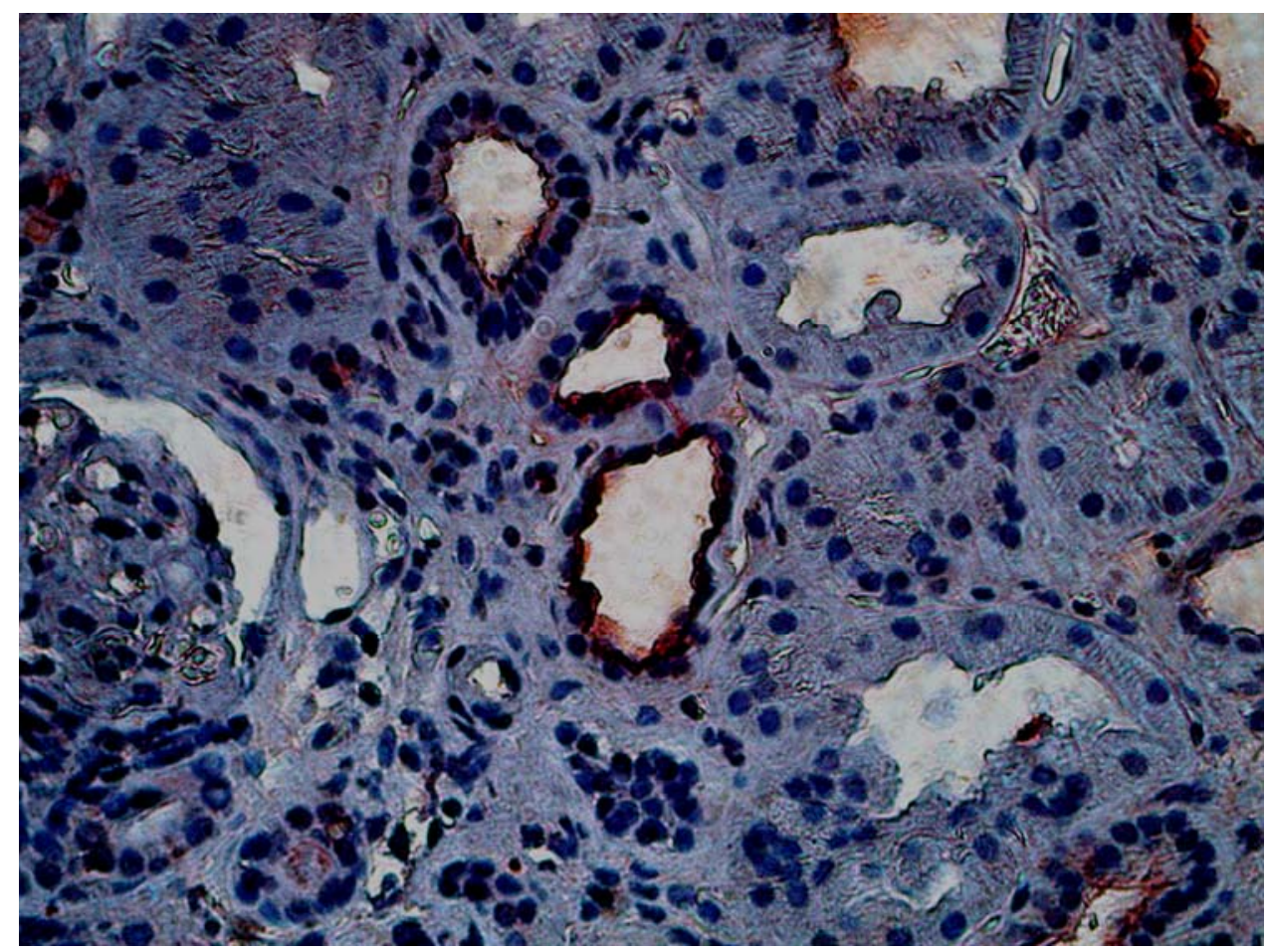

\section{Nephrosklerose (B)}

Abbildung 5 A und $B$ Immunhistochemie für BMP-4 in gesundem Nierengewebe (A) und in nephrosklerotischem Nierengewebe (B). Mit Antikörper für BMP-4 endoluminale Expression in den Tubuli (A, B) ohne Unterschiede in der Expression. 


\subsection{Real-time PCR}

\subsubsection{Einfluss der Stimulation von AT II auf die Expression von BMP-7}

Die Expression von BMP-7 wurde nach 12h-Stimulation von HK-2-Zellen mit AT II in Konzentrationen von $10^{-3} \mathrm{M}, 10^{-5} \mathrm{M}$ und $10^{-7} \mathrm{M}$ mittels real-time PCR quantifiziert. Für BMP-7 zeigte sich nach Stimulation in den niedrigeren Konzentrationen von $10^{-5}$ und $10^{-7} \mathrm{M}$ eine deutlich verminderte Expression von BMP-7 im Vergleich zu unstimulierten Tubuluszellen. Die stärkste Erniedrigung der BMP-7-Expression auf 13,65 \pm 26,73\% im Vergleich zu unstimulierten Zellen zeigte sich bei einer Konzentration von $10^{-5} \mathrm{M}$ AT-II.

In der statistischen Analyse zeigten sich hohe Standardabweichungen als Folge hoher PCRZyklenzahlen von 30-35 Zyklen. Eine signifikant verminderte Expression von BMP-7 zeigte sich nach Stimulation mit der höchsten verwendeten Konzentration von $10^{-3}$ AT II auf 15,3 \pm $24,19 \%(p<0,001)$ in der untersuchten Zellreihe.

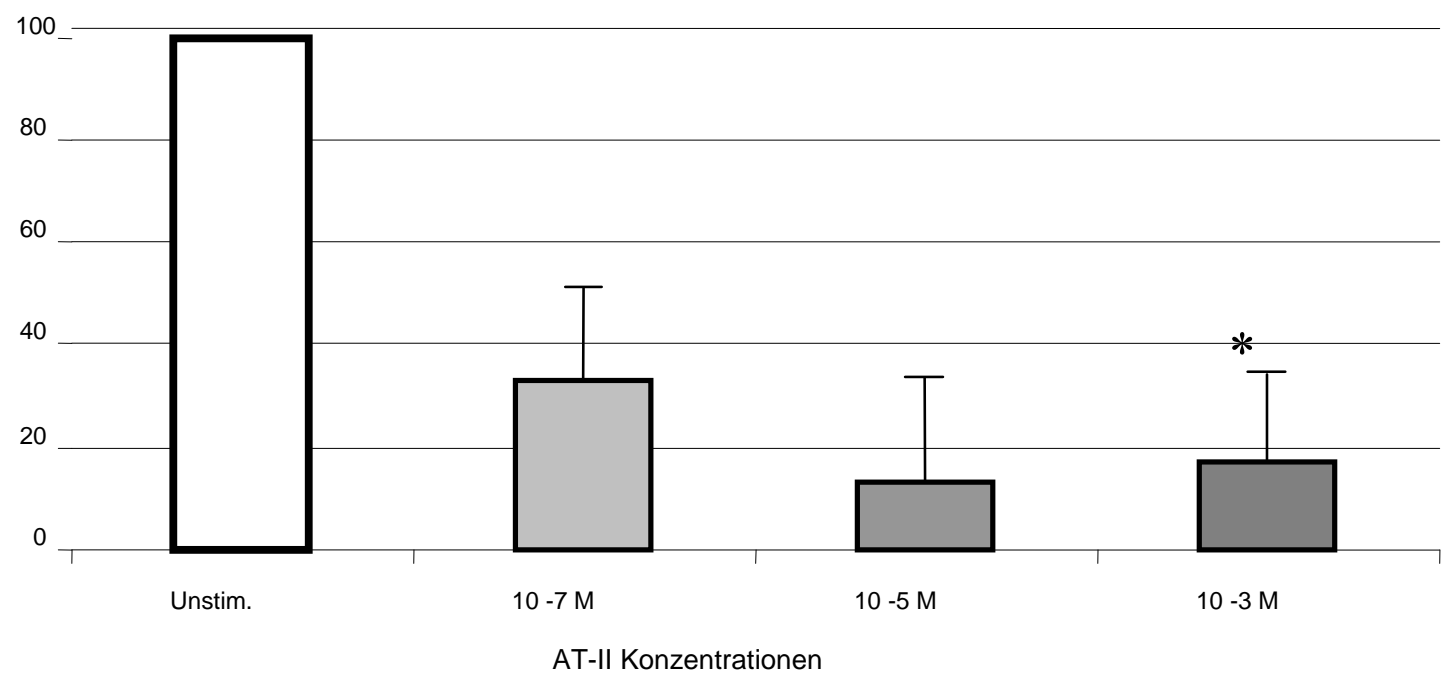

Abbildung 6 BMP-7-Expression in proximalen Tubuluszellen (HK-2) nach Stimulation mit AT II in unterschiedlichen Konzentrationen, dargestellt in \% von unstimulierten Zellen. Unter der höchsten Stimulation mit $10^{-3} \mathrm{M}$ AT II ließ sich eine signifikant verminderte Expression von BMP-7 erkennen. 


\subsubsection{Einfluss der Stimulation von AT II auf die Expression von BMP-4}

Die Expression von BMP-4 wurde ebenfalls nach 12h-Stimulation von HK-2-Zellen mit AT II in den oben genannten Konzentrationen mittels real-time PCR quantifiziert. Es fanden sich keine signifikanten Unterschiede in der Expression von BMP-4.

Bei einer Stimulation mit $10^{-7}$ und $10^{-5}$ M AT-II zeigte sich eine leicht verminderte Expression im Vergleich zur Negativkontrolle. Bei der höchsten Stimulationskonzentration von $10^{-3} \mathrm{M}$ AT-II zeigte sich ebenfalls eine leicht verminderte Expression von 89,07 \pm $11,92 \%$ ohne statistisch signifikanten Unterschied $(\mathrm{p}=0,153)$ im Vergleich $\mathrm{zu}$ den Kontrollbedingungen.

BMP-4

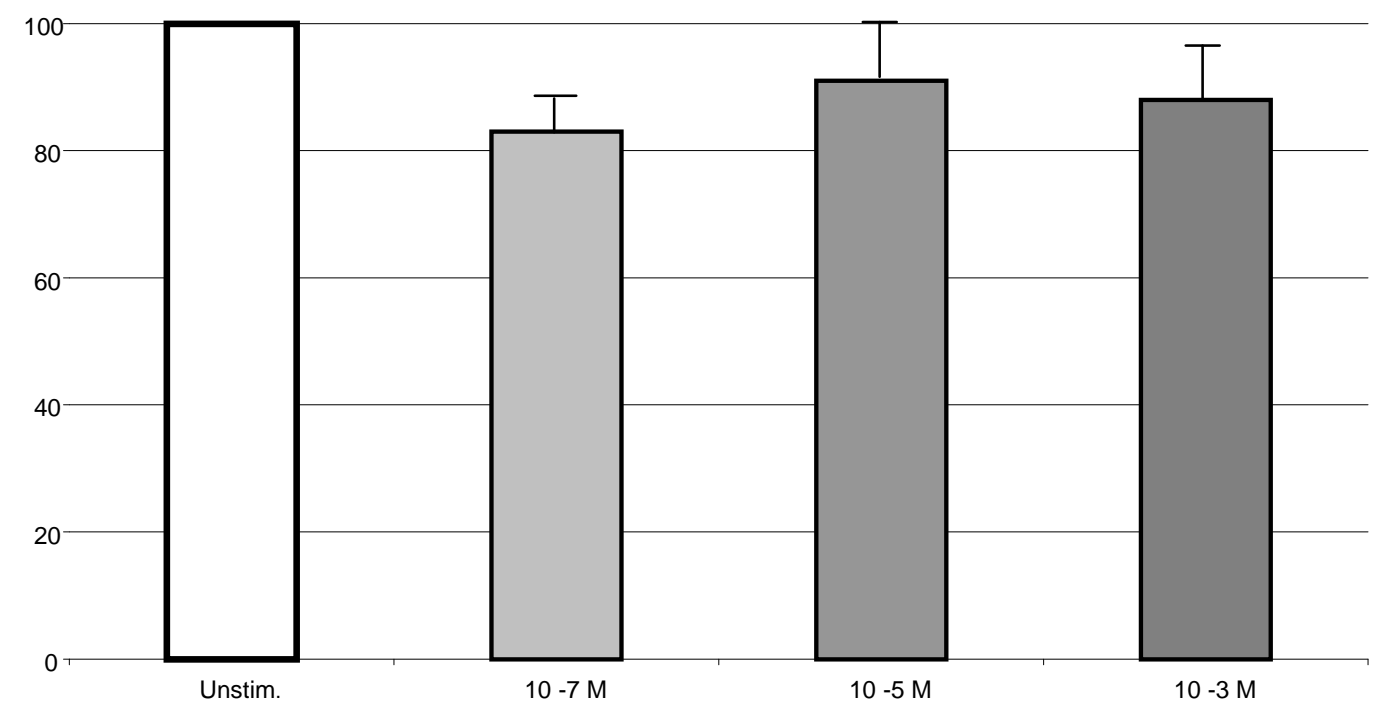

AT-II Konzentrationen

Abbildung 7 BMP-4-Expression in proximalen Tubuluszellen (HK-2) nach Stimulation mit AT II in unterschiedlichen Konzentrationen, dargestellt in \% von unstimulierten Zellen. Unter Stimulation mit AT II ließen sich keine signifikanten Unterschiede im Vergleich zu unstimulierten Zellen auf die Expression von BMP-4 erkennen. 


\subsection{Westernblot für BMP-4 und BMP-7}

Zum Nachweis von BMP-4 und BMP-7 auf Proteinebene sollte ein Immunoblot etabliert werden. Im Anschluss sollten die in der PCR durchgeführten Stimulationsversuche für den Nachweis von Regulationsmechanismen auf Proteinebene etabliert werden. Leider gelang in der Zeit der Fertigstellung dieser Arbeit keine Etablierung des Immunoblots, da mit verschiedenen verwendeten Antikörpern, Inkubationszeiten und Antikörperverdünnungen keine reproduzierbaren Ergebnisse erzielt werden konnten. Die Kochzeiten mit Mercaptoethanol wurden auf bis zu 15 min. ausgedehnt, um sicherzustellen, dass alle Disulfidbrücken aufgespalten werden und so keine Dimere mehr vorhanden sind. Am ehesten liegt die fehlende Detektionsmöglichkeit an der geringen Expression der BMPs im Nierengewebe und der geringen Sensitivität der vorhandenen Antikörper.

\subsection{Proliferationsassay}

Zur Untersuchung eines möglichen Einflusses der BMP's auf die Mitoserate der proximalen Tubuluszellen sowie auf Fibroblasten wurde ein auf der indirekten Messung der Inkorporation von BrdU basierender Proliferationsassay durchgeführt. Die Zelllinie HK-2 (proximale Tubuluszellen) wurde zunächst für $24 \mathrm{~h}$ in renal epithelial cell growth medium, die TK 173 (Fibroblasten) in DMEM-Medium mit $0,5 \mathrm{mM} / \mathrm{ml} \mathrm{L-Glutamin,} 10 \%(\mathrm{v} / \mathrm{v})$ FCS und 0,1\% Plasmocin kultiviert.

Im Anschluss erfolgte eine 24h dauernde Inkubation in IMDM ohne Zusätze. Darauf wurden die Zellen für 24 und 48h mit BMP-4 und BMP-7 in den Konzentrationen 1, 10 und 100 ng/ml stimuliert, als Negativkontrolle diente IMDM ohne Zusätze, als Positivkontrolle renal epithelial cell growth medium bei den HK-2-Zellen sowie DMEM mit den aufgeführten Supplementen für die TK-173-Zellen. Die Inkubation für 72h wurde nicht durchgeführt, da in Vorversuchen bei der Negativkontrolle der Zelllinie HK-2 eine längere Inkubation von den Zellen nicht toleriert wurde und ein Großteil der Zellen abstarb. 


\subsubsection{Einfluss von BMP-7 auf die Proliferationsrate von proximalen Tubuluszellen}

In humanen proximalen Tubuluszellen (HK-2-Zellen) konnte kein konzentrationsabhängiger Einfluss auf die Proliferationsrate nachgewiesen werden. Die Proliferation von HK-2-Zellen wurde durch BMP-7 in einer Konzentration von $1 \mathrm{ng} / \mathrm{ml}$ und $10 \mathrm{ng} / \mathrm{ml}$ geringgradig gesteigert (126\% und 122\% der Negativkontrolle). Bei einer Konzentration von $100 \mathrm{ng} / \mathrm{ml}$ waren keinerlei Unterschiede nachweisbar (100\% der Negativkontrolle). Es zeigte sich im Vergleich zur Negativkontrolle kein statistisch signifikanter Unterschied in der Proliferationsrate unter Stimulation mit BMP-7.

Proliferation HK 2

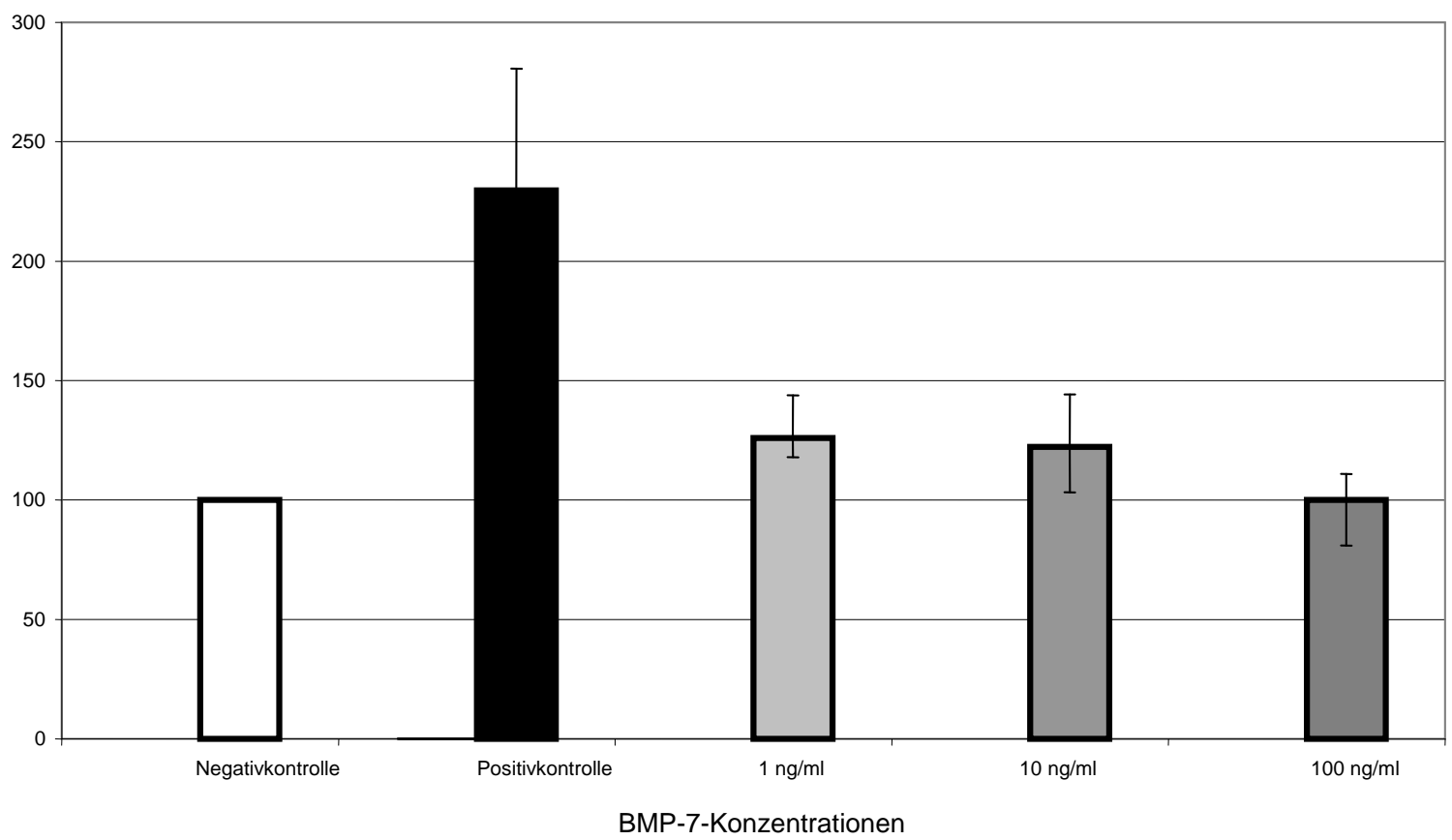

Abbildung 8 Proliferationsassay von HK-2-Zellen nach 48 h Stimulation mit BMP-7. Die dargestellten Werte sind Mittelwerte in \% von unstimulierten Zellen (Negativkontrolle) mit Minimum und Maximum aus drei unterschiedlichen Versuchsansätzen. Es war kein statistisch signifikanter Unterschied für die Stimulation mit BMP-7 im Vergleich zu unstimulierten Zellen nachweisbar. 


\subsubsection{Einfluss von BMP-4 auf die Proliferationsrate von proximalen Tubuluszellen}

Bei den HK-2-Zellen konnte auch für BMP-4 kein konzentrationsabhängiger Einfluss auf die Proliferationsrate beobachtet werden. Die Proliferation von HK-2-Zellen wurde durch BMP-4 in einer Konzentration von $10 \mathrm{ng} / \mathrm{ml}$ und $100 \mathrm{ng} / \mathrm{ml}$ geringgradig gesteigert (jeweils 122\% der Negativkontrolle). Bei einer Konzentration von $1 \mathrm{ng} / \mathrm{ml}$ konnte ein geringer antiproliferativer Effekt beobachtet werden (92\% der Negativkontrolle). Es zeigte sich im Vergleich zur Negativkontrolle kein statistisch signifikanter Unterschied in der Proliferationsrate unter Stimulation mit BMP-4.

Proliferation HK 2

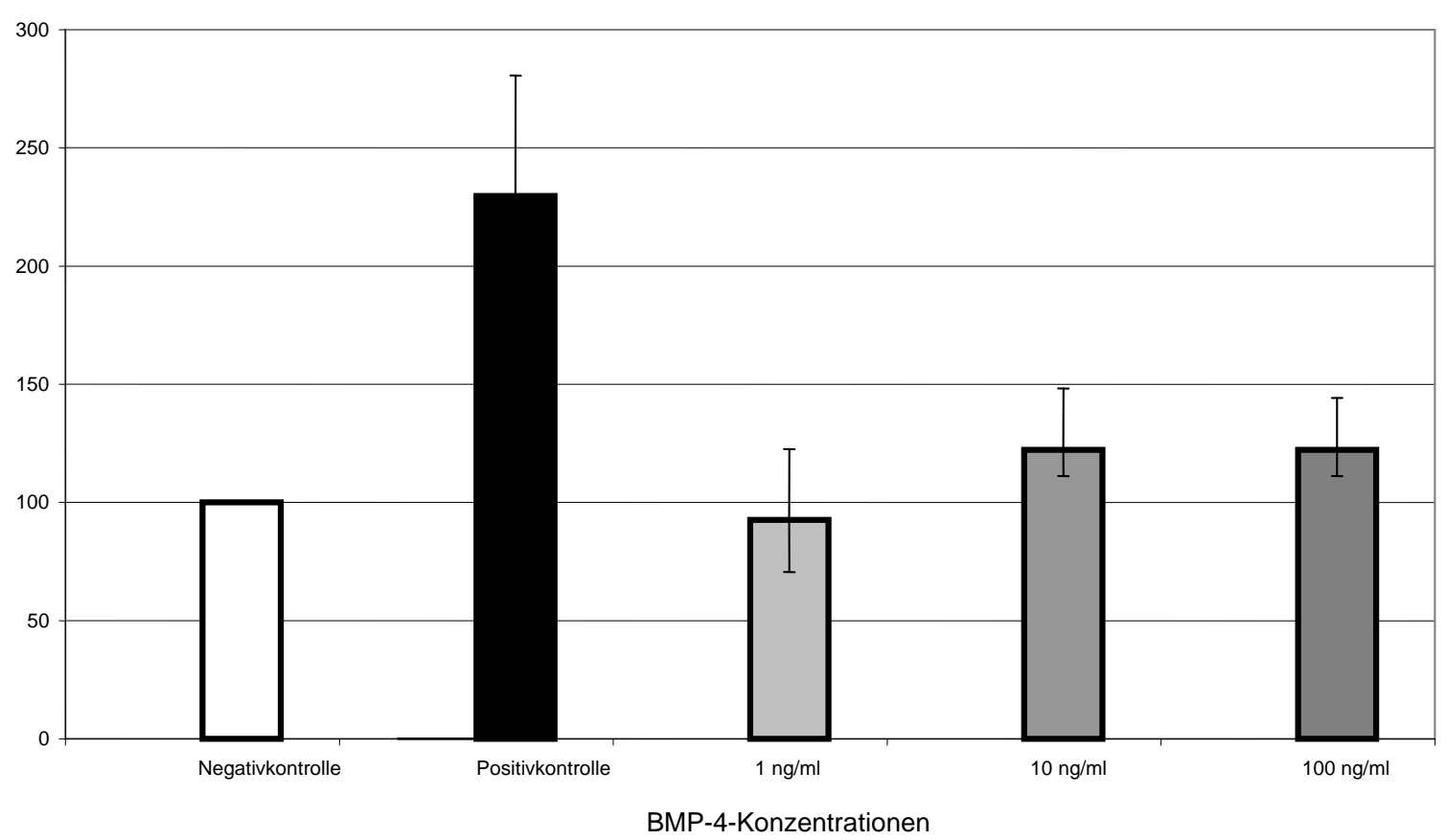

Abbildung 9 Proliferationsassay von HK-2-Zellen nach 48 h Stimulation mit BMP-4. Die dargestellten Werte sind Mittelwerte in \% von unstimulierten Zellen (Negativkontrolle) mit Minimum und Maximum aus drei unterschiedlichen Versuchsansätzen. Für die Stimulationsansätze zeigte sich kein statistisch signifikanter Unterschied im Vergleich zu unstimulierten Zellen. 


\subsubsection{Einfluss von BMP-7 auf die Proliferationsrate von Fibroblasten}

Die Inkubation der Fibroblastenreihe TK-173 mit BMP-7 zeigte keinen signifikanten Einfluss auf die Proliferationsrate. Bei einer Konzentration von $1 \mathrm{ng} / \mathrm{ml}$ BMP-7 konnte eine geringe Inhibition der Proliferation von TK-173-Zellen im Vergleich zur Negativkontrolle beobachtet werden ( $83 \%$ der Negativkontrolle), bei einer Konzentration von $10 \mathrm{ng} / \mathrm{ml}$ zeigte sich eine leichte Steigerung der Proliferation (106\% der Negativkontrolle). Bei der höchsten Stimulationskonzentration von $100 \mathrm{ng} / \mathrm{ml}$ fand sich eine Inhibition der Proliferation $(88 \%$ der Negativkontrolle). Es zeigten sich sehr hohe Schwankungsbreiten in den unterschiedlichen Versuchsansätzen. Statistisch signifikante Unterschiede in der Proliferationsrate waren im Vergleich zur Negativkontrolle unter Stimulation mit BMP-7 nicht nachweisbar.

Proliferation TK 173

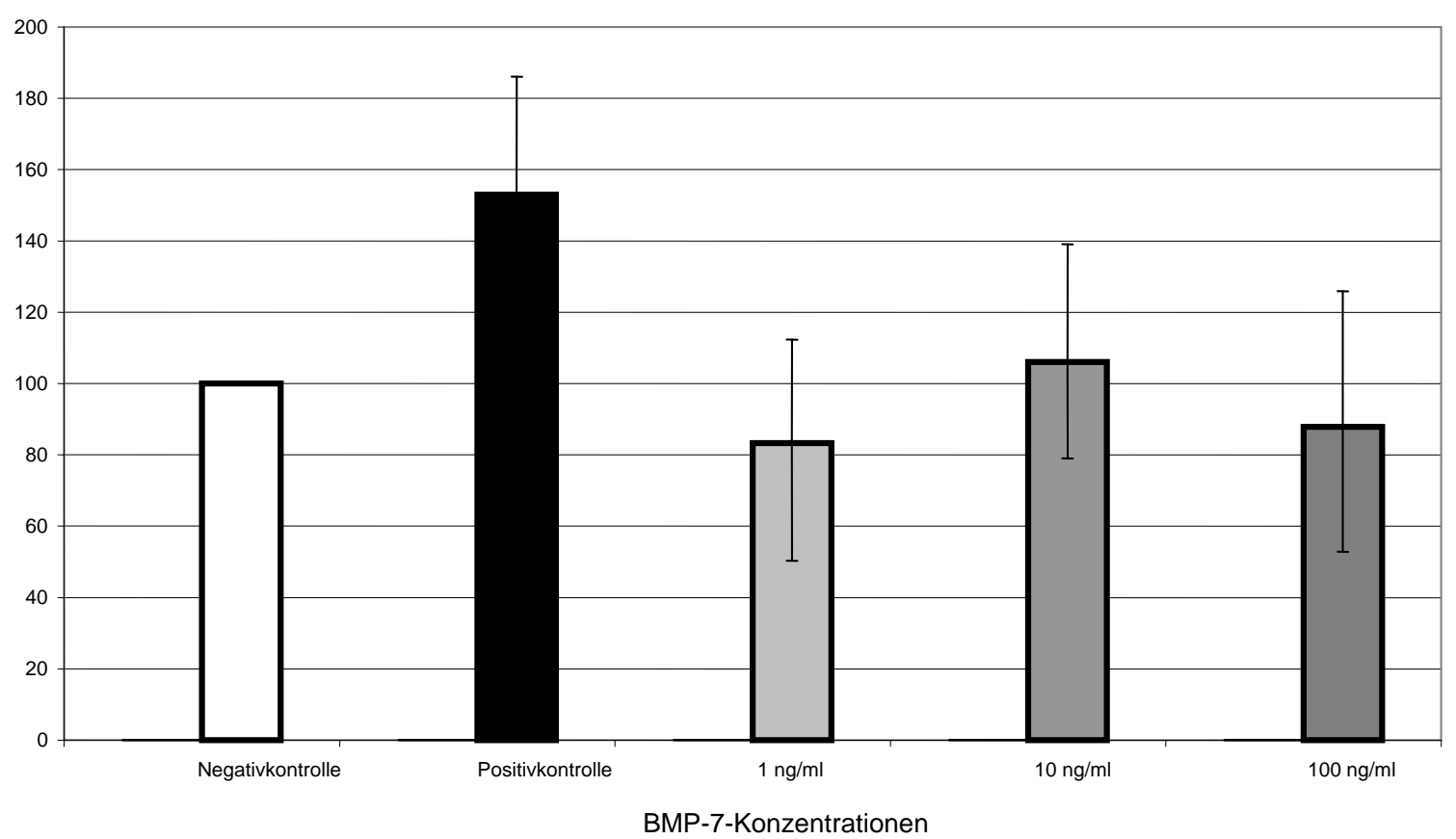

Abbildung 10 Proliferationsassay von TK-173-Zellen nach 48 h Stimulation mit BMP-7. Die dargestellten Werte sind Mittelwerte in \% von unstimulierten Zellen (Negativkontrolle) mit Minimum und Maximum aus drei unterschiedlichen Versuchsansätzen. Für die Stimulationsansätze zeigte sich kein statistisch signifikanter Unterschied im Vergleich zu unstimulierten Zellen. 


\subsubsection{Einfluss von BMP-4 auf die Proliferationsrate von Fibroblasten}

Die Inkubation der TK-173-Zellen mit BMP-4 zeigte keinen signifikanten Einfluss auf die Proliferationsrate. Bei einer Konzentration von 10 ng/ml BMP-4 konnte eine geringe Inhibition der Proliferation von TK-173-Zellen im Vergleich zur Negativkontrolle beobachtet werden (83\% der Negativkontrolle). Bei einer Konzentration von $100 \mathrm{ng} / \mathrm{ml}$ fand sich eine leichte Steigerung der Proliferation (107\% der Negativkontrolle). Es zeigte sich im Vergleich zur Negativkontrolle kein statistisch signifikanter Unterschied in der Proliferationsrate unter Stimulation mit BMP-4.

Proliferation TK 173

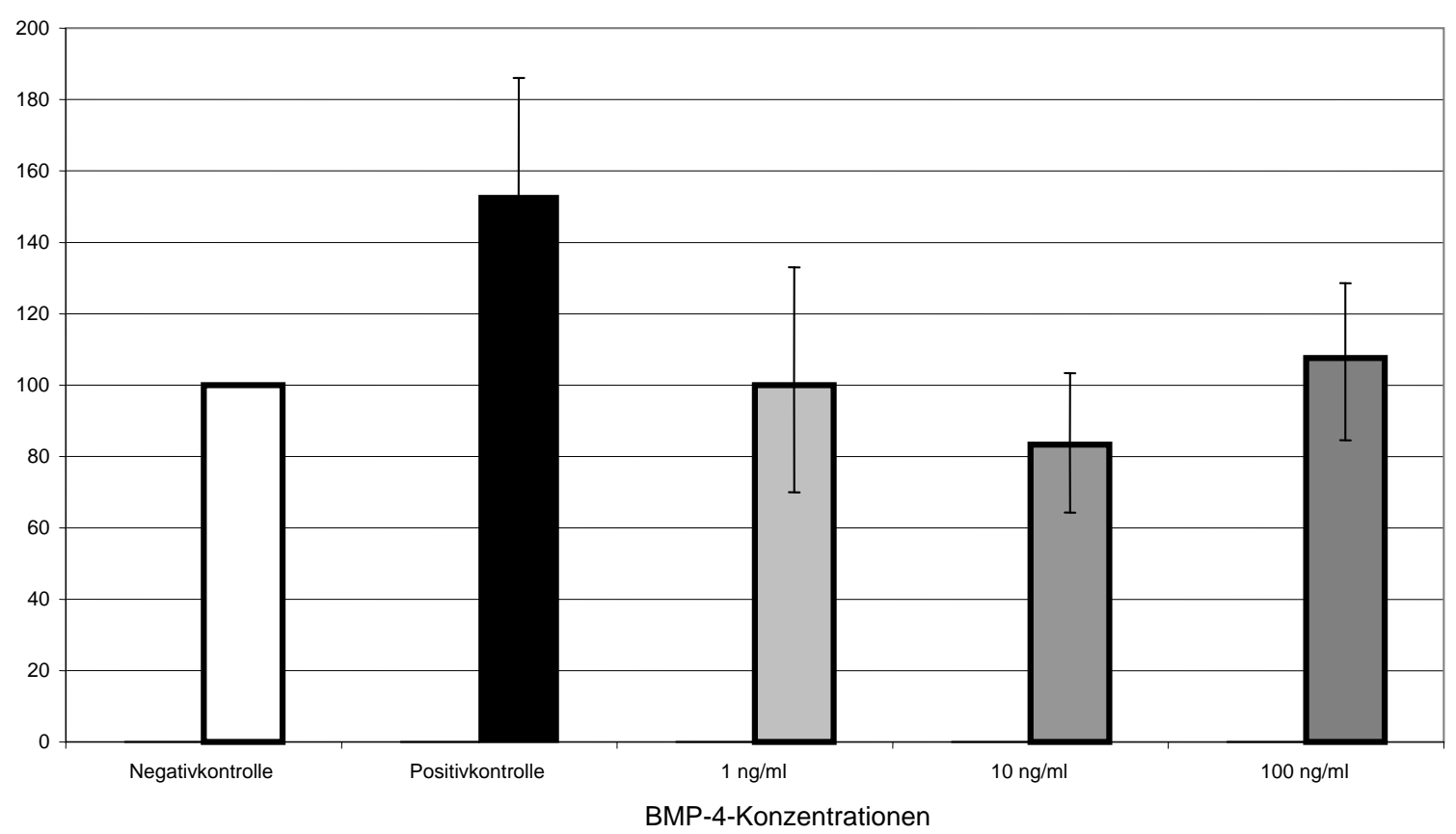

Abbildung 11 Proliferationsassay von TK-173-Zellen nach 48 h Stimulation mit BMP-4. Die dargestellten Werte sind Mittelwerte in \% von unstimulierten Zellen (Negativkontrolle) mit Minimum und Maximum aus drei unterschiedlichen Versuchsansätzen. Für die Stimulationsansätze zeigte sich kein statistisch signifikanter Unterschied im Vergleich zu unstimulierten Zellen. 


\section{Diskussion}

\subsection{Fibrose}

\subsubsection{Deutlich erhöhter Fibrosierungsgrad bei der Nephrosklerose}

Basis der Arbeiten war die Charakterisierung des Gewebes. Hierbei zeigte die MassonGoldner-Färbung einen deutlich erhöhten Fibrosierungsgrad bei den Gewebeproben aus nephrosklerotischen Nieren, was neben erhöhten Serumkreatininwerten und pathologischer Proteinausscheidung im Urin auf ein fortgeschrittenes Krankheitsstadium hinweist. Es muss darauf hingewiesen werden, dass nur begrenzte Gewebemengen zur Verfügung standen. Aus ethischen Gründen konnte kein zusätzliches Gewebe für Forschungszwecke entnommen werden. Für histologische Untersuchungen werden relativ große Gewebemengen benötigt, so dass für die von uns durchgeführten Versuche einschließlich einer Reihe von Vorversuchen an menschlichem Gewebe aus Nierenbiopsien diese Limitation toleriert werden musste. In der hier vorliegenden Arbeit erfolgte die Charakterisierung der Gewebeproben durch einen erfahrenen Nephropathologen (Prof. Dr. Gröne, Heidelberg). Kritisch bleibt anzumerken, dass es sich bei dem gesunden Gewebe aus Kontrollnieren um Präparate aus Tumornephrektomien handelte, wobei die gesunden Anteile der Organresektate verwendet wurden.

\subsubsection{Nierenfibrose als morphologisches Korrelat der Niereninsuffizienz}

Die Nierenfibrose stellt das morphologische Korrelat der Niereninsuffizienz bei der Nephrosklerose und zahlreichen anderen Erkrankungen dar (Strutz und Muller 1999). Erste Arbeiten, die systematisch einen Zusammenhang zwischen Morphologie und Nierenfunktion belegen, stammen aus den späten sechziger und frühen siebziger Jahren (Risdon et al. 1968; Schainuck et al. 1970; Striker et al. 1970). Erstmals konnte die Arbeitsgruppe von Bohle ein Jahrzehnt später in signifikantem Ausmaß nachweisen, dass die Serumkreatininkonzentration als negativ korreliertes Maß für die exkretorische Nierenfunktion mit der Zunahme des tubulointerstitiellen Raumes und dem Fibrosegrad zunimmt (Bohle et al. 1977; Bohle et al. 1979). Es gelang auch, auf der Grundlage des Fibroseausmaßes prognostische Aussagen zum Krankheitsverlauf zu treffen (Bohle et al. 1992; Bohle et al. 1994). Es werden verschiedene Hypothesen diskutiert, wie die Fibrosierung zu einer Einschränkung der renalen Funktion führt. Neben der Hypothese, dass Glomeruli ohne tubulären Anschluss gebildet werden (Marcussen 1995; 2000), steht heute eher die Annahme im Vordergrund, dass eine Verengung und der Untergang von postglomerulären Kapillaren zu funktionellen Einschränkungen des 
Organs führen. Erste Überlegungen hierzu wurden erstmals 1963 angestellt (Ljungqvist 1963). In weiteren Untersuchungen konnte diese Annahme bestätigt werden (Kang et al. 2002). Die reduzierte Kapillaranzahl führt zu einer Minderversorgung des Gewebes mit Sauerstoff mit konsekutiver Ausschüttung von profibrogenen Zytokinen und fortschreitendem Verlust der Nierenfunktion. Die Hypoxie führt hier neben weiteren Faktoren zu einer erhöhten Matrixsynthese in proximalen Tubuluszellen und Fibroblasten (Norman et al. 2000; Norman und Fine 2006). Wenn in frühen Stadien der Nephrosklerose eine bestimmte Anzahl von Nephronen untergegangen ist, kommt es zu einer kompensatorischen Dilatation afferenter Abschnitte der intakten Nephrone. Konsekutiv kommt es zu einer fokalen Glomerulosklerose dieser intakten Abschnitte (Harvey et al. 1992). Primär auffallend sind die histologischen Veränderungen an den Gefäßen. Hierbei kommt es in Folge des erhöhten Druckes zu einer Hyalinose der Vasa afferentia mit Verbreiterung der Tunica externa. Durch eine Verdoppelung der Membrana elastica interna kommt es zu einer Verdickung der Tunica intima und in der Folge zu einer glomerulären Sklerose und tubulärer Atrophie (Dasgupta et al. 2007). Im Zuge der dadurch auftretenden Gefäßverengungen kommt es zur Aktivierung des Renin-Angiotensin-Aldosteron-Systems, was eine weitere Blutdrucksteigerung zur Folge hat (Luke und Curtis 1993). Neben dem Grad der Fibrosierung finden sich in neueren Arbeiten zur Nephrosklerose differenzierte Untersuchungen glomerulosklerotischer Veränderungen und deren Folgen. Hill unterscheidet in seiner Übersichtsarbeit neben ungeschädigten Glomeruli zwei Typen von pathologisch veränderten Glomeruli. Zum einen gibt es ischämische Glomeruli mit unterschiedlichen Stadien eines Gefäßkollapses, zum anderen hypertrophierte Glomeruli, bei denen es zu einem Verlust der Autoregulation kommt, was neben der Ischämie zu einem Fortschreiten der Erkrankung beiträgt (Hill 2008).

\subsubsection{Zur Pathophysiologie der Fibrosierung}

Die Fibrosierung verläuft analog zur physiologischen bindegewebigen Defektheilung bei der regulären Wundheilung. Sie wird willkürlich in drei Abschnitte eingeteilt: Induktions-, Inflammations- und Postinflammationsphase (Kuncio et al. 1991). In der Induktionsphase kommt es zu einer Infiltration des interstitiellen Gewebes durch mononukleäre Zellen und Lymphozyten (Muller et al. 1992; Strutz und Neilson 1994). Es konnte gezeigt werden, dass eine Zunahme des Fibrosierungsgrades mit einer gesteigerten Mastzellinfiltration einhergeht (Kondo et al. 2001). 
Die Infiltration der immunkompetenten Zellen wird durch eine Reihe von Zytokinen vermittelt, die neben chemotaktischen auch profibrogene Effekte induzieren (Strutz und Neilson 1994). Bei den Zytokinen handelt es sich um eine Gruppe von Substanzen, durch die inflammatorische Prozesse im Rahmen der Fibrogenese gesteuert und beeinflusst werden. Zwei wichtige Substanzen stellen dabei TNF- $\alpha$ und Interleukin 1 dar. Sie sind in der Lage, eine Infiltration von Entzündungszellen (Leukozyten) zu induzieren (Wardle 1993).

Die zweite Phase der Fibrose ist durch eine gesteigerte Matrixbildung bei gleichzeitig vermindertem Matrixabbau gekennzeichnet, so dass das vorher bestehende Gleichgewicht in Richtung einer vermehrten Synthese verlagert wird (Jones CL et al. 1992). In diesem Abschnitt der inflammatorischen Matrixsynthese werden Fibroblasten durch zahlreiche Zytokine aus immigrierten und residenten (renalen) Zellen stimuliert und zur Synthese von Bestandteilen der extrazellulären Matrix angeregt. $\mathrm{Zu}$ den Bestandteilen der extrazellulären Matrix gehören Kollagene vom Typ I, III und IV sowie Proteoglykane und Fibronektin.

In der dritten Phase der postinflammatorischen Matrixsynthese unterscheidet sich die renale Fibrogenese entscheidend von der physiologischen Wundheilung. Während es dort zu einer Resolution kommt, in der Proliferations- und Synthesevorgänge zum Stillstand kommen, wird in der Niere die Matrixdeposition auch nach dem Abklingen des primären Entzündungsstimulus fortgesetzt. In der Folge kommt es dann zu relevanten morphologischen Veränderungen und in der Konsequenz zu einem Verlust der Organfunktion. In dieser Phase sind zahlreiche proliferierende Fibroblasten nachweisbar (Ng et al. 1998).

\subsection{Begrenzte therapeutische Möglichkeiten bei Nephrosklerose}

Die beschriebenen Mechanismen lassen sich nach heutigem Kenntnisstand nicht pharmakologisch aufhalten. Eine Stagnation des Verlustes der Nierenfunktion durch eine medikamentöse Behandlung kann in fortgeschrittenen Krankheitsstadien leider nicht bewirkt werden. Durch die Gabe von Hemmern des RAAS kann lediglich eine Verzögerung erreicht werden. Demographische Entwicklungen mit einem zunehmenden Alter der Bevölkerung gehen mit einer erhöhten Inzidenz der Nephrosklerose und anderen vaskulären Erkrankungen einher. Von klinischer Seite bleibt zu bemerken, dass der Einsatz von Hemmern des RAAS bei unbedachtem Einsatz gerade bei älteren Patienten auch Probleme wie Störungen des Elektrolythaushaltes, Auftreten eines akuten Nierenversagens und bei Polypharmazie Interaktion mit anderen Medikamenten mit sich bringen kann (Boyd et al. 2005; Turgut et al. 2010). Die Erkundung neuer therapeutischer Ansatzpunkte auf der Basis 
molekularbiologischer Erkenntnisse ist notwendig. Ein Ziel der laborexperimentellen Forschung ist die mittelfristige Entwicklung neuer Therapiestrategien zur Behandlung der immer bedeutsamer werdenden chronischen Erkrankungen. BMP's könnten aufgrund der Vorbefunde und der hier vorliegenden Ergebnisse für die Nephrosklerose und weitere Formen der chronischen Niereninsuffizienz einen interessanten Ansatzpunkt darstellen.

\subsection{Die Rolle von BMP's in der Pathophysiologie der Nephrosklerose}

Da für BMP-7 protektive und regeneratorische Effekte bei progressiven Nierenerkrankungen und der Atherosklerose im Tiermodell beschrieben und für BMP-4 pathogenetisch relevante Wirkungen bei der Atherosklerose postuliert wurden, erwarteten wir auch einen Zusammenhang mit dem pathogenetisch bedeutsamen RAAS in der Nephrosklerose. In der Zellkultur ließ sich eine mesenchymal-epitheliale Transition als Hinweis auf eine regenerative Wirkung von BMP-7 beobachten. Bei der Atherosklerose vermag BMP-7 im Mausmodell Kalzifizierungsprozesse zu antagonisieren (Zeisberg et al. 2005). Unsere Ergebnisse in der Immunhistochemie sowie in der PCR, die auf eine verminderte BMP-7-Konzentration bei der Nephrosklerose hinweisen, lassen eine Bedeutung von BMP-7 bei der Nephrosklerose vermuten.

Insbesondere stellen unsere Untersuchungen erste Ergebnisse der möglichen Rolle von BMP7 und BMP-4 bei der humanen Nephrosklerose dar. Die Verabreichung von BMP-7 stellt möglicherweise auf Basis der bisherigen Ergebnisse beim Menschen einen besonders interessanten Ansatz zur Therapie der Nephrosklerose dar. In Folgeexperimenten müssen jedoch die Wirkmechanismen exakter untersucht werden. Ein möglicher klinischer Einsatz von BMP-7 ist mit einigen Problemen assoziiert, was durch die bisherigen Erfahrungen im Einsatz von BMP-7 in der Traumatologie belegt wird.

\subsection{Bisherige Erfahrung im klinischen Einsatz von BMP-7 in der Traumatologie}

Im Bereich der Traumatologie bestehen bereits klinische Erfahrungen im Einsatz von BMP-7. Seit Mai 2001 ist rekombinantes humanes BMP-7 für den Einsatz bei fehlender Knochenheilung nach Frakturen zugelassen, wenn auch durch eine Spongiosaplastik kein wünschenswerter Erfolg erzielt werden konnte. Es bewirkt die Differenzierung von Stammzellen zu reifen Osteoblasten. Eine Applikation erfolgt intraoperativ lokal und führt zu klinisch erfreulichen Ergebnissen (Zimmermann et al. 2006). Kritisch muss angemerkt 
werden, dass eine Bostoner Arbeitsgruppe bei einem Teil von mit BMP-7 behandelten Patienten nach Applikation heterotope Ossifikationen beschrieb. Subkutane Injektionen von BMP-7 führten zu Ossifikationen im Bereich der Injektionsstellen. Diese konnten jedoch komplikationsfrei chirurgisch reseziert werden (Axelrad et al. 2008). Eine Wirkung am Knochen ist vor dem Hintergrund der Behandlung einer renalen Osteopathie, unter der ein Großteil der terminal niereninsuffizienten Patienten leidet, erstrebenswert. Eine lokale Applikation in der Niere erscheint eher schwierig. Ossifikationen am Organ könnten zu weiteren Komplikationen führen. Selbst wenn der Nachweis einer Wirksamkeit bei der Nephrosklerose und anderen progredienten Nierenerkrankungen erbracht werden kann, muss das Problem der Applikation noch gelöst werden.

\subsection{Charakterisierung von BMP-7 und BMP-4 in nephrosklerotisch verändertem und gesundem humanen Nierengewebe}

In dieser Arbeit ist es erstmalig gelungen, in der adulten humanen Niere an gesundem und nephrosklerotisch verändertem Nierengewebe die untersuchten BMP's nachzuweisen. Zur erstmaligen Charakterisierung der Expression von BMP-4 und BMP-7 wurden immunhistochemische Färbungen für beide Moleküle angefertigt. Bisher war noch kein Nachweis auf mRNA- und Proteinebene für die Expression von BMP-4 und BMP-7 in humanem Nierengewebe erbracht worden. Es sollte untersucht werden, wo sich eine Expression von BMP's in der Niere nachweisen lässt und ob sich die Expression der BMP's in gesundem Nierengewebe von der in nephrosklerotisch verändertem Gewebe unterscheidet. Für das protektiv regeneratorisch wirkende BMP-7 zeigten sich bei der Nephrosklerose wie im gesunden Nierengewebe ähnliche Expressionsmuster. Eine Expression zeigte sich vorwiegend endoluminal in den distalen Tubuluszellen sowie in den Sammelrohren, wobei die Expression insgesamt bei der Nephrosklerose leicht vermindert war. Die von uns nachgewiesene endoluminale Expression von BMP-7 im Bereich der distalen Tubuli und Sammelrohre deckt sich mit den Ergebnissen der Arbeitsgruppe von Wetzel, die ähnliche Expressionsmuster in gesundem humanen Nierengewebe finden konnte (Wetzel et al. 2006). Im Rahmen des Fortschreitens der Nephrosklerose könnte es zu einer Abnahme der Bildung von BMP-7 kommen. Da BMP-7 protektive Wirkungen zu haben scheint, könnte diese verminderte Expression zu einem Fortschreiten der Erkrankung beitragen. Eine Applikation von BMP-7 könnte daher eine Progression der Erkrankung verzögern oder aufhalten. Wünschenswert wäre es, eine Reversibilität der Umbauprozesse (wie im Tiermodell gesehen) zu erlangen. 
Für BMP-4 fand sich in der Immunhistochemie eine endoluminale Expression, die geringer ausgeprägt war, als die Expression von BMP-7. Es zeigten sich jedoch keine Unterschiede in der Lokalisation oder Quantität der Expression von BMP-4 zwischen den untersuchten Gewebeschnitten. Eine Erklärung hierfür könnte sein, dass die Sklerose schon weit fortgeschritten ist und die Unterschiede eher in einem früheren Stadium sichtbar wären, bevor eine stärkere Fibrosierung eingetreten ist. Eine vermehrte Expression von BMP-4 als krankheitsförderndem Zytokin wäre demnach in einer frühen Phase der Nephrosklerose nachweisbar, bevor die Fibrosierung ein Stadium wie in den von uns untersuchten Präparaten erreicht hat. In den Arbeiten von Dhore konnte BMP-4 jedoch auch bei fortgeschrittenen Stadien der Atherosklerose nachgewiesen werden. Ein direkter Vergleich der in unserer Arbeit untersuchten Nephrosklerose mit Atherosklerose erscheint schwierig (Dhore et al. 2001). In verschiedenen Tiermodellen konnte für BMP-4 ein möglicher Interaktionsweg mit dem RAAS aufgezeigt werden. Eine chinesische Arbeitsgruppe konnte kürzlich an Hauptschlagadern von Mäusen nachweisen, dass eine entzündliche endotheliale Dysfunktion durch BMP-4 über eine Hochregulation von Cyclooxygenase 2 (COX-2) reguliert wird. Besonders interessant ist, das in dieser Arbeit ein immunhistochemischer Nachweis sowie ein Nachweis auf Proteinebene im Westernblot gelang (Wong et al. 2010).

Eine deutsche Arbeitsgruppe konnte bei Applikation von AT-II in Ratten unter anderem eine direkte Steigerung der COX-2-RNA-Expressionsraten in Glomeruli nachweisen Diese Ergebnisse erhärten den Verdacht, dass ein Zusammenhang zwischen dem RAAS und der Funktion von BMP-4 auf diesem Niveau bestehen könnte (Doller et al. 2009). Folgeexperimente sollten sich auf die Untersuchung dieses möglichen Interaktionsfeldes konzentrieren.

\subsection{Unterschiedliche Expressionsmuster von BMP-7 in der PCR}

Unsere Vorannahmen und die Beobachtungen in der Immunhistochemie konnten durch Daten aus einem Verbundprojekt, der European renal cDNA Bank, die mittels PCR erhoben wurden, bestätigt werden. In diesem Projekt werden seit 1998 europaweit Gewebe aus Nierenbiopsien gesammelt und der Bank zugeführt (Cohen et al. 2002, Koziolek et al. 2007). So zeigte sich bei der Nephrosklerose die Expression von BMP-7 im Tubulointerstitium im Vergleich zu gesundem Nierengewebe vermindert (Bramlage et al. 2010).

Das könnte zu der Annahme führen, dass durch AT II vermittelt auf RNA-Ebene BMP-7 vermindert exprimiert wird. Es gibt zahlreiche Untersuchungen, die darauf hinweisen, dass sich bedeutende pathophysiologische Prozesse, die zu einer Funktionseinschränkung der 
Niere führen, im Tubulointerstitium abspielen. Eine verminderte Expression von BMP-7 lässt sich in verschiedenen nephrologischen Erkrankungen im Tiermodell beobachten (Bramlage et al. 2005). Eine Progression der Fibrosierung in späten Stadien von Nephropathien ist mit einem Verlust der BMP-7-Expression vergesellschaftet.

In den Daten aus dem genannten Verbundprojekt fanden sich in den Glomeruli keine signifikanten Unterschiede in der Expressionsrate von BMP-7 im Vergleich zwischen Glomeruli aus gesunden und Glomeruli aus nephrosklerotischen Nieren.

Eine mögliche Erklärung ist die insgesamt sehr niedrige Expression von BMP's in humanen Glomeruli, denn ein Nachweis fand sich erst bei relativ hohen PCR-Zyklenzahlen (30-35 PCR-Zyklen). Die Lokalisation von BMP-7 in der adulten Niere ist noch wenig erforscht und in der Literatur finden sich wie bereits angedeutet widersprüchliche Aussagen. Der Arbeitsgruppe von Wetzel gelang es nicht, BMP-7 in Glomeruli oder proximalen Tubuluszellen nachzuweisen. In der PCR zeigte sich ebenfalls keine Expression in isolierten Glomeruli humaner Nieren. In distalen Tubuli fand sich dagegen eine Expression von BMP-7, was sich mit unseren Ergebnissen in der Immunhistochemie deckt (Wetzel et al. 2006). Die Gruppe um Rudnicky dagegen konnte BMP-7 in proximalen Tubuluszellen nachweisen. Bei Patienten mit proteinurischer Nephropathie zeigte sich hier die Expression von BMP-7 im Vergleich zu gesunden Patienten (als möglicher körpereigener tubuloprotektiver Mechanismus) erhöht. In den Glomeruli fand sich ebenfalls keine Expression (Rudnicki et al. 2007).

In Glomeruli von Nagern konnte eine Expression von BMP-7 und seinen Rezeptoren nachgewiesen werden. In vivo finden sich hier zahlreiche Nachweise von BMP-7 in Glomeruli aus Nierengewebe von Ratten (Bosukonda et al. 2000; Biyikli et al. 2005) und Mäusen (Simon et al. 1999; Gould et al. 2002).

Die beschriebenen Beobachtungen decken sich mit einer Reihe von Untersuchungen unterschiedlicher Krankheitsmodelle im Tierversuch (Dube et al. 2004; Biyikli et al. 2005; Mitu und Hirschberg 2008). Das beinhaltet den akuten ischämischen Nierenschaden, die tubulointerstitielle Fibrose und die diabetische Nephropathie. Experimente an Nagern mit Streptozotozin-induziertem Diabetes konnten nach 15 Wochen eine um die Hälfte reduzierte renale Expression von BMP-7 und nach 30 Wochen eine Reduktion auf 10\% im Vergleich zu den Kontrolltieren zeigen (Wang SN et al. 2001).

In Zukunft müssen weitere standardisierte Untersuchungen an spezifischen Nierenerkrankungen erfolgen, um zu klinisch wegweisenden Erkenntnissen zu kommen. 
Für das akute Nierenversagen konnte in einer erst kürzlich veröffentlichten Arbeit in einem Mausmodell der Sepsis die Wirkung von Propofol auf die Zytokinexpression gezeigt werden. Propofol war in der Lage, den Anstieg der Nierenretentionsparameter und das Versterben der Mäuse im Vergleich zur Kontrollgruppe signifikant zu verzögern. Dieser klinisch verbesserte Verlauf des schweren Krankheitsbildes ging mit einer signifikant erhöhten BMP-7-Expression auf mRNA-Ebene im Nierengewebe der mit Propofol behandelten Mäuse einher. Gleichzeitig zeigte sich eine verminderte Expression von proinflammatorischen Zytokinen wie TNF- $\alpha$ und Monozyten- chemotaktischem Protein 1 (MCP-1). In vitro-Versuche mit Mesangiumzellen der Ratte (RMC) und renalen Epithelzellen der Maus (M1) bestätigten die Resultate (Hsing et al. 2011).

\subsection{Charakterisierung der BMP's in unterschiedlichen Krankheitsstadien notwendig}

In der hier vorliegenden Arbeit zeigte sich bei den Patienten in der Immunhistochemie eine pathologisch erhöhte Proteinausscheidung im Urin. Das lässt darauf schließen, dass es sich bei dem untersuchten Gewebe um fortgeschrittene Krankheitsstadien handelt. Die vermehrte Konzentration von Proteinen im Urin (Proteinurie) hat eine Wirkung auf epitheliale Tubuluszellen, die ihrerseits in einer vermehrten Synthese inflammatorischer und profibrogener Faktoren resultieren kann. Es kommt zu einer Aktivierung von Fibroblasten. Bei der hypertensiven Nephrosklerose stellt das Ausmaß der Proteinurie einen Prädiktor für die Krankheitsprogression dar und ist mit einer erniedrigten glomerulären Filtrationsrate assoziiert (Barri 2006; Strutz 2009).

Weitere Untersuchungen könnten sich mit der Verteilung von BMP's in früheren Krankheitsstadien auseinandersetzen. Da eine Diagnosestellung jedoch häufig relativ spät erfolgt und eine frühe Gewebeentnahme ethische Probleme mit sich führt, müssen zunächst im Tiermodell der Nephrosklerose unterschiedliche Stadien und BMP-Verteilungsmuster untersucht werden, um genauere Erkenntnisse über die mögliche Rolle der BMP's bei der Pathophysiologie der Fibrosierung zu erlangen.

Des Weiteren wären Untersuchungen des Zusammenhangs von Intensität und Verteilung der BMP-Expression und der glomerulären Morphologie interessant. Problematisch dürften sich hier jedoch die niedrigen Expressionsraten von BMP's in Glomeruli darstellen, die eine Detektion und den Nachweis von Unterschieden zunächst mit den gegenwärtig zur Verfügung stehenden Antikörpern zwischen verschiedenen Glomeruli erschweren. 


\subsection{Regulation der Expression von BMP's durch Angiotensin II und andere Zytokine}

Wie bereits erwähnt spielt das Renin-Angiotensin-Aldosteron-System (RAAS) eine wichtige Bedeutung bei der Pathophysiologie der Nephrosklerose. Daher erfolgte zur Untersuchung der Effekte von Angiotensin II auf die Expression von BMP-7 und BMP-4 in der hier vorliegenden Arbeit eine Stimulation von HK-2-Zellen mit Angiotensin II in verschiedenen Konzentrationen. Unsere Arbeitshypothese lautete, dass eine Suppression des protektiv wirkenden BMP-7 eintreten würde. In unseren Resultaten für BMP-7 zeigten sich niedrige Replikationsraten, was zu hohen Standardabweichungen führte. Dennoch war nach einer Stimulation mit $10^{-3}$ M AT-II die Expression von BMP-7 signifikant erniedrigt. Das könnte den Mechanismus der in der Immunhistochemie herabgeminderten BMP-7-Expression in nephrosklerotischen Nieren erklären. Angiotensin II nimmt durch die Steigerung des Gefäßwiderstandes und die direkte Stimulation von Fibrosierungsprozessen eine zentrale Rolle bei der Pathogenese der Nephrosklerose ein. Dabei können die Wirkungen direkt über den AT-I-Rezeptor oder indirekt über die Stimulation einer vermehrten TGF- $\beta 1$-Expression in Fibroblasten und Tubulusepithelzellen vermittelt werden (Border und Noble 1998). Eine erhöhte Expression von TGF- $\beta$ konnte bei einem Modell der Nephrosklerose bei der hypertensiven Ratte festgestellt werden (Hamaguchi et al. 1995). Im Mausmodell der unilateralen ureteralen Obstruktion (UUO) konnte gezeigt werden, dass bei TNF- $\alpha$-Rezeptordefizienten Mäusen im Vergleich $\mathrm{zu}$ den Kontrolltieren eine verminderte Entzündungsaktivität sowie eine geringere Fibrosierung nachzuweisen war (Guo et al. 1999). Die Synthese von TGF- $\beta 1$ wird auch durch weitere Faktoren wie Endothelin-1 (ET-1), atriales natriuretisches Peptid (ANP), Insulin-like growth factor 1 (IGF-1) und Thromboxan gesteuert (Eddy 2000). Es induziert in Synergie mit EGF die Epithelial-Mesenchymale Transition. TGF $\beta-1$ wird als inaktive Form sezerniert. Die Aktivierung des Moleküls wird in erster Linie durch Thrombospondin 1 vermittelt (Crawford et al. 1998).

Im Mausmodell der Hautfibrose konnte eine Arbeitsgruppe synergistische Effekte durch die externe Applikation von TGF- $\beta$ und CTGF beschreiben (Mori et al. 1999). Für die Niere werden diese Effekte ebenfalls propagiert (Qi et al. 2008). In Keloidnarben von Afroamerikanern finden sich exzessive TGF- $\beta$-Konzentrationen, was auf einen möglichen relevanten Zusammenhang mit der eingangs erläuterten genetisch bedingten erhöhten renalen Suszeptibilität dieser ethnischen Gruppe hinweist (Dustan 1992).

Erstmals konnte die Arbeitsgruppe um Wolf nachweisen, dass die durch AT II induzierte Synthese von extrazellulären Matrixkomponenten in Tubulusepithelzellen über eine gesteigerte Expression von TGF- $\beta$ vermittelt wird (Wolf et al. 1993). Zudem ging in 
Folgeexperimenten eine Stimulation der Zellen mit AT II mit einer gesteigerten Expression des TGF-Typ-II Rezeptors einher (Wolf et al. 1999). Der Einsatz von Inhibitoren des RAAS führt bei Patienten mit Nephrosklerose zu einer Senkung des Blutdrucks und einer Reduktion der Proteinurie, die das Fortschreiten einer Fibrosierung deutlich begünstigt (de Zeeuw et al. 2004). Neben den hämodynamischen Konsequenzen lässt sich die renoprotektive Wirkung durch eine Hemmung der AT-II-gesteuerten Zytokinausschüttung, die verminderte Produktion von Fibrosemediatoren wie TGF- $\beta 1$ und eine geringere Bildung von Sauerstoffradikalen erklären (Dzau 2001).

Durch das nephrotoxische Immunsuppressivum Cyclosporin (CsA) kam es in einem Modell der Ratte zu einer Suppression der BMP-7-Expression in den untersuchten Tieren. Durch die Gabe von ACE-Hemmern konnte bei einem Teil der Tiere diese Supression reduziert werden, wodurch sich der Verdacht auf einen Zusammenhang mit dem RAAS verstärkt (Tuglular et al. 2004). Auch hier muss betont werden, dass es sich um Ergebnisse aus einem Nagermodell handelte und daraus keine direkten Schlussfolgerungen auf die Wirkungen in menschlichen Zellen gezogen werden können. Unsere Annahmen werden durch Beobachtungen gestützt, in denen durch eine Hemmung des RAAS mittels Telmisartan die Expression inflammatorischer Zytokine gehemmt und die von protektiven Wachstumsfaktoren gesteigert wurde (Dai et al. 2007; Tian et al. 2009).

In Folgeversuchen werden die Auswirkungen von TGF-1 $\beta$ als zentrales Agens der Nierenfibrose (das finale morphologisches Korrelat der $\mathrm{zu}$ terminalem Nierenversagen führenden Erkrankungen) und der Einfluss von Hemmern des RAAS auf die Expression von BMP's in der humanen Zellkultur untersucht. Erste Ergebnisse liefern hier bereits signifikante Zusammenhänge. Die Arbeitsgruppe von Xu konnte zeigen, dass BMP-7 die TGF- $\beta$ induzierte EMT humaner proximaler Tubuluszellen hemmt (Xu et al. 2009), während die Arbeitsgruppe um Dudas es nicht schaffte diese Ergebnisse zu replizieren (Dudas et al. 2009). Ein wichtiger Unterschied war die in den Studien gewählte unterschiedliche Konzentration von BMP-7. Während Xu und Mitarbeiter Konzentrationen von $400 \mathrm{ng} / \mathrm{ml}$ wählten, wurden die Experimente in der anderen Arbeitsgruppe mit Konzentrationen von bis $\mathrm{zu} 100 \mathrm{ng} / \mathrm{ml}$ durchgeführt. Vukicevic konnte mit seiner Arbeitsgruppe am Rattenmodell des ischämisch induzierten akuten Nierenversagens protektive Wirkungen von BMP-7 nachweisen (Vukicevic et al. 1998). Ein wichtiger Mechanismus könnte hier die signifikante Reduktion der TNF- $\alpha$-induzierten proinflammatorischen Zytokinexpression in humanen proximalen Tubuluszellen sein (Gould et al. 2002). 
Zur Untersuchung der Effekte von Angiotensin II auf die Expression von BMP-4 erfolgte ebenfalls eine Stimulation von HK-2-Zellen mit Angiotensin II. Unter Stimulation von AT II erwarteten wir eine Steigerung der Expression des atherogenen BMP-4 auf mRNA-Ebene. Es konnte kein konzentrationsabhängiger Einfluss von Angiotensin II auf die Expression des krankheitsprogressiven BMP-4 gefunden werden. In der Literatur finden sich Hinweise, dass BMP-4 in frühen und späten Phasen der Atherosklerose eine progressive Funktion ausübt (Dhore et al. 2001; Sorescu et al. 2004). Möglich wäre, dass Angiotensin nicht direkt mit der Expression der untersuchten BMP's interagiert oder in humanen Zellreihen komplexere multifaktorielle Vorgänge ablaufen, wie wir sie auch für die Proliferation und die Apoptose vermuten. Weitere Experimente in unserer Arbeitsgruppe konzentrieren sich auf dieses multifaktorielle Geschehen.

Ein Nachweis von BMP's auf Proteinebene mittels Immunoblot gelang in der hier vorliegenden Arbeit leider nicht. Dieses ist wohl am ehesten durch eine geringe Expression der BMPs im Nierengewebe begründet, die einen definitiven Nachweis mittels Immunoblot erschwert.

\subsection{Auswirkungen von BMP's auf die Proliferationsraten von humanen Fibroblasten und Tubuluszellen - Mögliche BMP-Interaktion mit zahlreichen Zytokinen und Noxen}

Die Stimulation von humanen proximalen Tubuluszellen mit BMP-4 sowie BMP-7 für 48h in Konzentrationen von 1,10 und $100 \mathrm{ng} / \mathrm{ml}$ im Proliferationsassay lieferte keine signifikanten Hinweise auf eine proliferationsfördernde oder eine proliferationshemmende Wirkung von BMP's im Vergleich zur Negativkontrolle. Tubulusepithelzellen wird in der Pathophysiologie des Verlustes der renalen Funktion eine besondere Bedeutung zugesprochen.

Der während der Organogenese BMP-7-defizienter Mäuse beschriebene Untergang der Mesenchymzellen, aus denen sich durch Mesenchymal-Epitheliale Transition (MET) die Tubulusepithelzellen entwickeln zeigt, dass BMP-7 ein wichtiges Zytokin für die Entwicklung der Tubuluszellen ist. Die Behandlung von Mäusen mit BMP-7 in einem Modell der chronischen Niereninsuffizienz (der nephrotoxischen Serum-Glomerulonephritis) verhinderte den Untergang von Tubuluszellen. Der verspätete Beginn einer Behandlung bei bereits geschädigten Nieren führte sogar zu einem Rückgang der tubulären Atrophie, was die Vermutung nahe legt, dass BMP-7 einen proliferativen Effekt auf Tubuluszellen hat (Zeisberg et al. 2003 b).

Daher wurde zur Untersuchung der Wirkung von BMP's auf Tubuluszellen eine Analyse der Proliferationsrate durchgeführt. Es zeigten sich keine Effekte von BMP-7 auf die untersuchten 
Zellreihen. Die Vermutung liegt nahe, dass BMP's synergistisch und über Kreuzreagibilität mit anderen Zytokinen die im Nagermodell beschriebenen protektiven und regenerativen Effekte bewirken. In den verwendeten Konzentrationen (1, 10 und 100 ng/ml) haben BMP's keine direkten Auswirkungen auf die Proliferationsraten der untersuchten ungeschädigten Zellen. Ein möglicher Erklärungsansatz liegt in der Annahme, dass BMP's nicht in der Lage sind, eine direkte Stimulation der Proliferation von ungeschädigten Zellen auszuüben. Die von uns untersuchten Zellreihen stammten aus ungeschädigtem Nierengewebe und in unseren Experimenten setzten wir die Zellen nicht Entzündungsreizen oder anderen Noxen aus, sondern untersuchten die Einflüsse unter nichtschädigenden Bedingungen. Es könnte sein, dass ein Einfluss auf die Proliferationsrate nur in Anwesenheit von Fibrosemediatoren wie z.B. TGF- $\beta$ nachgewiesen werden kann, indem hier BMP-7 eine protektive Wirkung ausübt und eine Inhibition der Apoptose bewirkt. Möglicherweise wirkt BMP-7 hier auch an unterschiedlichen Stellen. Es finden sich zum Beispiel Hinweise darauf, dass BMP-7 die durch Aldosteron vermittelte mesangiale Zellproliferation hemmt und einen möglichen renoprotektiven Effekt über die Inhibition der Expression eines Mineralocorticoidrezeptors bewirkt (Otani et al. 2007). In einer neueren Arbeit einer chinesischen Arbeitsgruppe wurde die protektive Wirkung von BMP-7 bei einer Noxe, der eine Vielzahl von Menschen in China ausgesetzt ist, im Zellkulturmodell nachgewiesen. Die Aristolochiasäuren (AS) finden sich in einigen Pflanzen, die in der traditionellen chinesischen Medizin eingesetzt werden. Sie wirken toxisch auf renale Tubuluszellen und führen zu einem Krankheitsbild einer rapid progressiven renalen Fibrose. Die gleichzeitige Applikation von BMP-7 mit AS in toxischer Dosierung bei HK-2-Zellen, wie sie auch in der hier vorliegenden Arbeit verwendet wurden, führte zu einer gesteigerten Proliferationsrate und einer verminderten Apoptoserate die mit einer verminderten Caspase-3-Aktivierung einherging. Als weiteres Ergebnis zeigte sich eine Inhibition der EMT, auf die im Verlauf noch eingegangen werden soll. Die Effekte waren dosisabhängig. Es wurden im Vergleich zu unserer Arbeit sehr hohe Dosen bis zu 1000 ng/ml verwendet (Wang $Z$ et al. 2010).

In einem Modell der unilateralen ureteralen Obstruktion konnte die Applikation von BMP-7 die Apoptose von Tubuluszellen deutlich hemmen und so die Unversehrtheit der Tubuli bewirken (Hruska et al. 2000). Ein Untersuchungsgegenstand weiterer Studien könnte die Untersuchung der Proliferations- und Apoptoseraten der Zellreihen in Interaktion von BMP's mit nephrotoxischen und fibrosefördernden Substanzen sein. Die Arbeitsgruppe von Motazed konnte an immortalisierten humanen proximalen Tubuluszellen (HKC-8) eine durch BMP-7 vermittelte Reduktion der durch TGF- $\beta 1$ vermittelten Fibronektinproduktion als Hinweis auf 
einen möglichen antifibrotischen Wirkmechanismus von BMP-7 nachweisen. Die Wirkung von BMP-7 auf intrazelluläre Signalkaskaden war dosisabhängig. So wurde bei hohen Konzentrationen von $200 \mathrm{ng} / \mathrm{ml}$ eine Aktivierung der Smad-Proteine 1, 5 und 8 nachgewiesen und bei niedrigen Konzentrationen eine Aktivierung der MAP-Kinase (p38 mitogenaktiviertes Protein), die auch in die durch TGF- $\beta 1$ vermittelte Stimulation der Synthese von interzellulären Matrixkomponenten wie Fibronektin involviert ist. Die gemeinsame Inkubation von BMP-7 und TGF- $\beta 1$ vermochte eine Fibronektinsezernierung im Vergleich zur TGF- $\beta 1$-Kontrollgruppe zu reduzieren (Motazed et al. 2008).

Bei der renalen Fibrosierung kommt es zu einer gesteigerten Proliferationsrate interstitieller Fibroblasten. Für ein mögliches Therapeutikum wären proliferationshemmende Effekte auf renale Fibroblasten von Vorteil. In der von uns untersuchten Zellreihe TK-173 zeigte sich keine signifikante Reduktion der Proliferationsrate durch die Applikation von BMP-7 in den genannten Konzentrationen. Hoffnungsvoll ist die Antagonisierung der entzündlichen Einflüsse und TGF-beta induzierten Schädigungsmechanismen von BMP-7. Hier konnte gezeigt werden, dass es durch BMP-7 zu einer Hemmung der Epithelial-mesenchymalen Transition (EMT) und einer Umkehr der durch TGF- $\beta$ vermittelten Umbauprozesse kommen kann.

\subsection{Die EMT als Untersuchungsgegenstand weiterer Forschung zum Einfluss von BMP's auf renale Zellpopulationen}

Unter EMT versteht man die phänotypische Umwandlung von Epithelzellen in Zellen mit Charakteristika von Mesenchymzellen. Dieses Phänomen wurde erstmals 1982 an verschiedenen Epithelzellen beschrieben, die in einer dreidimensionalen Kollagenmatrix Eigenschaften von Epithelzellen wie die apikal-basale Zellpolarität aufgaben und Charakteristika von immigrierenden mesenchymalen Zellen annahmen, obwohl man bis zur Veröffentlichung der Arbeit davon ausgegangen war, dass der epitheliale Phänotyp relativ stabil sei (Greenburg und Hay 1982). In der renalen Fibrogenese konnte die EMT erstmals im Modell der anti-tubulären Basalmembrannephritis beschrieben (Strutz et al. 1995) und im Anschluss mehrfach bestätigt werden (Ng et al. 1998; Yang und Liu 2002; Zeisberg und Kalluri 2004). Im transgenen Mausmodell konnte anhand genetisch markierter Tubulusepithelzellen deren Migration in den tubulointerstitiellen Raum und Partizipation an der extrazellulären Matrixsynthese (EMS) nachgewiesen werden. Etwa ein Drittel der aktivierten Fibroblasten entstammten in diesem Modell einer tubulären Herkunft (Iwano et al. 2002). 
Für die Regulation der EMT sind verschiedene Zytokine verantwortlich. So kann FGF-2 zelluläre Prozesse in Gang setzen, die die Transition der Zellen fördern (Strutz et al. 2002).

In vitro konnte gezeigt werden, dass einzelne Zytokine deutlich geringere Einflüsse ausüben, als die Kombination unterschiedlicher Mediatoren. Die deutlichsten Effekte wurden durch eine Kombination von TGF- $\beta 1$ und EGF hervorgerufen (Okada et al. 1997).

Des Weiteren tragen Komponenten der interstitiellen extrazellulären Matrix wie Kollagen I zur EMT bei, während Bestandteile der tubulären Basalmembran (wie Kollagen IV) den epithelialen Phänotyp eher stabilisieren (Zeisberg et al. 2001). Eine Erhaltung der Integrität der tubulären Basalmembran, durch die Ausschaltung bestimmter Metalloproteinasen, konnte die Transition von Epithelzellen und die konsekutive Progression der Niereninsuffizienz aufhalten (Yang et al. 2002).

Zusammenfassend wird angenommen, dass renale Epithelzellen, die auf einer geschädigten Basalmembran sitzen und FGF-2, TGF- $\beta 1$ und EGF ausgesetzt werden, beginnen, FSP-1 zu exprimieren und zu Fibroblasten zu transformieren, um dann in das Interstitium zu wandern und dort EMT zu betreiben und damit die Transformation weiterer epithelialer Zellen zu fördern. Das führt zu tubulärer Atrophie und progressiver Niereninsuffizienz.

Es finden sich Hinweise darauf, dass BMP-7 eine Mesenchymal-Epitheliale Transition vermittelt (Zeisberg et al. 2005). Eine Londoner Arbeitsgruppe untersuchte kürzlich die Wirkung von BMP-7 und BMP-4 auf Lungenfibroblasten. In den Versuchen konnte die TGF$\beta$-induzierte extrazelluläre Matrixproteinsynthese auf RNA- und auf Proteinebene erstaunlicherweise durch BMP-4, aber nicht durch BMP-7 reduziert werden. Diese Ergebnisse belegen die Komplexität der BMP-Wirkungen in verschiedenen Organsystemen (Pegorier et al. 2010).

In glatten Muskelzellen konnte gezeigt werden, dass BMP-7 die Proliferation von glatten Muskelzellen hemmen, aber auch die Apoptose verhindern kann (Dorai und Sampath 2001).

Die Ausschaltung einzelner Zytokine bzw. Zytokinrezeptoren stellt eine mögliche Therapiestrategie zur Hemmung der Fibroblastenproliferation dar. Es gilt jedoch zu bedenken, dass sich ein lokaler Einsatz solcher Stoffe im Nierengewebe schwierig gestaltet, und die generalisierte Hemmung zu erheblichen Nebenwirkungen führen kann. Die Hemmung des Chemokinrezeptors CCR1 im Modell der UUO konnte Inflammation und Fibrosierung deutlich reduzieren (Anders et al. 2002). Ein Großteil möglicher Strategien zur Fibroseinhibition konnte bis jetzt lediglich im Zellkultur- oder im Tiermodell geprüft werden. So konnte gezeigt werden, dass das Xanthinderivat Pentoxifyllin inhibitorische Effekte auf die Fibroblastenproliferation und -aktivierung sowie die EMS ausüben kann. Es fanden sich 
Anhaltspunkte dafür, dass diese Inhibition über eine Herabsetzung der FGF-2-Synthese vermittelt wird (Strutz et al. 2000).

In unseren Zellkulturexperimenten verwendeten wir immortalisierte Zellreihen und konzentrierten uns lediglich auf die Proliferationsrate. Interessant wäre ein Modell, das mit nativen Zellen arbeitet und den Phänotyp berücksichtigt. Die Arbeitsgruppe von Dudas untersuchte bereits die Wirkung von BMP-7 an primären humanen proximalen Tubuluszellen (RPTEC) und konnte keine Antagonisierung der Wirkung von TGF- $\beta 1$ im Hinblick auf eine EMT nachweisen (Dudas et al. 2009). BMP's vermitteln ihre Wirkung über die SmadProteine 1, 5 und 8. Die Wirkung von TGF- $\beta$ dagegen wird durch die Bindung an den ALK-5Rezeptor vermittelt. Über intrazelluläre Signalkaskaden, in die die Smad-Proteine 2 und 3 involviert sind, wird beispielsweise die EMT gefördert. Die Arbeitsgruppe um Zeisberg konnte zeigen, dass BMP-7 über Smad-Protein 5 die Kaskade der TGF- $\beta$-vermittelten EMT, die sich in einer verminderten Expression von Ecadherin, einem epithelialen Adhäsionsmolekül zeigt, inhibiert und auch umkehren kann (Zeisberg et al. 2003 b). Diese eindrücklichen Effekte wurden zunächst in einem Mausmodell der chronischen Niereninsuffizienz gezeigt. In Folgeexperimenten der Arbeitsgruppe konnte an der adulten Fibroblastenreihe TK-173, wie sie auch in der vorliegenden Arbeit verwendet wurde, eine mesenchymal-epitheliale Transition, gemessen an der erhöhten Expression von E-cadherin, bei einer Stimulation mit BMP-7 in einer Konzentration von $1000 \mathrm{ng} / \mathrm{ml}$ beobachtet werden. In unseren Experimenten wurden dagegen Konzentrationen bis 100 ng/ml verwendet. Wahrscheinlich ist eine enge Interaktion mit anderen die Pathologie fördernden Mediatoren wie Angiotensin II, die in weiteren Stimulationsexperimenten untersucht werden sollten. Die hier vorliegenden Ergebnisse legen eine weitere Untersuchung von BMP-4 bzw. BMP-7 in Interaktion mit TGF- $\beta$, Aldosteron sowie weiteren erwähnten und bei der Nephrosklerose pathophysiologisch relevanten Zytokinen nahe. Gegebenenfalls sollten auch eine Untersuchung mit höheren Stimulationskonzentrationen im humanen Zellkulturmodell vorgenommen werden. Dieses wird weiteren Studien vorbehalten sein. 


\section{Zusammenfassung}

Bone Morphogenetic Proteins (BMP) bilden eine Subfamilie der TGF- $\beta$-Superfamilie. BMP-7 hat in verschiedenen tierexperimentellen Krankheitsmodellen renoprotektive und regenerative Effekte. Über die Funktion von BMP-7 in der humanen Niere ist bis zum heutigen Zeitpunkt wenig bekannt. BMP-4 spielt eine progressive Rolle bei der Atherosklerose. Über die Funktion in der Nephrosklerose ist zu diesem Molekül sehr wenig bekannt.

In der vorliegenden Arbeit konnte erstmalig die Expression von BMP-4 und BMP-7 im gesunden humanen Nierengewebe und bei der Nephrosklerose nachgewiesen werden. Zunächst konnte als Hinweis auf ein fortgeschrittenes Krankheitsstadium mittels MassonGoldner-Färbung ein deutlicher Rückgang an funktionellem Gewebe in den Schnitten aus nephrosklerotischen Nieren belegt werden. In der Immunhistochemie konnte dargestellt werden, dass eine Expression von BMP-4 und BMP-7 vornehmlich in den distalen Tubuli und den Sammelrohren stattfindet. Es wurde gezeigt, dass es bei gleichen Expressionsmustern bei der humanen Nephrosklerose zu einer verminderten Expression von BMP-7 kommt. Für BMP-4 konnte gezeigt werden, dass im fortgeschrittenen Stadium der Nephrosklerose keine quantitativ veränderte Expression stattfindet.

Bei der Nephrosklerose zeigte sich eine signifikant verminderte Expression im Tubulointerstitium, ein Hinweis darauf, dass BMP-7 in der humanen Nephrosklerose in vivo herunterreguliert wird.

Angiotensin II führt bei den betroffenen Patienten über eine Blutdrucksteigerung und eine TGF-1 $\beta$-Überexpression zu einem Fortschreiten der Niereninsuffizienz. Eine mögliche Ursache für die verminderte Expression von BMP-7 kann die durch erhöhte AT-II-Spiegel verminderte Expression in proximalen Tubuluszellen sein, wie sie in unseren Stimulationsversuchen mittels RT-PCR nachgewiesen werden konnte.

Erstmals konnte in dieser Arbeit gezeigt werden, dass die Expression von BMP-4 durch die reine Applikation von Angiotensin II nicht wesentlich beeinflusst wird.

Es konnten keine signifikanten Einflüsse von BMP-4 und BMP-7 auf die Proliferationsraten von proximalen Tubuluszellen und Fibroblasten gezeigt werden. In weiteren in-vitroExperimenten wird zurzeit die Funktion der BMP's in Interaktion mit TGF- $\beta 1$ und Hemmern des RAAS untersucht. 


\section{Anhang: Abkürzungsverzeichnis}

ACE Angiotensinkonvertierungsenzym (Angiotensin converting enzyme)

Alk Activin Receptor-Like Kinase

ANP Atriales natriuretisches Peptid

AS Aristolochiasäure

AT I Angiotensin I

AT II Angiotensin II

BMP-4 Bone Morphogenetic Protein 4

BMP-7 Bone Morphogenetic Protein 7

${ }^{\circ} \mathrm{C} \quad$ Grad Celsius

cAMP Zyklisches Adenosinmonophosphat

CCR-1 Chemokin Rezeptor Typ 1

CsA Cyclosporin A

CT-Wert Schwellenwert-Zyklus (Cycle Threshold)

DAPI Diamidino-2-phenylindol

DMEM Dulbecco's Modified Eagle Medium

DMSO Dimethylsulfoxid

ECM Extrazelluläre Matrix

ECM Extrazelluläre Matrix (Extracellular Matrix)

EDTA Ethylendiamintetraessigsäure

EGF Endothelinwachstumsfaktor (Endothelin-Growth-Factor)

EMS Extrazelluläre Matrixsynthese

EMT Epithelial-mesenchymale Transition

ET-1 Endothelin 1

FACS Durchflusszytometrie (Fluorescence-activated cell sorting)

FCS Foetales Kälberserum

FGF-2 Fibroblastenwachstumsfaktor 2 (Fibroblast-Growth-Factor 2)

FSP-1 Fibroblastenspezifisches Protein

FSP-1 Fibroblastenspezifisches Protein 1 (Fibroblast-Specific-Protein 1)

GFP Grün fluoreszierendes Protein

GFR Glomeruläre Filtrationsrate

ICAM-1 Interzelluläres Adhäsionsmolekül 1 (Intracellular Adhesion Molecule)

IGF-1 Insulinähnlicher Wachstumsfaktor 1 (Insulin-like Growth-Factor 1) 


$\begin{array}{ll}\text { IMDM } & \text { (inhibitor on non-diabetic renal disease) } \\ \text { IMH } & \text { Immunhistochemie } \\ \text { kD } & \text { Kilo-Dalton } \\ \text { LDL } & \text { Lipoprotein niedriger Dichte (Low density Lipoprotein) } \\ \text { MCP-1 } & \text { Monozyten - chemotaktisches Protein 1 } \\ \text { MET } & \text { Mesenchymal-epitheliale Transition } \\ \text { MMP } & \text { Matrix-Metalloproteinasen } \\ \text { NADPH } & \text { Nikotinamin-Adenin-Dinukleotid-Phosphat } \\ \text { NO } & \text { Stickstoffmonoxid } \\ \text { PBS } & \text { Phosphate Buffered Saline } \\ \text { PCR } & \text { Polymerasekettenreaktion (Polymerase Chain Reaction) } \\ \text { PDGF } & \text { Plättchenabgeleiteter Wachstumsfaktor (Platelet Derived Growth Factor) } \\ \text { PMSF } & \text { Phenylmethansulfonsäurefluorid } \\ \text { PPIA } & \text { Cyclophilin A } \\ \text { PS } & \text { Phosphatidylserin } \\ \text { RAAS } & \text { Renin-Angiotensin-Aldosteron-System } \\ \text { ROS } & \text { Reaktive Sauerstoffspezies } \\ \text { TGF } & \text { Transformierender Wachstumsfaktor (Transforming Growth Factor) } \\ \text { TNF- } \alpha & \text { Tumornekrosefaktor alpha } \\ \text { WB } & \text { Westernblot } \\ \text { UUO } & \text { Unilaterale Ureterale Obstruktion } \\ \end{array}$




\section{Literaturverzeichnis}

Anders HJ, Vielhauer V, Frink M, Linde Y, Cohen CD, Blattner SM, Kretzler M, Strutz F, Mack M, Grone HJ, Onuffer J, Horuk R, Nelson PJ und Schlondorff D (2002): A chemokine receptor CCR-1 antagonist reduces renal fibrosis after unilateral ureter ligation. $\mathrm{J}$ Clin Invest 109, 251-9.

Axelrad TW, Steen B, Lowenberg DW, Creevy WR und Einhorn TA (2008): Heterotopic ossification after the use of commercially available recombinant human bone morphogenetic proteins in four patients. J Bone Joint Surg Br 90, 1617-22.

Bach G (1963): [A Minor Modification Of The Goldner (Masson) Trichromium Staining Technic.]. Z Wiss Mikrosk $\underline{65}$, 320-1.

Barri YM (2006): Hypertension and kidney disease: a deadly connection. Curr Cardiol Rep $\underline{8}$, 411-7.

Bechtel W und Zeisberg M (2009): [Bone Morphogenic Protein-7 (BMP7) and the kidneys: insights into the future management of chronic kidney diseases]. Dtsch Med Wochenschr 134, 1688-91.

Biyikli NK, Tugtepe H, Cakalagaoglu F, Ilki A und Alpay H (2005): Downregulation of the expression of bone morphogenetic protein 7 in experimental pyelonephritis. Pediatr Nephrol 20, 1230-6.

Bohle A, Bader R, Grund KE, Mackensen S und Neunhoeffer (1977): Serum creatinine concentration and renal interstitial volume. Analysis of correlations in endocapillary (acute) glomerulonephritis and in moderately severe mesangioproliferative glomerulonephritis. Virchows Arch A Pathol Anat Histol 375, 87-96.

Bohle A, Christ H, Grund KE und Mackensen S (1979): The role of the interstitium of the renal cortex in renal disease. Contrib Nephrol 16, 109-14.

Bohle A, Wehrmann M, Bogenschutz O, Batz C, Vogl W, Schmitt H, Muller CA und Muller GA (1992): The long-term prognosis of the primary glomerulonephritides. A morphological and clinical analysis of 1747 cases. Pathol Res Pract 188, 908-24.

Bohle A, Strutz F und Muller GA (1994): On the pathogenesis of chronic renal failure in primary glomerulopathies: a view from the interstitium. Exp Nephrol 2, 205-10.

Border WA und Noble NA (1994): Transforming growth factor beta in tissue fibrosis. N Engl J Med 331, 1286-92.

Border WA und Noble NA (1998): Interactions of transforming growth factor-beta and angiotensin II in renal fibrosis. Hypertension 31, 181-8.

Bosukonda D, Shih MS, Sampath KT und Vukicevic S (2000): Characterization of receptors for osteogenic protein-1/bone morphogenetic protein-7 (OP-1/BMP-7) in rat kidneys. Kidney Int $\underline{58}, 1902-11$.

Boyd CM, Darer J, Boult C, Fried LP, Boult L und Wu AW (2005): Clinical practice guidelines and quality of care for older patients with multiple comorbid diseases: implications for pay for performance. JAMA 294, 716-24.

Bradford MM (1976): A rapid and sensitive method for the quantitation of microgram quantities of protein utilizing the principle of protein-dye binding. Anal Biochem 72, 248-54.

Bramlage CP, Haupl T, Kaps C, Bramlage P, Muller GA und Strutz F (2005): [Bone morphogenetic proteins in the skeletal system]. Z Rheumatol 64, 416-22.

Bramlage CP, Tampe B, Koziolek M, Maatouk I, Bevanda J, Bramlage P, Ahrens K, Lange K, Schmid H, Cohen CD, Kretzler M und Muller GA (2010): Bone Morphogenetic Protein (BMP)-7 expression is decreased in human hypertensive nephrosclerosis. BMC Nephrology 11 ,

Chomczynski P und Sacchi N (1987): Single-step method of RNA isolation by acid guanidinium thiocyanate-phenol-chloroform extraction. Anal Biochem 162, 156-9. 
Chomczynski P und Sacchi N (2006): The single-step method of RNA isolation by acid guanidinium thiocyanate-phenol-chloroform extraction: twenty-something years on. Nat Protoc $1,581-5$.

Cohen CD, Frach K, Schlondorff D und Kretzler M (2002): Quantitative gene expression analysis in renal biopsies: a novel protocol for a high-throughput multicenter application. Kidney Int 61, 133-40.

Crawford SE, Stellmach V, Murphy-Ullrich JE, Ribeiro SM, Lawler J, Hynes RO, Boivin GP und Bouck N (1998): Thrombospondin-1 is a major activator of TGF-beta1 in vivo. Cell 93, 1159-70.

Csiszar A, Labinskyy N, Smith KE, Rivera A, Bakker EN, Jo H, Gardner J, Orosz Z und Ungvari Z (2007): Downregulation of bone morphogenetic protein 4 expression in coronary arterial endothelial cells: role of shear stress and the cAMP/protein kinase A pathway. Arterioscler Thromb Vasc Biol 27, 776-82.

Dai Q, Xu M, Yao M und Sun B (2007): Angiotensin AT1 receptor antagonists exert antiinflammatory effects in spontaneously hypertensive rats. Br J Pharmacol $\underline{152}$, 1042-8.

Dasgupta I, Porter C, Innes A und Burden R (2007): "Benign" hypertensive nephrosclerosis. QJM 100, 113-9.

Davies MR, Lund RJ und Hruska KA (2003): BMP-7 is an efficacious treatment of vascular calcification in a murine model of atherosclerosis and chronic renal failure. J Am Soc Nephrol $\underline{14}, 1559-67$.

Derynck R, Zhang Y und Feng XH (1998): Smads: transcriptional activators of TGF-beta responses. Cell 95, 737-40.

de Zeeuw D, Remuzzi G, Parving HH, Keane WF, Zhang Z, Shahinfar S, Snapinn S, Cooper ME, Mitch WE und Brenner BM (2004): Proteinuria, a target for renoprotection in patients with type 2 diabetic nephropathy: lessons from RENAAL. Kidney Int 65, 2309-20.

Dhore CR, Cleutjens JP, Lutgens E, Cleutjens KB, Geusens PP, Kitslaar PJ, Tordoir JH, Spronk HM, Vermeer C und Daemen MJ (2001): Differential expression of bone matrix regulatory proteins in human atherosclerotic plaques. Arterioscler Thromb Vasc Biol 21, 1998-2003.

Doller A, Gauer S, Sobkowiak E, Geiger H, Pfeilschifter J und Eberhardt W (2009): Angiotensin II induces renal plasminogen activator inhibitor-1 and cyclooxygenase-2 expression post-transcriptionally via activation of the mRNA-stabilizing factor human-antigen R. Am J Pathol 174, 1252-63.

Dorai H und Sampath TK (2001): Bone morphogenetic protein-7 modulates genes that maintain the vascular smooth muscle cell phenotype in culture. J Bone Joint Surg Am $\underline{83-A}$ Suppl 1, S70-8.

Dube PH, Almanzar MM, Frazier KS, Jones WK, Charette MF und Paredes A (2004): Osteogenic Protein-1: gene expression and treatment in rat remnant kidney model. Toxicol Pathol 32, 384-92.

Ducy P und Karsenty G (2000): The family of bone morphogenetic proteins. Kidney Int 57 , 2207-14.

Dudas PL, Argentieri RL und Farrell FX (2009): BMP-7 fails to attenuate TGF-beta1induced epithelial-to-mesenchymal transition in human proximal tubule epithelial cells. Nephrol Dial Transplant 24, 1406-16.

Dudley AT, Lyons KM und Robertson EJ (1995): A requirement for bone morphogenetic protein-7 during development of the mammalian kidney and eye. Genes Dev $\underline{9}, 2795-807$.

Dunn NR, Winnier GE, Hargett LK, Schrick JJ, Fogo AB und Hogan BL (1997): Haploinsufficient phenotypes in Bmp4 heterozygous null mice and modification by mutations in Gli3 and Alx4. Dev Biol 188, 235-47.

Dustan HP (1992): Growth factors and racial differences in severity of hypertension and renal diseases. Lancet $\underline{339}, 1339-40$. 
Dzau VJ (2001): Theodore Cooper Lecture: Tissue angiotensin and pathobiology of vascular disease: a unifying hypothesis. Hypertension 37, 1047-52.

Eddy AA (2000): Molecular basis of renal fibrosis. Pediatr Nephrol 15, 290-301.

Frei U und Schober-Halstenberg HJ: Nierenersatztherapie in Deutschland, Bericht über Dialysebehandlung und Nierentransplantation in Deutschland 2005/2006, QUASI Niere, Berlin 2008

Gould SE, Day M, Jones SS und Dorai H (2002): BMP-7 regulates chemokine, cytokine, and hemodynamic gene expression in proximal tubule cells. Kidney Int 61, 51-60.

Gratzner HG (1982): Monoclonal antibody to 5-bromo- and 5-iododeoxyuridine: A new reagent for detection of DNA replication. Science $\underline{218}, 474-5$.

Greenburg G und Hay ED (1982): Epithelia suspended in collagen gels can lose polarity and express characteristics of migrating mesenchymal cells. J Cell Biol 95, 333-9.

Guo G, Morrissey J, McCracken R, Tolley T und Klahr S (1999): Role of TNFR1 and TNFR2 receptors in tubulointerstitial fibrosis of obstructive nephropathy. Am J Physiol 277, F766-72.

Guzik TJ, West NE, Black E, McDonald D, Ratnatunga C, Pillai R und Channon KM (2000): Vascular superoxide production by NAD(P)H oxidase: association with endothelial dysfunction and clinical risk factors. Circ Res $\underline{86}$, E85-90.

Hamaguchi A, Kim S, Ohta K, Yagi K, Yukimura T, Miura K, Fukuda T und Iwao H (1995): Transforming growth factor-beta 1 expression and phenotypic modulation in the kidney of hypertensive rats. Hypertension 26, 199-207.

Harvey JM, Howie AJ, Lee SJ, Newbold KM, Adu D, Michael J und Beevers DG (1992): Renal biopsy findings in hypertensive patients with proteinuria. Lancet $\underline{340}$, 1435-6.

Heldin CH, Miyazono K und ten Dijke P (1997): TGF-beta signalling from cell membrane to nucleus through SMAD proteins. Nature $\underline{390}, 465-71$.

Hill GS (2008): Hypertensive nephrosclerosis. Curr Opin Nephrol Hypertens 17, 266-70.

Hruska KA, Guo G, Wozniak M, Martin D, Miller S, Liapis H, Loveday K, Klahr S, Sampath TK und Morrissey J (2000): Osteogenic protein-1 prevents renal fibrogenesis associated with ureteral obstruction. Am J Physiol Renal Physiol 279, F130-43.

Hsing CH, Chou W, Wang JJ, Chen HW und Yeh CH (2011): Propofol increases bone morphogenetic protein-7 and decreases oxidative stress in sepsis-induced acute kidney injury. Nephrol Dial Transplant 26, 1162-72.

Iwano M, Plieth D, Danoff TM, Xue C, Okada H und Neilson EG (2002): Evidence that fibroblasts derive from epithelium during tissue fibrosis. J Clin Invest 110, 341-50.

Jones CL, Buch S, Post M, McCulloch L, Liu E und Eddy AA (1992): Renal extracellular matrix accumulation in acute puromycin aminonucleoside nephrosis in rats. Am J Pathol $\underline{141}$, 1381-96.

Jones CM, Lyons KM und Hogan BL (1991): Involvement of Bone Morphogenetic Protein-4 (BMP-4) and Vgr-1 in morphogenesis and neurogenesis in the mouse. Development 111, 53142.

Juncos LA, Garvin J, Carretero OA und Ito S (1995): Flow modulates myogenic responses in isolated microperfused rabbit afferent arterioles via endothelium-derived nitric oxide. $\mathrm{J}$ Clin Invest 95, 2741-8.

Kang DH, Kanellis J, Hugo C, Truong L, Anderson S, Kerjaschki D, Schreiner GF und Johnson RJ (2002): Role of the microvascular endothelium in progressive renal disease. J Am Soc Nephrol 13, 806-16.

Kingsley DM (1994): The TGF-beta superfamily: new members, new receptors, and new genetic tests of function in different organisms. Genes Dev $\underline{8}, 133-46$.

Kondo S, Kagami S, Kido H, Strutz F, Muller GA und Kuroda Y (2001): Role of mast cell tryptase in renal interstitial fibrosis. J Am Soc Nephrol 12, 1668-76. 
Kopp JB, Factor VM, Mozes M, Nagy P, Sanderson N, Bottinger EP, Klotman PE und Thorgeirsson SS (1996): Transgenic mice with increased plasma levels of TGF-beta 1 develop progressive renal disease. Lab Invest 74, 991-1003.

Koziolek MJ, Schmid H, Cohen CD, Blaschke S, Hemmerlein B, Zapf A, Muller GA und Strutz F (2007): Potential role of fractalkine receptor expression in human renal fibrogenesis. Kidney Int 72, 599-607

Kron S, Budde, K: Vaskuläre Nierenschädigung; in: Harrisons Innere Medizin, Band 2 ; hrsg. v. Dietel, M. Suttorp, N., Zeitz, M.; ABW Wissenschaftsverlag, Berlin. 2009, 2235-2241.

Kuncio GS, Neilson EG und Haverty T (1991): Mechanisms of tubulointerstitial fibrosis. Kidney Int 39, 550-6.

Laemmli UK (1970): Cleavage of structural proteins during the assembly of the head of bacteriophage T4. Nature 227, 680-5.

Libby P (2002): Inflammation in atherosclerosis. Nature $\underline{420}$, 868-74.

Ljungqvist A (1963): The Intrarenal Arterial Pattern In The Normal And Diseased Human Kidney. A Micro-Angiographic And Histologic Study. Acta Med Scand 174, SUPPL401:138.

Luke R und Curtis J: Nephrosclerosis. Little Brown and Co., Boston, MA, 1993

Luo G, Hofmann C, Bronckers AL, Sohocki M, Bradley A und Karsenty G (1995): BMP-7 is an inducer of nephrogenesis, and is also required for eye development and skeletal patterning. Genes Dev $\underline{9}, 2808-20$.

Marcussen N (1995): Atubular glomeruli in chronic renal disease. Curr Top Pathol 88, 145-74.

Marcussen N (2000): Tubulointerstitial damage leads to atubular glomeruli: significance and possible role in progression. Nephrol Dial Transplant 15 Suppl 6, 74-5.

Massague J (1992): Receptors for the TGF-beta family. Cell $\underline{69}$, 1067-70.

Massague J (2000): How cells read TGF-beta signals. Nat Rev Mol Cell Biol 1, 169-78.

Miriyala S, Gongora Nieto MC, Mingone C, Smith D, Dikalov S, Harrison DG und Jo H (2006): Bone morphogenic protein-4 induces hypertension in mice: role of noggin, vascular NADPH oxidases, and impaired vasorelaxation. Circulation 113, 2818-25.

Mitu G und Hirschberg R (2008): Bone morphogenetic protein-7 (BMP7) in chronic kidney disease. Front Biosci 13, 4726-39.

Miyazaki Y, Oshima K, Fogo A, Hogan BL und Ichikawa I (2000): Bone morphogenetic protein 4 regulates the budding site and elongation of the mouse ureter. J Clin Invest 105 , 863-73.

Miyazaki Y, Oshima K, Fogo A und Ichikawa I (2003): Evidence that bone morphogenetic protein 4 has multiple biological functions during kidney and urinary tract development. Kidney Int $\underline{63}, 835-44$.

Mori T, Kawara S, Shinozaki M, Hayashi N, Kakinuma T, Igarashi A, Takigawa M, Nakanishi T und Takehara K (1999): Role and interaction of connective tissue growth factor with transforming growth factor-beta in persistent fibrosis: A mouse fibrosis model. $\mathrm{J}$ Cell Physiol 181, 153-9.

Motazed R, Colville-Nash P, Kwan JT und Dockrell ME (2008): BMP-7 and proximal tubule epithelial cells: activation of multiple signaling pathways reveals a novel anti-fibrotic mechanism. Pharm Res 25, 2440-6.

Muller GA, Markovic-Lipkovski J, Frank J und Rodemann HP (1992): The role of interstitial cells in the progression of renal diseases. J Am Soc Nephrol 2, S198-205.

Muller GA, Frank J, Rodemann HP und Engler-Blum G (1995): Human renal fibroblast cell lines (tFKIF and tNKF) are new tools to investigate pathophysiologic mechanisms of renal interstitial fibrosis. Exp Nephrol $\underline{3}, 127-33$.

Mulligan RC und Berg P (1981): Factors governing the expression of a bacterial gene in mammalian cells. Mol Cell Biol 1, 449-59. 
Ng YY, Huang TP, Yang WC, Chen ZP, Yang AH, Mu W, Nikolic-Paterson DJ, Atkins RC und Lan HY (1998): Tubular epithelial-myofibroblast transdifferentiation in progressive tubulointerstitial fibrosis in 5/6 nephrectomized rats. Kidney Int 54, 864-76.

Norman JT und Fine LG (2006): Intrarenal oxygenation in chronic renal failure. Clin Exp Pharmacol Physiol 33, 989-96.

Norman JT, Clark IM und Garcia PL (2000): Hypoxia promotes fibrogenesis in human renal fibroblasts. Kidney Int 58, 2351-66.

O'Dea DF, Murphy SW, Hefferton D und Parfrey PS (1998): Higher risk for renal failure in first-degree relatives of white patients with end-stage renal disease: a population-based study. Am J Kidney Dis 32, 794-801.

Pollard JW (1990): Basic cell culture. Methods Mol Biol 5, 1-12.

Okada H, Danoff TM, Kalluri R und Neilson EG (1997): Early role of Fsp1 in epithelialmesenchymal transformation. Am J Physiol 273, F563-74.

Otani H, Otsuka F, Inagaki K, Takeda M, Miyoshi T, Suzuki J, Mukai T, Ogura T und Makino H (2007): Antagonistic effects of bone morphogenetic protein-4 and -7 on renal mesangial cell proliferation induced by aldosterone through MAPK activation. Am J Physiol Renal Physiol 292, F1513-25.

Ozkaynak E, Rueger DC, Drier EA, Corbett C, Ridge RJ, Sampath TK und Oppermann H (1990): OP-1 cDNA encodes an osteogenic protein in the TGF-beta family. EMBO J $\underline{9}$, 2085-93.

Pegorier S, Campbell GA, Kay AB und Lloyd CM (2010): Bone morphogenetic protein (BMP)-4 and BMP-7 regulate differentially transforming growth factor (TGF)-beta1 in normal human lung fibroblasts (NHLF). Respir Res $\underline{11}, 85$.

Qi W, Chen X, Poronnik P und Pollock CA (2008): Transforming growth factorbeta/connective tissue growth factor axis in the kidney. Int J Biochem Cell Biol 40, 9-13.

Radonic A, Thulke S, Mackay IM, Landt O, Siegert W und Nitsche A (2004): Guideline to reference gene selection for quantitative real-time PCR. Biochem Biophys Res Commun $\underline{313}$, 856-62.

Riccioni G, Vitulano N, Zanasi A, Bellocci F und d'Orazio N (2010): Aliskiren: beyond blood pressure reduction. Expert Opin Investig Drugs 19, 1265-74.

Risdon RA, Sloper JC und De Wardener HE (1968): Relationship between renal function and histological changes found in renal-biopsy specimens from patients with persistent glomerular nephritis. Lancet 1968, 2, 363-6.

Rudnicki M, Eder S, Perco P, Enrich J, Scheiber K, Koppelstatter C, Schratzberger G, Mayer B, Oberbauer R, Meyer TW und Mayer G (2007): Gene expression profiles of human proximal tubular epithelial cells in proteinuric nephropathies. Kidney Int 71, 325-35.

Ruiz-Ortega M und Egido J (1997): Angiotensin II modulates cell growth-related events and synthesis of matrix proteins in renal interstitial fibroblasts. Kidney Int 52, 1497-510.

Ryan MJ, Johnson G, Kirk J, Fuerstenberg SM, Zager RA und Torok-Storb B (1994): HK-2: an immortalized proximal tubule epithelial cell line from normal adult human kidney. Kidney Int $\underline{45}$, 48-57.

Schainuck LI, Striker GE, Cutler RE und Benditt EP (1970): Structural-functional correlations in renal disease. II. The correlations. Hum Pathol 1, 631-41.

Simon M, Maresh JG, Harris SE, Hernandez JD, Arar M, Olson MS und Abboud HE (1999): Expression of bone morphogenetic protein-7 mRNA in normal and ischemic adult rat kidney. Am J Physiol 276, F382-9.

Sorescu GP, Sykes M, Weiss D, Platt MO, Saha A, Hwang J, Boyd N, Boo YC, Vega JD, Taylor WR und Jo H (2003): Bone morphogenic protein 4 produced in endothelial cells by oscillatory shear stress stimulates an inflammatory response. J Biol Chem $\underline{278}, 31128-35$.

Sorescu GP, Song H, Tressel SL, Hwang J, Dikalov S, Smith DA, Boyd NL, Platt MO, Lassegue B, Griendling KK und Jo H (2004): Bone morphogenic protein 4 produced in 
endothelial cells by oscillatory shear stress induces monocyte adhesion by stimulating reactive oxygen species production from a nox1-based NADPH oxidase. Circ Res 95, 773-9.

Striker GE, Schainuck LI, Cutler RE und Benditt EP (1970): Structural-functional correlations in renal disease. I. A method for assaying and classifying histopathologic changes in renal disease. Hum Pathol $\underline{1}, 615-30$.

Strutz FM (2009): EMT and proteinuria as progression factors. Kidney Int $\underline{75}$, 475-81.

Strutz F und Neilson EG (1994): The role of lymphocytes in the progression of interstitial disease. Kidney Int Suppl 45, S106-10.

Strutz F und Muller GA (1999): Interstitial pathomechanisms underlying progressive tubulointerstitial damage. Kidney Blood Press Res 22, 71-80.

Strutz F, Okada H, Lo CW, Danoff T, Carone RL, Tomaszewski JE und Neilson EG (1995): Identification and characterization of a fibroblast marker: FSP1. J Cell Biol 130, 393405.

Strutz F, Heeg M, Kochsiek T, Siemers G, Zeisberg M und Muller GA (2000): Effects of pentoxifylline, pentifylline and gamma-interferon on proliferation, differentiation, and matrix synthesis of human renal fibroblasts. Nephrol Dial Transplant 15, 1535-46.

Strutz F, Zeisberg M, Ziyadeh FN, Yang CQ, Kalluri R, Muller GA und Neilson EG (2002): Role of basic fibroblast growth factor-2 in epithelial-mesenchymal transformation. Kidney Int $\underline{61}, 1714-28$.

ten Dijke P, Yamashita H, Sampath TK, Reddi AH, Estevez M, Riddle DL, Ichijo H, Heldin CH und Miyazono K (1994): Identification of type I receptors for osteogenic protein1 and bone morphogenetic protein-4. J Biol Chem 269, 16985-8.

Tian Q, Miyazaki R, Ichiki T, Imayama I, Inanaga K, Ohtsubo H, Yano K, Takeda K und Sunagawa K (2009): Inhibition of tumor necrosis factor-alpha-induced interleukin-6 expression by telmisartan through cross-talk of peroxisome proliferator-activated receptorgamma with nuclear factor kappaB and CCAAT/enhancer-binding protein-beta. Hypertension $\underline{53}, 798-804$.

Tuglular S, Gogas Yavuz D, Cakalagaoglu F, Citak L, Arikan H, Kocak H, Ozener C und Akoglu E (2004): Cyclosporine-A induced nephrotoxicity is associated with decreased renal bone morphogenetic protein-7 expression in rats. Transplant Proc 36, 131-3.

Turgut F, Balogun RA und Abdel-Rahman EM (2010): Renin-angiotensin-aldosterone system blockade effects on the kidney in the elderly: benefits and limitations. Clin J Am Soc Nephrol $\underline{5}, 1330-9$.

Urist MR (1965): Bone: formation by autoinduction. Science 150, 893-9.

Urist MR, DeLange RJ und Finerman GA (1983): Bone cell differentiation and growth factors. Science 220, 680-6.

Van Dijk SJ, Specht PA, Lazar J, Jacob HJ und Provoost AP (2006): Synergistic QTL interactions between Rf- 1 and $\mathrm{Rf}-3$ increase renal damage susceptibility in double congenic rats. Kidney Int $\underline{69}, 1369-76$.

Vukicevic S, Basic V, Rogic D, Basic N, Shih MS, Shepard A, Jin D, Dattatreyamurty B, Jones W, Dorai H, Ryan S, Griffiths D, Maliakal J, Jelic M, Pastorcic M, Stavljenic A und Sampath TK (1998): Osteogenic protein-1 (bone morphogenetic protein-7) reduces severity of injury after ischemic acute renal failure in rat. J Clin Invest 102, 202-14.

Wang SN, Lapage J und Hirschberg R (2001): Loss of tubular bone morphogenetic protein-7 in diabetic nephropathy. J Am Soc Nephrol 12, 2392-9.

Wang Z, Zhao J, Zhang J, Wei J, Zhang J und Huang Y (2010): Protective effect of BMP-7 against aristolochic acid-induced renal tubular epithelial cell injury. Toxicol Lett $\underline{198}, 348-57$. Wardle EN (1993): Cytokines: an overview. Eur J Med 2, 417-23.

Wetzel P, Haag J, Campean V, Goldschmeding R, Atalla A, Amann K und Aigner T

(2006): Bone morphogenetic protein-7 expression and activity in the human adult normal kidney is predominantly localized to the distal nephron. Kidney Int 70, 717-23. 
Wiederkehr M, Toto R, Fenves AZ und Ram CV (2005): Hypertension and the kidney. Semin Nephrol 25, 236-45.

Winnier G, Blessing M, Labosky PA und Hogan BL (1995): Bone morphogenetic protein-4 is required for mesoderm formation and patterning in the mouse. Genes Dev $\underline{9}, 2105-16$.

Wittwer CT, Herrmann MG, Moss AA und Rasmussen RP (1997): Continuous fluorescence monitoring of rapid cycle DNA amplification. Biotechniques 22, 130-1, 134-8.

Wolf G, Mueller E, Stahl RA und Ziyadeh FN (1993): Angiotensin II-induced hypertrophy of cultured murine proximal tubular cells is mediated by endogenous transforming growth factor-beta. J Clin Invest 92, 1366-72.

Wolf G, Kalluri R, Ziyadeh FN, Neilson EG und Stahl RA (1999): Angiotensin II induces alpha3(IV) collagen expression in cultured murine proximal tubular cells. Proc Assoc Am Physicians 111, 357-64.

Wong WT, Tian XY, Chen Y, Leung FP, Liu L, Lee HK, Ng CF, Xu A, Yao X, Vanhoutte PM, Tipoe GL und Huang Y (2010): Bone Morphogenic Protein-4 Impairs Endothelial Function Through Oxidative Stress-Dependent Cyclooxygenase-2 Upregulation. Implications on Hypertension. Circ Res 107, 984-91

Wrana JL (2000): Regulation of Smad activity. Cell 100, 189-92.

Xu Y, Wan J, Jiang D und Wu X (2009): BMP-7 counteracts TGF-beta1-induced epithelialto-mesenchymal transition in human renal proximal tubular epithelial cells. J Nephrol 22 , 403-10.

Yamashita H, Ten Dijke P, Heldin CH und Miyazono K (1996): Bone morphogenetic protein receptors. Bone 19, 569-74.

Yang J und Liu Y (2002): Blockage of tubular epithelial to myofibroblast transition by hepatocyte growth factor prevents renal interstitial fibrosis. J Am Soc Nephrol 13, 96-107.

Yang J, Shultz RW, Mars WM, Wegner RE, Li Y, Dai C, Nejak K und Liu Y (2002): Disruption of tissue-type plasminogen activator gene in mice reduces renal interstitial fibrosis in obstructive nephropathy. J Clin Invest 110, 1525-38.

Zarins CK, Giddens DP, Bharadvaj BK, Sottiurai VS, Mabon RF und Glagov S (1983): Carotid bifurcation atherosclerosis. Quantitative correlation of plaque localization with flow velocity profiles and wall shear stress. Circ Res $\underline{53}, 502-14$.

Zeisberg M und Kalluri R (2004): The role of epithelial-to-mesenchymal transition in renal fibrosis. J Mol Med $\underline{82}, 175-81$.

Zeisberg M, Bonner G, Maeshima Y, Colorado P, Muller GA, Strutz F und Kalluri R (2001): Renal fibrosis: collagen composition and assembly regulates epithelial-mesenchymal transdifferentiation. Am J Pathol 159, 1313-21.

Zeisberg M, Bottiglio C, Kumar N, Maeshima Y, Strutz F, Muller GA und Kalluri R (2003 a): Bone morphogenic protein-7 inhibits progression of chronic renal fibrosis associated with two genetic mouse models. Am J Physiol Renal Physiol 285, F1060-7.

Zeisberg M, Hanai J, Sugimoto H, Mammoto T, Charytan D, Strutz F und Kalluri R (2003 b): BMP-7 counteracts TGF-beta1-induced epithelial-to-mesenchymal transition and

Zeisberg M, Shah AA und Kalluri R (2005): Bone morphogenic protein-7 induces mesenchymal to epithelial transition in adult renal fibroblasts and facilitates regeneration of injured kidney. J Biol Chem $\underline{280}$, 8094-100.reverses chronic renal injury. Nat Med $\underline{9}$, 964-8.

Zimmermann G, Moghaddam A, Wagner C, Vock B und Wentzensen A (2006): [Clinical experience with bone morphogenetic protein 7 (BMP 7) in nonunions of long bones]. Unfallchirurg 109, 528-37. 


\section{Danksagungen}

Herrn Prof. Dr. med. F. Strutz und Herrn Prof. Dr. med. G.A. Müller danke ich für die Überlassung des Themas, die gute Beratung und Diskussionsmöglichkeiten in zahlreichen Besprechungen.

Ganz besonders danke ich Herrn Dr. med. Carsten Bramlage für die freundschaftliche, kompetente Betreuung der experimentellen Arbeiten. Den medizinisch-technischen Assistentinnen Frau Swantje Wehn und Frau Christina Lauterberg danke ich für die Unterstützung. Herrn Prof. Dr. med. Gröne (DKFZ Heidelberg) danke ich für die freundliche Überlassung der Abbildung einer Nephrosklerose.

Frau Dr. Katharina Lange von der Abteilung Medizinische Statistik danke ich für die sehr hilfreiche Unterstützung der statistischen Auswertung der Ergebnisse. 


\section{Lebenslauf}

Ich wurde als Sohn meiner Mutter Dina Maatouk und meines Vaters Dr. Hussein Maatouk am 16.08.1979 in Bad Homburg geboren. Meine Kindheit verbrachte ich in Dortmund und besuchte dort von 1985 bis 1989 die Comenius Grundschule. Im Anschluss wechselte ich auf das Stadtgymnasium Dortmund, wo ich 1998 mein Abitur erlangte. Nach Ableisten meines 13-monatigen Zivildienstes bis Juli 1999 in den Städtischen Kliniken Dortmund begann ich im Wintersemester 1998 mein Medizinstudium an der Georg-August Universität in Göttingen. Das Studienjahr 2002/2003 absolvierte ich an der Fakultät Necker-Universität René Descartes in Paris in Frankreich und setzte im Anschluss mein Studium in Göttingen fort. Mein praktisches Jahr absovierte ich am Universitätsklinikum Göttingen (Unfallchirurgie), am Kantonsspital Wetzikon in der Schweiz (Innere Medizin) sowie im niedersächsischen Landeskrankenhaus Tiefenbrunn bei Göttingen (Psychosomatik). Im April 2007 legte ich das dritte Staatsexamen an der Universität Göttingen ab. Seit September 2007 bin ich als wissenschaftlicher Mitarbeiter und Assistenzarzt (Innere Medizin) in der Abteilung für Allgemeine Innere Medizin und Psychosomatik am Department Innere Medizin und am Zentrum für Psychosoziale Medizin des Universitätsklinikums Heidelberg tätig. 